\title{
Absolute Viscosity of Water at $20^{\circ} \mathrm{C}$
}

\author{
J. F. Swindells, J. R. Coe, Jr., and T. B. Godfrey
}

\begin{abstract}
An accurate knowledge of the viscosities of liquids in absolute units is of fundamental importance in many scientific fields. The measurement of these viscosities is almost universally based upon the absolute viscosity of water at $20^{\circ} \mathrm{C}$ as a primary standard. During the past 50 years there has been an increasing need for a more accurate determination of this standard. Consequently, with the cooperation of the Society of Rheology and some financial assistance from the Chemical Foundation, this project was undertaken by the National Bureau of Standards and has now been completed.

The determination was made by the method of capillary flow. By means of a calibrated injector, various known constant rates of flow were produced in capillaries of measured dimensions, and observations were made of the corresponding pressure drops through the capillaries. The effects of the ends of the capillaries were rendered negligible by the simultaneous treatment of data obtained with pairs of capillaries having essentially the same diameters but different lengths.

The value found for the viscosity of water is 0.010019 poise as compared with 0.01005 poise, which has generally been accepted for the past 30 years. The estimated accuracy of the new determination is \pm 0.000003 poise.

As a result of this work, beginning on July 1, 1952, the National Bureau of Standards is planning to use the value 0.01002 poise for the absolute viscosity of water at $20^{\circ} \mathrm{C}$ as the basis for the calibration of viscometers and standard-sample oils. It is recommended that other laboratories adopt this value as the primary reference standard for comparative measurements of viscosity.
\end{abstract}

\section{Introduction}

The viscosity of a liquid is its internal resistance to flow. The accurate measurement of viscosity in absolute units is a difficult undertaking, and the difficulty is magnified greatly as the accuracy desired is increased. However, if the viscosity of one liquid is known, viscosities of other liquids in terms of that of the known may be determined very accurately with relative ease. Because of its ready availability, water at $20^{\circ} \mathrm{C}$ has been generally adopted in the United States as the primary reference standard, its viscosity being taken to be 0.01005 poise [1]. ${ }^{1}$ Other values reported in the literature [2], however, are in disagreement with this value by as much as \pm 4 parts in 1,000 .

In view of this uncertainty, in October 1931, chiefly at the instance of the late E. C. Bingham, the National Bureau of Standards began a redetermination of the viscosity of water at $20^{\circ} \mathrm{C}$. This work had the cooperation of the Society of Rheology, through whom (during the first 2 years) considerable financial assistance was obtained from The Chemical Foundation. The problem was assigned to J. R. Coe, with the program subject to the review of N. E. Dorsey, who gave valuable advice and encouragement. It was agreed that, although other methods might also be explored, measurements should be made by the capillary flow method. An accuracy of at least 1 part in 1,000 was to be sought.

By the end of 1932, the apparatus and experimental procedures described below had been largely determined upon, much of the apparatus had been designed in detail, and some of it had been built or procured. In addition, rough experiments to establish the feasibility of the method had been concluded. Initially, sufficiently uniform tubes were not

\footnotetext{
${ }_{1}^{1}$ Figures in brackets indicate the literature references given on $\mathrm{p} .23$.
}

easily available, and a machine to lap the bores of glass tubes was built as an alternative to attempting to find suitable tubes by the examination of many. This work was described in a progress report in December 1932 [3]. This part of the project was not completed, because it was found in 1933 that satisfactory capillaries were then being made by the Jena Glass Works in Germany. During the period 1933 to 1938 , work on the project was subjected to frequent interruptions and necessary delays.

In the fall of 1938 conditions made it possible for T. B. Godfrey to join J. R. Coe in the work, which was continued without interruption until the fall of 1941, when it was again delayed by reason of the war. During the period 1938 to 1941 the apparatus was completed and assembled, the methods of calibration and flow measurement worked out in detail, and two series of flow measurements completed. Tentative values for the viscosity of water at $20^{\circ} \mathrm{C}^{2}$ and at other temperatures based on these early measurements were reported in a letter to the Editor of the Journal of Applied Physics [4]. It was recognized, however, that with the completion of so small a part of the contemplated series of measurements, only the necessity of indefinitely suspending work justified any statement at that time.

Work on the determination was resumed in January 1947 by J. F. Swindells, who completed the experimental program and reduced all the data.

\section{Theory of the Capillary Method}

When accurate viscometric measurements are desired it is necessary to limit the conditions to laminar flow within the capillary tube. Turbulent flow is governed by factors that make conditions

2 The value of 0.010020 poise for the viscosity at $20^{\circ} \mathrm{C}$, which was reported at that time, is in good agreement with the value $0.010019 \pm 0.000003$, which is the final result of the completed determination. 
unsuitable for evaluating the viscosity. According to the laws of similarity, it has been shown [5] that the type of flow in a capillary is characterized by a dimensionless ratio, the Reynolds number, 2 vrD $/ \eta$, in which $v$ is the mean velocity, $r$ is the radius, and $D$ and $\eta$ are the density and viscosity, respectively, of the flowing liquid. Under ordinary conditions of capillary flow, sustained turbulence is not to be expected [5, chapter III] at Reynolds numbers less than 2,000. The present measurements were conducted in the range 100 to 650 , and consequently the flow is assumed to be laminar, except possibly at the ends of the capillaries.

The system under consideration consists of a capillary having square-cut ends and located between two chambers that are large with respect to the bore of the capillary. The liquid in one chamber is accelerated from essential rest to the velocity in the capillary and then is brought to essential rest in the exit chamber. The measured quantities used in calculating the viscosity are $P$, the pressure drop between the two chambers; $l$, the length of the capillary; $r$, its radius; and $Q$, the volume rate of flow.

In the portion of a cylindrical tube remote from the ends the distribution of velocities across the tube is parabolic, and Poiseuille's laws are known to apply when the flow is laminar. These laws are expressed by the equation

$$
\frac{d p}{d l}=\frac{8 \eta Q}{\pi r^{4}}
$$

where $d p / d l$ is the pressure gradient. Two kinds of corrections are necessary to modify eq 1 so that in its integrated form it will hold for a tube of finite length, in which account must be taken of the special conditions existing at the ends of the tube. First, the liquid entering the capillary is accelerated at the expense of the measured pressure drop. The amount of this conversion of static pressure to kinetic energy may be expressed as a part of the measured pressure drop by the addition of a term

$$
\frac{m D Q^{2}}{\pi^{2} r^{4}}
$$

in which $m$ is a coefficient whose magnitude depends in part upon the flow pattern at the entrance end of the tube. Within the range of Reynolds numbers covered here, it is probable that the kinetic energy of the flowing liquid is entirely dissipated as heat in the exit chamber [6]. However, if there should be some conversion of kinetic energy to static pressure in the process of deceleration, it would be accounted for in the magnitude of $m$.

The second correction that is required to account for the phenomena peculiar to the ends of the tube is the result of the work done against viscous forces in the rearrangement of the velocity distribution. The effect of this resistance in the converging and diverging streamlines at the ends of the tube is proportional to the radius and may be expressed as a hypothetical addition to the length. The effective length of the tube then becomes $l+n r$, in which $n$ is a constant. A rather complete discussion of both of these corrections is given by Barr [7].

The complete equation for the flow through a capillary tube is usually expressed in one of the following equivalent forms:

$$
\begin{aligned}
\eta & =\frac{\pi r^{4} P}{8 Q(l+n r)}-\frac{m D Q}{8 \pi(l+n r)}, \\
P & =\frac{8 Q \eta}{\pi r^{4}}(l+n r)+\frac{m D Q^{2}}{\pi^{2} r^{4}}, \\
\frac{P}{Q} & =\frac{8 \eta}{\pi r^{4}}(l+n r)+\frac{m D}{\pi^{2} r^{4}} \cdot Q .
\end{aligned}
$$

To calculate the viscosity from measurements made with a single capillary, numerical values must be assigned to $m$ and $n$. If, for a given liquid, the values of the pressure drop corresponding to various rates of flow are measured, values of $P / Q$ may be plotted against $Q$, and a straight line results as long as $m$ and $n$ remain constant. Such data may be used to demonstrate the constancy of $m$ and $n$ under given conditions and also to evaluate $m$ for a particular capillary through use of eq 4 .

When using capillaries of relatively large lengthradius ratios, it is obvious that $n$ is less significant. Conversely, this fact has prevented its evaluation with much certainty. Most of the published experimental values lie between zero and unity [7], but in many cases the experimental error is nearly as large as the quantity being measured. The most reliable work seems to have been performed by Bond [8], who concluded that $n=0.566 \pm 0.020$ for the tubes that he used. However, some of Bond's measurements were made with capillaries that were not sufficiently long for the parabolic distribution of velocities to become completely established, and consequently his results may not be strictly applicable to longer tubes.

It is desirable, therefore, to calculate the viscosity from flow measurements that render uncertainties in the value of $n$ completely negligible. This may be accomplished through the simultaneous solution of data obtained in two capillaries having the same radius but different lengths. If we denote the measured quantities associated with the longer capillary by the subscript 1 , and those pertaining to the shorter by the subscript 2, we obtain from eq 3 for the longer capillary

$$
P_{1}=\frac{8 Q \eta}{\pi r^{4}}\left(l_{1}+n r\right)+\frac{m D Q^{2}}{\pi^{2} r^{4}}
$$

and for the same rate of flow in the shorter

$$
P_{2}=\frac{8 Q \eta}{\pi r^{4}}\left(l_{2}+n r\right)+\frac{m D Q^{2}}{\pi^{2} r^{4}} .
$$

Subtracting eq 6 from eq 5 


$$
\begin{gathered}
P_{1}-P_{2}=\frac{8 Q \eta}{\pi r^{4}}\left(l_{1}-l_{2}\right), \\
\eta=\frac{\pi r^{4}\left(P_{1}-P_{2}\right)}{8 Q\left(l_{1}-l_{2}\right)} .
\end{gathered}
$$

However, it is not practicable to select two lengths of capillary having identical radii, even if they are cut from the same length of tubing. Also, while the flow data may show $m$ and $n$ to be constants for each tube, they may not be the same for both. Consequently, assigning the proper subscripts to $r, m$, and $n$ in eq 5 and 6 and proceeding as before, the more general equation becomes

$$
\eta=\frac{\frac{\pi}{8 Q}\left(P_{1} r_{1}^{4}-P_{2} r_{2}^{4}\right)-\frac{D Q}{8 \pi}\left(m_{1}-m_{2}\right)}{\left(l_{1}-l_{2}\right)+\left(n_{1} r_{1}-n_{2} r_{2}\right)} .
$$

But if any reasonable values whatever are assigned to $n_{1}$ and $n_{2}$, and $r_{1}$ does not differ greatly from $r_{2}$, the quantity $\left(n_{1} r_{1}-n_{2} r_{2}\right)$ will be negligible with respect to $\left(l_{1}-l_{2}\right)$ within the order of accuracy with which the lengths can be measured. Accordingly, the viscosity may be calculated by the equation

$$
\eta=\frac{\frac{\pi}{8 Q}\left(P_{1} r_{1}^{4}-P_{2} r_{2}^{4}\right)-\frac{D Q}{8 \pi}\left(m_{1}-m_{2}\right)}{l_{1}-l_{2}},
$$

in which values for $m_{1}$ and $m_{2}$ are obtained from the flow data through use of eq 4 , as mentioned above.

\section{Apparatus}

\subsection{General Description}

The experimental method involves flowing water through a capillary at various known constant rates and measuring the corresponding pressure drops through the capillary by means of a differential mercury manometer. The general arrangement of the apparatus used in making the flow measurements is shown diagrammatically in figure 1 . The main elements are the viscometer, the injector for producing the flow of water through the capillary, and the differential mercury manometer. The

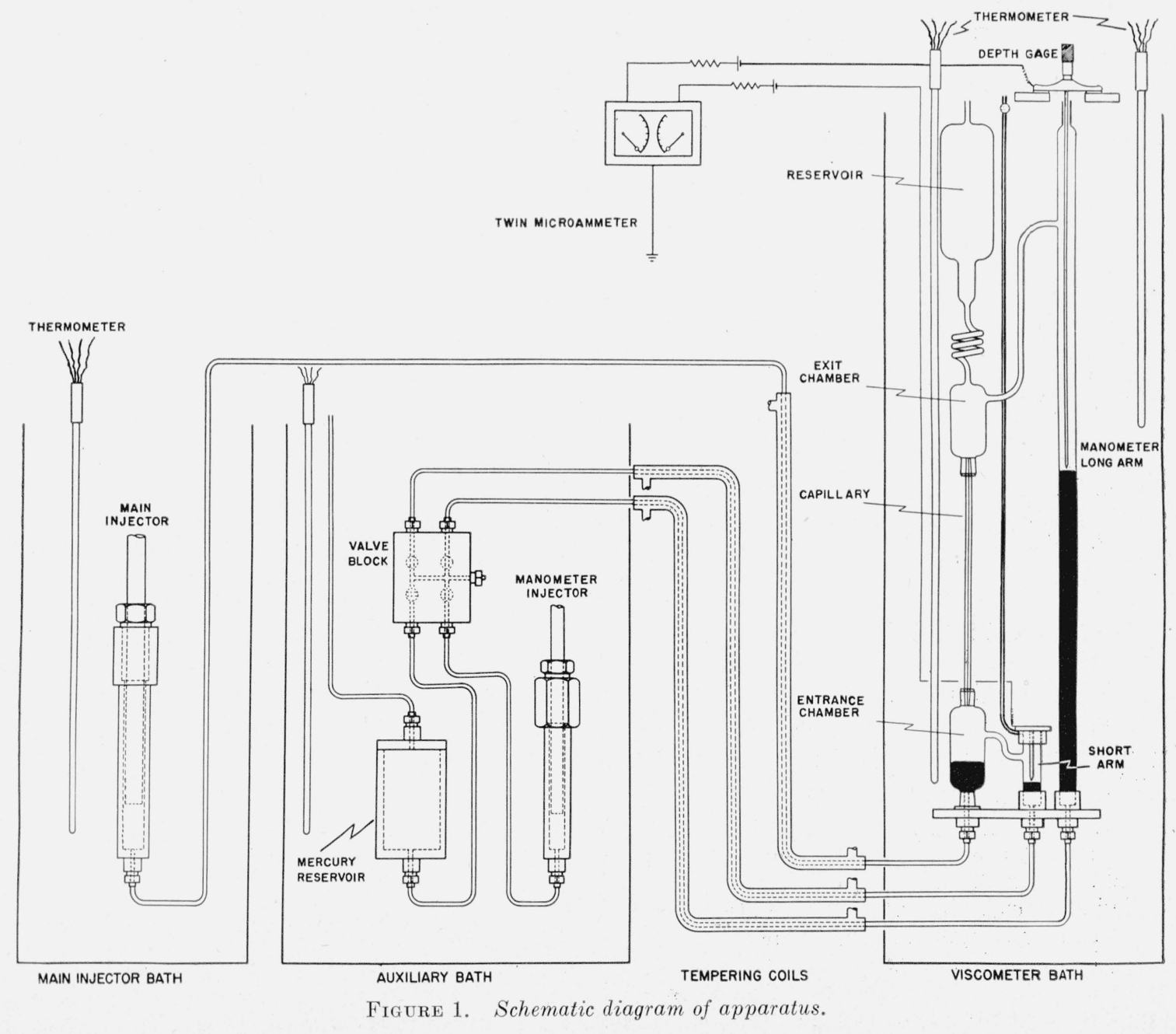


viscometer consists of a capillary mounted vertically between glass entrance and exit chambers. Glass tubes connect the entrance and exit chambers to the short and long arms of the manometer, respectively. A reservoir above the viscometer is connected to the exit chamber by a spiral of glass tubing as shown. Mercury in the entrance chamber and the two arms of the manometer is represented by the black areas. The parts of the viscometer and manometer above the mercury are filled with water to a level in the reservoir that is higher than the point where the side tube from the exit chamber connects with the manometer.

The various rates of flow are produced in the capillary by injecting mercury into the entrance chamber at various constant rates, thus displacing water upward through the capillary. The water flows from the exit chamber into both the long arm of the manometer and the reservoir, maintaining the same level in each. The mercury is injected by means of an accurately ground and lapped piston driven at a uniform rate. The piston is geared to a synchronous motor operating on a source of electric power of controlled frequency. Different rates of flow are obtained by changing the gear combinations.

The manometer consists of a mercury-filled U-tube, in which the short arm level is adjusted to a fixed height, and the level in the long arm is adjusted by addition or removal of mercury until the resulting mercury column balances the pressure drops through the capillary. The mercury in the manometer is manipulated by means of the manometer injector and mercury reservoir shown in the auxiliary bath. Constant-volume stopcocks are provided to shut off the two arms of the manometer from each other and for injecting mercury into either arm independently.

The viscometer and manometer are mounted together in a liquid bath maintained at the test temperature of $20^{\circ} \mathrm{C}$. The temperatures of the main injector and the auxiliary apparatus for the manometer are held constant in separate baths, which are maintained somewhat above room temperature for ease in thermostatting. The connecting mercury lines between the injector and auxiliary baths and the viscometer bath are jacketed with liquid pumped from the viscometer bath to bring the mercury nearly to $20^{\circ} \mathrm{C}$ before it enters the manometer or viscometer.

\subsection{Main Injector}

The function of the injector mechanism is to provide a known constant flow of mercury into the entrance chamber of the viscometer, thus forcing water through the capillary at a rate that is constant when the manometer is at equilibrium.

Figure 2 shows the injector and its driving mechanism without the constant-temperature bath

The injector consists of a vertically mounted, mercury-filled steel cylinder into which a steel piston is forced by a rigidly coupled screw. The screw, held from turning by outriders bearing on tracks parallel to its axis, is moved by a rotating nut held between thrust-type ball bearings. On the periphery of the

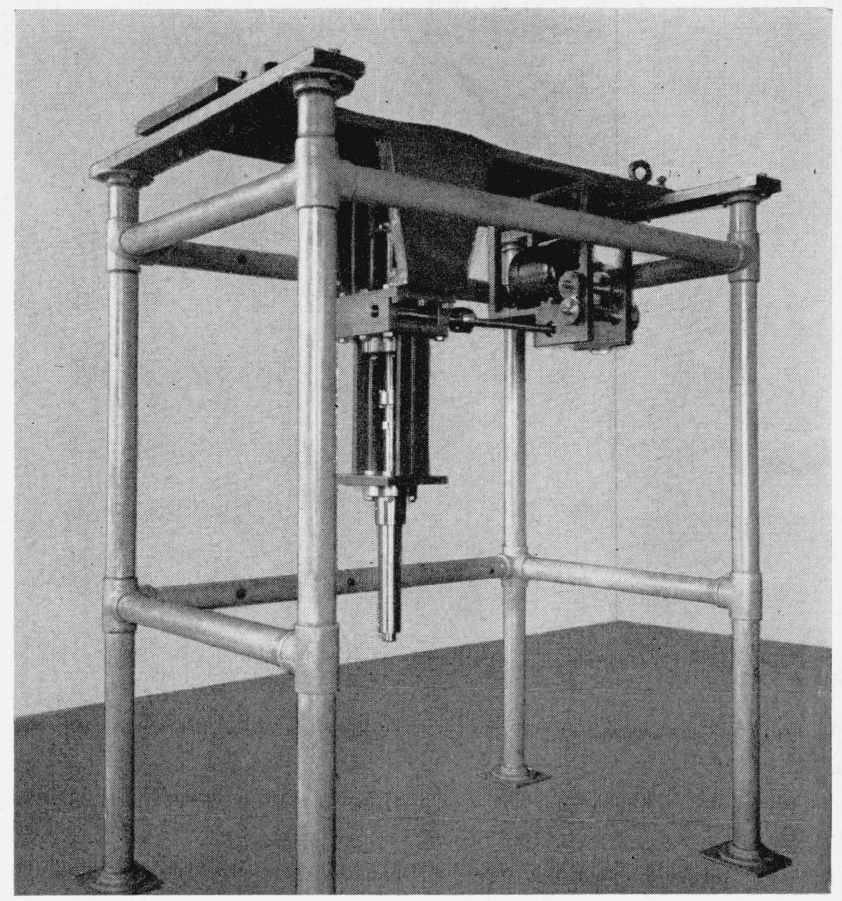

Figure 2. Main injector with thermostat removed.

nut is a worm gear driven by a worm on a horizontal drive shaft. This mechanism is driven through a change gear box by a synchronous motor.

The piston, nominally 1 in. in diameter, is made of hardened, ground, and lapped Ketos steel. Its diameter is uniform to \pm 0.00004 in. The piston enters the steel cylinder through a vacuum-tight gland that contains cloth impregnated with ceresin wax. The cylinder has an inside diameter of $1 \frac{11}{8} \mathrm{in}$; thus there is a $1 / 16$-in. radial clearance between cylinder and piston. With a clearance of this magnitude, the formation of voids is unlikely except in the packing gland, and the volume of mercury expelled from the cylinder should be precisely the volume of the entering piston. The cylinder was thoroughly pumped out and filled with mercury under vacuum.

The screw is made of hardened steel. It has a maximum diameter of $1 \mathrm{in}$., and an 8-pitch Acme thread. The mating threads of the nut are made of Babbit metal. The worm gear that forms the periphery of the nut is of mild steel, and the mating worm is of hardened steel. These parts were specially machined so as to have no periodic error greater than 1 part in 10,000 of their lead. The worm and gear give a 40-to-1 reduction.

Speeds are changed by changing one or both pairs of meshed gears mounted outside the gear box. These are commercial grade, 32-pitch, 1/2-in. face, helical gears. The drive is a 3 -phase, 110 -volt, $1 / 4^{-}$ horsepower, synchronous motor.

Power for driving the injector mechanism is obtained from a constant-frequency generator driven by a special motor that takes its power from the commercial lines but has its speed automatically held in synchrony with a highly accurate 60 -cycle 
signal originating in a quartz-crystal oscillator maintained by the Radio Division of the Bureau. The piston and cylinder are immersed in a stirred oil bath whose temperature can be maintained at a chosen point within $\pm 0.002^{\circ} \mathrm{C}$. The worm-gear mechanism, gear box, and motor are in a cork-lined inclosure directly above the oil bath.

The rate of delivery of mercury from the injector is calculated from the measured delivery per turn of the worm drive shaft and the rotational speed of the shaft. The speed of the shaft is calculated from the motor speed and the ratio of the gears employed. Variations in speed caused by imperfections in the change gears can be neglected as they are of short period and tend to be integrated by the slow reaction of the manometer to changes in pressure. (The time constants for the system will be discussed later.) Variations in motor speed arising from frequency fluctuations in the power supply are guarded against. A permanent magnet, held in a collar, is installed on the drive-motor shaft in such a way that it induces pulses in a stationary coil with every revolution. The frequency of these pulses is compared with that of the 60-cycle control signal. If the power supply shifts more than $120^{\circ}$ in phase with respect to the 60-cycle control sional, a buzzer sounds. An oscillograph is used to determine whether buzzer warnings indicate oscillations or actual gain or loss of cycles With these safeguards in operation, the drive speed is taken to be $1,800 \mathrm{rpm}$ without error.

The displacement of mercury by the piston per drive-shaft turn was determined by advancing the piston through its stroke in steps, catching and weighing the mercury displaced in each step. For this purpose a revolution counter and a divided drum were attached to the drive shaft, permitting reading of intervals to \pm 0.001 turn. The mercury is ejected through a delivery tube attached to the mercury line from the cylinder. This tube, similar to those used in ice calorimetry [9], was made by blowing a small spherical bulb at one end of a glass capillary tube. This bulb was then ground off in a plane perpendicular to the axis of the tube until the wall at the bottom was just broken through. With such a terminal configuration, the tube being mounted vertically, the mercury thread tends to break, leaving the bulb full, and variations in the delivery of mercury are minimized.

The smallest interval into which the total stroke of the piston can be divided is governed by the precision with which the mercury thread in the delivery tube can be broken, and the constancy of volume of the somewhat elastic cylinder and connecting tube. Repeated measurements of the mass delivered by the piston over a short part of its stroke showed a standard deviation of $3 \mathrm{mg}$ from the mean.

The total delivery for a complete stroke of the piston is $109 \mathrm{~cm}^{3}(1,470 \mathrm{~g}$ of mercury). The drive shaft makes 2,700 turns in driving the piston through this distance. For calibration, the total stroke was divided into 20 approximately equal intervals, each corresponding to about 135 turns of the drive shaft and a displacement of $73.5 \mathrm{~g}$ of mercury. In each interval the injector was driven under power for the required number of turns and allowed to coast to rest. The next interval was begun from this point of rest. In this way the slack in the drive was always kept in the same direction, minimizing variations arising from play in the driving gears and screw. The determination of the exact length of a particular interval in terms of number of turns of the drive shaft was obtained from the difference of two readings of the counter and divided drum on the shaft. As each reading was made to \pm 0.001 turn, the length of each interval could be determined to \pm 0.002 turn, or 1.5 parts in 100,000 .

The increments of mercury were weighed with an accuracy of about 0.3 part in 100,000 .

The mean rate of delivery for the entire stroke, expressed as mass displacement of mercury per turn of the drive shaft, was calculated by summing the masses of mercury delivered in all of the intervals and dividing by the total number of turns for the complete stroke. The uniformity of the rate of displacement throughout the stroke was obtained by a comparison of the rate calculated for each interval with the mean rate.

The first calibrations of the injector indicated that rate of displacement was not constant throughout the entire stroke of the piston, being more uniform during the second half of the stroke. As a consequence, only the second half of the piston stroke was employed in the earlier measurements.

Six calibrations were completed prior to 1941, five being made with the injector at $30^{\circ} \mathrm{C}$ and one at $35^{\circ} \mathrm{C}$. The mean rates of delivery obtained in these calibrations for the portion of the stroke used in the flow measurements (intervals 12 through 19) are given in table 1 . The rates at $35^{\circ} \mathrm{C}$ were computed from the calibrations made at $30^{\circ} \mathrm{C}$, using $37.8 \times 10^{-6} /{ }^{\circ} \mathrm{C}$ as the cubical coefficient of thermal expansion for the Ketos steel piston [12] and $181.0 \times 10^{-6} /{ }^{\circ} \mathrm{C}$ for the coefficient for mercury. (See appendix $\mathrm{A}$.)

TABLE 1. Main injector calibrations, March 1939 through January 1940

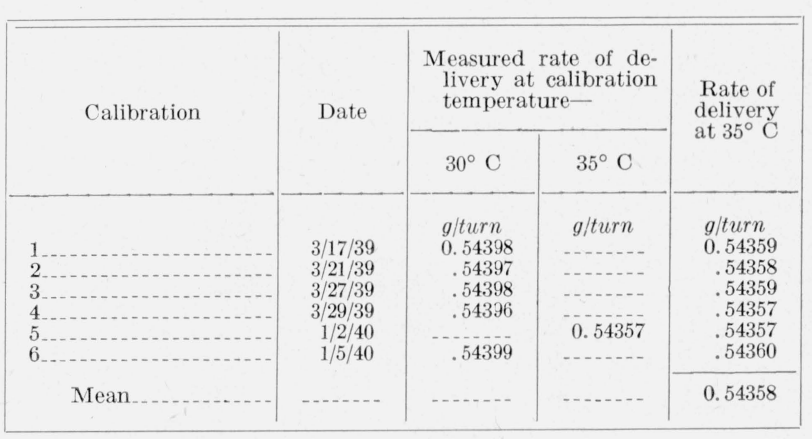

Deviations from the mean rates of delivery for each calibration are shown in table 2 . The computed standard deviation from the mean of a given calibration is given, and the standard deviation from the mean of each interval is given for the six calibrations. On the basis of the experiments with the delivery tube 
which showed a standard deviation of $3 \mathrm{mg}$ of mercury as previously stated, the deviation to be expected from this cause would be \pm 4 parts in 100,000 for intervals of this size. It is seen that the deviations in the first four calibrations are about twice this great and are over 10 times as large in the last two. It must be concluded then that variations in rate of delivery do exist along the piston. There are also real variations from calibration to calibration, especially in the last two. The relatively large changes between the fourth, fifth, and sixth may have been caused by slight shifts in the packing gland. These variations are not considered serious as the agreement between the mean rates, as shown in table 1 , is very good for all six calibrations, and short-period variations along the stroke of the piston tend to be integrated by the manometer.

TABLE 2. Deviations in parts per 100,000 from the mean rate of delivery for each calibration

\begin{tabular}{|c|c|c|c|c|c|c|c|}
\hline \multirow{2}{*}{ Interval } & \multicolumn{6}{|c|}{ Calibration } & \multirow{2}{*}{$\begin{array}{l}\text { Standard } \\
\text { deviation } \\
\text { each } \\
\text { interval }\end{array}$} \\
\hline & 1 & 2 & 3 & 4 & 5 & 6 & \\
\hline $\begin{array}{l}12 \\
13 \\
14 \\
15\end{array}$ & $\begin{array}{r}-1 \\
+21 \\
-2 \\
-5\end{array}$ & $\begin{array}{r}-3 \\
+16 \\
-5 \\
-2\end{array}$ & $\begin{array}{l}+3 \\
-1 \\
+4 \\
+5\end{array}$ & $\begin{array}{l}-5 \\
+4 \\
-1 \\
+3\end{array}$ & $\begin{array}{r}-31 \\
+78 \\
-58 \\
+7\end{array}$ & $\begin{array}{r}+13 \\
-5 \\
+60 \\
+18\end{array}$ & $\begin{array}{c} \pm 12 \\
\pm 27 \\
\pm 30 \\
\pm 8\end{array}$ \\
\hline $\begin{array}{l}16 \\
17 \\
18 \\
19\end{array}$ & $\begin{array}{r}+4 \\
-17 \\
-2 \\
+2\end{array}$ & $\begin{array}{r}-2 \\
-10 \\
+1 \\
+6\end{array}$ & $\begin{array}{l}-6 \\
-7 \\
-1 \\
+3\end{array}$ & $\begin{array}{r}-16 \\
+9 \\
+5 \\
+1\end{array}$ & $\begin{array}{r}+52 \\
-10 \\
-31 \\
-8\end{array}$ & $\begin{array}{l}-66 \\
+41 \\
-51 \\
-12\end{array}$ & $\begin{array}{l} \pm 33 \\
\pm 22 \\
\pm 26 \\
\pm 8\end{array}$ \\
\hline $\begin{array}{l}\text { Standard } \\
\text { deviation }\end{array}$ & \pm 9 & \pm 8 & \pm 5 & \pm 8 & \pm 46 & \pm 44 & \\
\hline
\end{tabular}

It should be pointed out that the variations in the separation of the mercury at the end of the delivery tube enter only twice in the determinations of the mean rates given in table 1 . A deficiency in delivery at the end of 1 interval results in a high delivery in the following interval, and only the start of the first and the end of the last interval have any effect. The expected deviation from this cause is thus reduced to \pm 0.5 part in 100,000 for the portion of the piston 8 intervals long.

The earlier flow measurements (series I and II, to be identified later) were made with this filling with the injector thermostatted at $35^{\circ} \mathrm{C}$, and rates of flow in the viscometer were based on the value of $0.54358 \mathrm{~g} /$ turn, which is the mean of the values given in table 1 .

Following these calibrations, work on the project was interrupted until January 1947. When the work was resumed in January 1947, the laboratory was air-conditioned. This made it possible to thermostat the injector at $30^{\circ} \mathrm{C}$ instead of $35^{\circ} \mathrm{C}$. After the injector had been disassembled, cleaned, and refilled, three calibrations of the rate of delivery of the injector at $30^{\circ} \mathrm{C}$ were completed before making flow measurements. These data indicated that the useful part of the stroke of the piston could be extended to include intervals 5 through 19 without seriously affecting uniformity of delivery. Consequently this longer portion of the stroke was used for the later measurements.
Six calibrations were made in 1947 and 1948 on this filling of the injector before the injector was again refilled. The results of these six calibrations are given in table 3 . In calibrations 10,11 , and 12 , the stroke of the piston was not interrupted at the end of each interval, the total delivery of the injector for intervals 5 through 19 being collected and weighed in one bulk. The weighings of these relatively large quantities of mercury were made by the Mass Section of the Bureau with an accuracy of 1 part in 100,000. No significant difference was apparent in the mean rate of delivery as determined in bulk as compared with the calibrations by intervals.

TABLE 3. Calibrations with second filling of injector

\begin{tabular}{|c|c|c|}
\hline Calibration & Date & $\begin{array}{l}\text { Measured } \\
\text { rate at } \\
30^{\circ} \mathrm{C}\end{array}$ \\
\hline $\begin{array}{l}7 \\
8 \\
9 \\
9 \\
10 \mathrm{a}^{\mathrm{a}}- \\
12 \mathrm{a}^{-}\end{array}$ & $\begin{array}{r}4 / 2 / 47 \\
7 / 7 / 47 \\
7 / 22 / 47 \\
8 / 4 / 47 \\
1 / 3 / 48 \\
1 / 3 / 48\end{array}$ & $\begin{array}{l}\text { g/turn } \\
0.54391 \\
.54393 \\
.54393 \\
.54392 \\
.54391 \\
.54390\end{array}$ \\
\hline Mean & & 0.54392 \\
\hline
\end{tabular}

a Calibrations not made by increments.

The deviations for calibrations 7, 8, and 9 are given in table 4. They are seen to be somewhat larger than those for the first four calibrations with the initial filling but are much smaller than those for 5 and 6.

TABLE 4. Second filling of injector

Deviations in parts per 100,000 from mean rate of delivery for each calibration

\begin{tabular}{|c|c|c|c|c|}
\hline \multirow{2}{*}{ Interval } & \multicolumn{3}{|c|}{ Calibration } & \multirow{2}{*}{$\begin{array}{c}\text { Standard } \\
\text { deviation } \\
\text { each } \\
\text { interval }\end{array}$} \\
\hline & 7 & 8 & 9 & \\
\hline $\begin{array}{l}5 \\
6 \\
7 \\
8 \\
9\end{array}$ & $\begin{array}{r}-8 \\
-1 \\
-25 \\
+7 \\
-18\end{array}$ & $\begin{array}{r}-2 \\
-29 \\
-12 \\
+9 \\
-19\end{array}$ & $\begin{array}{r}+2 \\
-15 \\
-17 \\
-8 \\
-13\end{array}$ & $\begin{array}{r} \pm 6 \\
\pm 14 \\
\pm 8 \\
\pm 11 \\
\pm 3\end{array}$ \\
\hline $\begin{array}{l}10 \\
11 \\
12 \\
14\end{array}$ & $\begin{array}{r}+13 \\
-12 \\
+1 \\
+24 \\
-9\end{array}$ & $\begin{array}{r}+13 \\
-10 \\
+1 \\
+24 \\
+2\end{array}$ & $\begin{array}{l}+15 \\
-14 \\
+10 \\
+27 \\
-3\end{array}$ & $\begin{array}{l} \pm 2 \\
\pm 2 \\
\pm 6 \\
\pm 2 \\
\pm 6\end{array}$ \\
\hline $\begin{array}{l}15 \\
16 \\
17 \\
18 \\
19\end{array}$ & $\begin{array}{r}+6 \\
-8 \\
+6 \\
+18 \\
+3\end{array}$ & $\begin{array}{r}+13 \\
+3 \\
-27 \\
+8 \\
+26\end{array}$ & $\begin{array}{r}+14 \\
-9 \\
-19 \\
+10 \\
+19\end{array}$ & $\begin{array}{r} \pm 5 \\
\pm 8 \\
\pm 20 \\
\pm 5 \\
\pm 14\end{array}$ \\
\hline $\begin{array}{l}\text { Standard } \\
\text { deviation_. }\end{array}$ & \pm 14 & \pm 17 & \pm 17 & \\
\hline
\end{tabular}

Flow series III and IV were made with this second filling with the injector thermostated at $30^{\circ} \mathrm{C}$, and rates of flow were calculated by using the mean value of $0.54392 \mathrm{~g} /$ turn shown in table 3 .

Following the fourth series of flow tests, the injector was again cleaned and refilled. The results of the five calibrations made with this third filling are given in tables 5 and 6 . The deviations shown in 
table 6 are about the same as were found for the second filling. The data given in table 5 indicate an increase in the delivery rate of about 7 parts in 100,000 over the period of about a year and a half covered by these calibrations. This was not considered serious, and as with the previous fillings, the mean of the five calibrations was used in calculating the flow rates. The latest flow tests, series V through XII, were completed with this filling, $0.54396 \mathrm{~g} /$ turn being taken as the rate of delivery for the injector.

TABLE 5. Calibrations with third filling of injector

\begin{tabular}{|c|c|c|}
\hline Calibration & Date & $\begin{array}{c}\text { Measured } \\
\text { rate at } \\
30^{\circ} \mathrm{C}\end{array}$ \\
\hline $\begin{array}{l}13 \\
14 \\
15 \\
16 \\
17\end{array}$ & $\begin{array}{r}5 / 24 / 48 \\
12 / 8 / 48 \\
1 / 6 / 49 \\
8 / 19 / 49 \\
10 / 21 / 49\end{array}$ & $\begin{array}{l}\text { g/turn } \\
0.54393 \\
.54395 \\
.5496 \\
.54397 \\
.54397\end{array}$ \\
\hline Mean_... & & 0.54396 \\
\hline
\end{tabular}

TABLE 6. Third filling of injector

Deviations in parts per 100,000 from mean rate of delivery for each calibration

\begin{tabular}{|c|c|c|c|c|c|c|}
\hline \multirow{2}{*}{ Interval } & \multicolumn{5}{|c|}{ Calibration } & \multirow{2}{*}{$\begin{array}{c}\text { Standard } \\
\text { deviatior } \\
\text { each } \\
\text { interval }\end{array}$} \\
\hline & 13 & 14 & 15 & 16 & 17 & \\
\hline $\begin{array}{l}5 \\
6 \\
7 \\
8 \\
9\end{array}$ & $\begin{array}{r}-7 \\
-20 \\
-9 \\
+19 \\
-20\end{array}$ & $\begin{array}{r}-4 \\
-10 \\
-17 \\
+21 \\
-23\end{array}$ & $\begin{array}{r}+4 \\
-5 \\
-8 \\
+22 \\
-7\end{array}$ & $\begin{array}{r}+5 \\
0 \\
-2 \\
+26 \\
-25\end{array}$ & $\begin{array}{r}+5 \\
-6 \\
+6 \\
+24 \\
-13\end{array}$ & $\begin{array}{l} \pm 7 \\
\pm 5 \\
\pm 8 \\
\pm 3 \\
\pm 8 \\
\pm 8\end{array}$ \\
\hline $\begin{array}{l}10 \\
11 \\
12 \\
13 \\
14\end{array}$ & $\begin{array}{r}-2 \\
+12 \\
-17 \\
+30 \\
+2\end{array}$ & $\begin{array}{r}+13 \\
+6 \\
-8 \\
+29 \\
-12\end{array}$ & $\begin{array}{r}-6 \\
+11 \\
-22 \\
+25 \\
-5\end{array}$ & $\begin{array}{r}+20 \\
+23 \\
-2 \\
+21 \\
-10\end{array}$ & $\begin{array}{r}+10 \\
+22 \\
+2 \\
+30 \\
+4\end{array}$ & $\begin{array}{r} \pm 11 \\
\pm 8 \\
\pm 11 \\
\pm 4 \\
\pm 8\end{array}$ \\
\hline $\begin{array}{l}15 \\
16 \\
17 \\
18 \\
19\end{array}$ & $\begin{array}{r}+4 \\
-6 \\
-31 \\
+17 \\
+31\end{array}$ & $\begin{array}{r}+1 \\
-6 \\
-25 \\
+8 \\
+27\end{array}$ & $\begin{array}{r}-4 \\
-9 \\
-31 \\
-7 \\
+43\end{array}$ & $\begin{array}{r}-6 \\
-28 \\
-30 \\
-1 \\
+8\end{array}$ & $\begin{array}{r}-9 \\
-32 \\
-58 \\
-7 \\
+23\end{array}$ & $\begin{array}{r} \pm 6 \\
\pm 15 \\
\pm 13 \\
\pm 11 \\
\pm 13\end{array}$ \\
\hline $\begin{array}{l}\text { Standard } \\
\text { de via- } \\
\text { tion. }\end{array}$ & \pm 19 & \pm 18 & \pm 18 & \pm 18 & \pm 22 & \\
\hline
\end{tabular}

The over-all performance of the injector was very satisfactory. No significant changes in the mean delivery rate were found even after the injector had been idle for the period of 6 years between the first and second fillings. The mean of the six calibrations with the first filling was recalculated to include the intervals 5 through 19 and found to be $0.54394 \mathrm{~g} /$ turn. This result compares very favorably with the values of 0.54392 and 0.54396 , which were obtained with the second and third fillings, respectively, and it is felt that the mean rates of delivery used were known to somewhat better than 1 part in 10,000 .

\subsection{Manometer}

The general operation of the manometer has been described above. Both arms of the manometer are constructed of glass tubing, the inside diameter of which is $0.97 \mathrm{in}$.
The lower ends are ground on a taper and cemented into matching stainless-steel seats, which connect to the mercury lines, as shown in figure 1 . These connectors are mounted in a duralumin frame, which also supports the upper parts of the manometer and viscometer.

The short arm is about $3.5 \mathrm{in}$. high and is ground at the top to fit a stainless-steel cap which is cemented in place. The small tube that runs from the side of the cap to a gas-tight valve situated above the liquid level in the bath, serves to vent air from the top of the short arm when the apparatus is being filled with water. A weight, not shown in the figure, bears on the cap to prevent its being unseated under pressure.

The level of the mercury in the short arm is adjusted until it just makes contact with a fixed stainless-steel rod that projects downward from the cap as shown. This rod terminates in a point having an included angle of $60^{\circ}$. Contact between mercury and rod is determined electrically as described below.

The heights of mercury in the long arm are measured from a fixed surface plate above the mercury by means of calibrated stainless-steel depth gage rods, which fit in a micrometer head having a range of 1 in. These rods are ${ }^{3} / 16 \mathrm{in}$. in diameter and cover the range from 11 to $50 \mathrm{in}$. in 1-in. steps. They terminate in pointed tips similar to the tip of the fixed rod in the short arm. The surface plate is bolted to the duralumin frame, which supports the viscometer and manometer. The depth gage is clamped in a position directly over the long arm, as shown in the figure. Glass flats are used to insulate the gage electrically from the surface plate. The rods pass through a hole in the steel plate and enter the long arm, which extends above the liquid level in the viscometer bath.

The electric circuit in each arm, used to locate the mercury surface, consists of a 1.5 -volt dry cell, a 30,000-ohm resistor, and a microammeter, all in series with the contact. With pointed tips on the rods and reasonably clean mercury-water interfaces, the mercury does not cling to the point, and contact is sharply indicated. It was found essential that the potential of the rods be negative with respect to the mercury. When the rod is made positive a nonconducting layer is immediately formed. Even with negative contacts, some electrolytic action takes place, and if the current is left on too long (several hours) a troublesome precipitate may form on the mercury surface. It is not necessary to insulate the rods from the water. For convenience in matching the contacts in the two arms, twin micro-

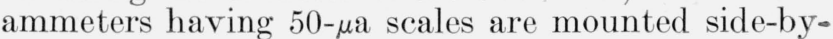
side.

The long arm is mounted as nearly vertical as possible, and the surface plate is carefully leveled. Nevertheless, the rods did not always make contact with the mercury in the center of the meniscus. In these cases the rods were rotated in the gage head until a minimum micrometer reading was obtained. This procedure was followed during the first three series of flow measurements. Thereafter the gage 
rod in use was provided with a brass centering disk fastened near its tip. This disk has a diameter of $3 / 4$ in. Thus the tip was constrained within a $1 / 4$-in.diameter circle at the center of the mercury meniscus. Calculation of the shape of the mercury meniscus [11] indicates that the error in locating the apex is not more than 0.0003 in. with the tip so restricted.

Loss of sensitivity in the long arm was encountered occasionally when the meniscus became contaminated with foreign matter. This surface was cleaned by applying vacuum to a long glass tube that was inserted in the long arm until its tip just touched the mercury surface.

It is estimated that the height of the column of mercury in the manometer may be measured with a precision of 0.0005 in. or better over the range of 0 to $40 \mathrm{in}$.

The auxiliary apparatus for manipulating the mercury in the manometer system has been mentioned previously. Coarse adjustment of the mercury in the long arm is attained by forcing mercury from the reservoir by gas pressure applied through a connection in the gas-tight cover, as shown in figure 1. Fine adjustments in either arm are made with the manometer injector. This injector is essentially similar in design to the main mercury injector. It has a $3 / 4-i n$. piston fixed to a 12-pitch Acme screw. The piston is driven manually through a worm and gear having a 40-to-1 ratio. One turn of the hand crank on the drive shaft raises or lowers the mercury level in one arm by 0.0012 in.

The valves in the steel valve block are of the plugand-barrel type. The rotating plugs are Ketos steel cylinders, hardened, ground, and lapped into hardened Ketos steel sleeves held in the mild steel body of the valve block. In the open position, 1/8-in. transverse holes through the plug and block are brought into alinement. In the closed position reliance is placed upon the very small clearance between plugs and sleeves to insure mercury tightness. The valve stems pass through vacuum-tight packing glands, which permit evacuation of the system for filling with mercury.

The first step in using the manometer is to obtain the manometer zero, which is a measure of the vertical distance between the contact point in the short arm and the surface plate on which the micrometer depth gage head rests. With no flow of mercury into the entrance reservoir of the viscometer, the manometer will come to equilibrium with the mercury at the same level in each arm. Mercury is added to the manometer system until this equilibrium is reached at the level of the contact in the short arm. The mercury level in the long arm is then measured from the surface plate, using the longest rod in the depth gage. The micrometer head reading for this condition is a measure of the desired vertical distance and is called the manometer zero. This reading is designated by $M_{0}$.

To obtain the height of mercury in the manometer for a given flow condition, mercury is forced into the long arm until it stands at its anticipated height. Then, with the main injector running and water flowing through the capillary at the desired rate, the two arms of the manometer are opened to each other. Mercury is added or withdrawn from the manometer system as necessary until equilibrium is reached with the mercury in the short arm at the level of the contact point. The mercury then stands as shown approximately in figure 1 . The distance from the surface plate to the level of mercury in the long arm is measured by means of a gage rod of suitable length. The micrometer head reading for this condition is designated by $M_{Q}$. The differential height of mercury in the manometer is calculated from the difference between this reading and the manometer zero. The height of mercury is equal to $M_{0}$ minus $M_{Q}$ plus the difference in length between the longest gage rod and the particular rod used in obtaining $M_{Q}$.

When the differential heights of mercury are measured in this manner, the actual lengths of the gage rods need not be known, and hence only differences between the longest, which is used in obtaining the manometer zero, and each of the other rods are determined. As it was not practical to cut the rods such that the differences in length were in steps of exactly 1 in., this was closely approximated, and the actual differences were measured, using Hoke gage blocks. These calibrations were repeated as often as was necessary to follow the changes in the lengths of the rods. It is felt that the corrections were known to within at least 0.0004 in. The results of these calibrations are given in detail in appendix B.

\subsection{Viscometer}

The viscometer is arranged as shown in figure 1 . The capillary is mounted vertically between two terminal chambers. Terminal pieces are permanently cemented to the ends of the capillary with a phenolic elastomer (Permacel JX-5). The outer surfaces of the terminal pieces are conically ground to fit the tapered joints in the hemispherical ends of the chambers, as shown. The tapered joints are sealed with Apiezon, Hard Wax W to insure water tightness and permit the interchanging of the different capillaries used in the viscometer. The lower, or entrance, chamber is constructed of glass and is about $2.2 \mathrm{in}$. in diameter and $4.5 \mathrm{in}$. high. Its lower end terminates in a tapered joint that is cemented with the Hard Wax W, to the end of a fitting connecting to the mercury line from the main injector. The wax joints are coated with an automobile gasket shellac to protect the wax from the solvent action of the bath oil. The exit chamber, also of glass, is about $1.7 \mathrm{in}$. in diameter and $4 \mathrm{in}$. high. It is connected by glass tubing to both the reservoir and the long arm of the manometer, as shown. By this means the same water level is maintained in both the viscometer and manometer. The capacity of the reservoir is sufficient to accommodate the volume of water that is displaced through the capillary by a full stroke of the main injector.

In this system, an increase or decrease in the height of mercury in the short arm of the manometer 
requires a corresponding flow of water out of, or into, the short arm through the side tube connecting it with the entrance chamber. Thus, until equilibrium is reached, the rate of flow of water through the capillary will not correspond to the rate of flow of mercury into the entrance chamber, but at any time will depend on the pressure indicated by the differential height of mercury, $h$, in the manometer. If $q$ is the rate of flow through the capillary and $Q$ is the rate of flow of mercury into the entrance chamber, it can be shown that $q$ approaches $Q$ as $h$ approaches the limiting value corresponding to flow $Q$ through the capillary.

As there is flow through the tube connecting the exit reservoir with the long arm, this tube offers some viscous resistance in series with the capillary. It can be shown that the pressure drop through the capillary plus this connecting tube is given by $h\left(D_{\mathrm{Hg}}-D_{\mathrm{W}}\right) g$, where $D_{\mathrm{Hg}}$ and $D_{\mathrm{w}}$ are the densities of mercury and water, respectively, and $g$ is the acceleration of gravity. However, neglecting for the time being the small viscous resistance offered by the connecting tube, and using only the relatively large first term in eq 3 , we can write

If

$$
h=\frac{8 \eta(l+n r)}{\pi r^{4}\left(D_{\mathrm{Hg}}-D_{\mathrm{W}}\right) g} \cdot q \cdot
$$

$$
\frac{8 \eta(l+n r)}{\pi r^{4}\left(D_{\mathrm{Hg}}-D_{\mathrm{W}}\right) g}=k,
$$

eq 10 is rewritten

$$
q=\frac{h}{k}
$$

For the condition where $q$ is not equal to $Q$, the flow of water into or out of the short arm of the manometer is given by $A(1 / 2) d h / d t$, in which $A$ is the cross-sectional area of the manometer tubing and $d h / d t$ is the rate of change of pressure head. The total flow may then be expressed as

$$
Q=\frac{h}{k}+\frac{A}{2} \frac{d h}{d t} .
$$

Integrating with $Q$ constant gives

$$
h=k Q+C \cdot e^{-\frac{2 t}{k A}},
$$

in which $C$ is a constant. This equation shows that the height of mercury in the manometer approaches a value corresponding to flow $Q$ through the capillary, being precisely $k Q$ at infinite time.

In practice, the manometer is preset to approximately its final height and then allowed to approach its precise equilibrium value. The flow time until final readings may be taken depends on the accuracy attainable in measuring the height of mercury in the manometer.

Letting $\Delta h_{0}$ represent the amount by which $h$ differs from $k Q$ at the start of flow and $\Delta h_{t}$ the dif- ference after time $t$ has elapsed, we can write

$$
\frac{\Delta h_{0}}{\Delta h_{t}}=e^{\frac{2 t}{k A}},
$$

from which

$$
t=\frac{k A}{2} \ln \left(\frac{\Delta h_{0}}{\Delta h_{t}}\right)
$$

Thus, through use of eq 15 one can calculate the time required to reduce $\Delta h_{t}$ to any desired fraction of $\Delta h_{0}$.

The results are given in table 7 for each of the capillaries used. These times are designated as time constants of the manometer and are shown for various values of the ratio $\Delta h_{t} / \Delta h_{0}$. The capillary designations given in the table will be identified later.

TABLE 7. Manometer time constants in minutes

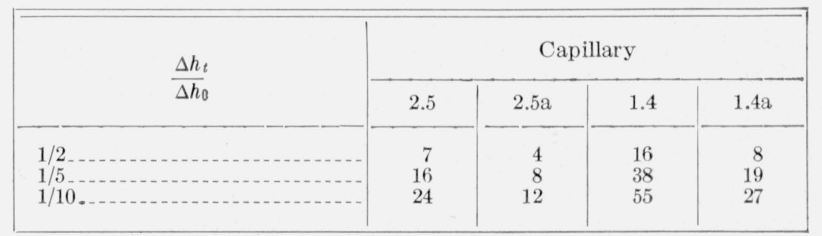

It is evident that with time constants of the magnitudes shown in table 7 , periodic variations in $Q$ resulting from imperfections in the change gears and injector delivery will not introduce appreciable error in the measured pressure.

As mentioned before, the measured pressure includes the pressure drop through the tube connecting the exit reservoir and the long arm. If $P$ is the difference in pressure between the end reservoirs, $l_{T}$ is the length of the connecting tube, $r_{T}$ is the radius of the connecting tube, $B$ is the cross-sectional area of the reservoir, and the other symbols are as before, it is seen that

$$
h\left(D_{\mathrm{Hg}}-D_{\mathrm{W}}\right) g=P\left[1+\frac{l_{T}}{l} \cdot \frac{r^{4}}{r_{T}^{4}}\left(\frac{A}{A+B}\right)\right],
$$

or

$$
P=h\left(D_{\mathrm{Hg}}-D_{\mathrm{W}}\right) g\left[\frac{1}{1+\frac{l_{T}}{l} \cdot \frac{r^{4}}{r_{T}^{4}}\left(\frac{A}{A+B}\right)}\right] \text {. }
$$

The calculated value of this factor by which $h\left(D_{\mathrm{Hg}}-\right.$ $\left.D_{\mathrm{W}}\right) g$ must be multiplied to give the pressure drop across the capillary alone is as follows for each capillary used:

\begin{tabular}{|c|r|}
\hline Capillary & Factor \\
\cline { 2 - 2 } & \\
\hline 2.5 & 0.999995 \\
\hline $1.5 \mathrm{a}$ & 999980 \\
$1.4 \mathrm{a}$ & 999997 \\
\hline
\end{tabular}


While these corrections are insignificant relative to the precision with which the manometric measurements were made, the corrections were applied.

\subsection{Temperature Control}

The oil baths by means of which the temperatures of the various parts of the apparatus are maintained constant consist of metal tanks insulated with a minimum thickness of 3 in. of ground cork. Inside each tank and close to the side is a vertical stirrer tube 6 in. in diameter extending from above the oil surface to a point a few inches above the bottom. A propeller on an axial shaft in the tube draws oil from the bath through a port just below the oil level and discharges it into the tank near the bottom with sufficient velocity to keep the main body of oil in fairly rapid motion. Electric heating coils and mercury-in-steel thermoregulators, annular in form, are mounted, one above the other, in the stirrer tubes in such fashion that oil flows down over both their inner and outer surfaces.

The viscometer bath is held at $20^{\circ} \mathrm{C}$ by artificial cooling. To effect this cooling a tank of light oil is maintained at $15^{\circ} \pm 0.1^{\circ} \mathrm{C}$ by a refrigerating system in conjunction with an automatically controlled electric heater. The oil from this tank is pumped at a steady rate through a coil in the stirrer tube in the viscometer bath, and the temperature is controlled by a thermostatically regulated heater. This system of temperature regulation was used during the first two series of flow measurements and provided control to $\pm 0.004 \mathrm{deg} \mathrm{C}$. Following these tests the apparatus was idle for 6 years. When work was resumed, it was found that this thermoregulator was insensitive. For the later flow measurements this bath was controlled by manual regulation of a variable transformer. Although tedious, the control was of the order of $\pm 0.001 \mathrm{deg}$ C. As the viscosity of water changes by only 1 part in 10,000 for a temperature change of $0.004 \mathrm{deg} \mathrm{C}$ in the neighborhood of $20^{\circ} \mathrm{C}$, this control was more than adequate.

The main injector and auxiliary baths were held above room temperature, and therefore no artificial cooling was required. The injector bath was found to hold its temperature consistently to $\pm 0.002 \mathrm{deg}$ C. The thermoregulator in the auxiliary bath was not designed to be as sensitive as the other two, and the temperature control in this bath was \pm 0.01 $\operatorname{deg}$ C. Temperature variations of the magnitudes found in these baths cannot affect the measurements by as much as 1 part in 100,000 .

Standard electric circuits were used with the thermoregulators. Steady currents through the heating coils, not quite sufficient to maintain temperature, were periodically augmented by intermittent currents controlled by the regulators. By means of motor-driven variable resistors, the steady currents were automatically adjusted to changing room temperature, temperature distribution in bath insulation, and line voltage.

Two thermometers were used in the viscometer bath, one at the level of the entrance chamber of the viscometer and the other at the level of the exit chamber. Temperature gradients were so small that readings on these two thermometers always agreed within $0.002 \mathrm{deg} \mathrm{C}$.

When flow measurements are being made the mercury leaves the injector at a temperature $10 \mathrm{deg}$ or more higher than that of the viscometer bath. In order to bring the temperature of the mercury close to $20 \mathrm{deg} \mathrm{C}$ before it enters the entrance chamber of the viscometer, oil is pumped from the viscometer bath through a copper jacket placed around the mercury line. The returning oil is discharged into the top of the viscometer bath stirrer tube, and hence its effect is to improve stirring rather than to increase temperature gradients throughout the bath. Experiments were performed to measure the effectiveness of the precooling of the mercury entering the viscometer. A thermometer was introduced into the entrance chamber through the ground joint normally holding the capillary. With the viscometer bath at $20^{\circ} \mathrm{C}$ and the main injector bath at $35^{\circ} \mathrm{C}$, the temperature of the water in the chamber was measured at various rates of flow of mercury into the chamber. Even at the highest rates of flow used $\left(0.25 \mathrm{~cm}^{3} / \mathrm{sec}\right)$, no measurable temperature difference between the water and the bath liquid was observed.

Temperatures were measured with platinum resistance thermometers and a Mueller thermometer bridge. The thermometers were calibrated several times at the steam and sulfur points, and more frequent readings were taken at the ice point or triple point of water. Every 2 months, or oftener, the bridge was calibrated in terms of a 10 -ohm secondary standard. Regular calibrations of the standard were made by the Resistance Measurements Section of the Bureau. It is believed that temperature measurements were made with an accuracy of $\pm 0.001 \mathrm{deg} \mathrm{C}$.

\section{Capillaries and Their Measurement}

\subsection{Selection and Preparation}

Flow measurements were made with four capillaries. One length of capiallary was selected in each of two diameters, and, after measuring their dimensions and making the necessary flow measurements, they were cut in half, and the measurements were repeated with one half-length of each tube. In this manner flow data were obtained on two pairs of capillaries, the tubes in each pair being close to the same diameter but having different lengths.

The capillaries were selected from FS PrecisionBore capillary tubing obtained from the FishSchurman Corp. The first selection was made in 1938 from three tubes of Jena Duran Glass 3891-III having external diameters of about $5 \mathrm{~mm}$ and internal diameters of about $0.5 \mathrm{~mm}$. The capillary selected was numbered 2.5 and the half-length, which was later cut from this tube, was numbered $2.5 \mathrm{a}$. Three more tubes were obtained from the same company in 1947. These were of Pyrex and had about the same external diameter but had a bore diameter of $0.4 \mathrm{~mm}$. The capillary chosen from this stock 
was designated as No. 1.4 and the half-length as 1.4a.

The tubes were chosen for uniformity and straightness of bore and freedom from blemishes. The character of the inner surfaces was examined under a microscope with the bores filled with water, while the examination for uniformity of bore was made with the tubes mercury-filled. The uniformity of the tubes was such that the selection could be made from the first few obtained.

An unused length from the stock of Jena glass was sectioned part way along its bore in such a way as to expose the surface of the bore for examination. A portion of the exposed surface was photographed at a magnification of $\times 200$ and is shown in figure $3, \mathrm{~A}$.

This section is typical of the surface of the bore of capillaries 2.5 and $2.5 \mathrm{a}$. The surface shown in figure $3, \mathrm{~B}$ is typical of the Pyrex capillaries 1.4 and 1.4a. It is seen that both of these surfaces are characterized by many longitudinal grooves. These grooves vary in width between about 0.002 and 0.008 $\mathrm{mm}$ and are considerably less deep than wide. The Pyrex capillaries are singularly free from very many other markings. The Jena capillaries have regions of pits and elevations superimposed upon the grooved markings. All of these surface markings are so small in relation to the diameters of the capillaries, however, that it is believed their viscometric effects cannot be serious.

To examine for uniformity of bore the mercuryfilled capillary was immersed in oil having the same index of refraction as the glass. Diameter measurements were made with a microscope having a filar micrometer eyepiece. Such measurements were made at points spaced $5 \mathrm{~cm}$ apart, except that the points nearest the two ends of a tube were taken 1 $\mathrm{cm}$ from the end. Measurements were made at each point in four radial directions spaced $45^{\circ}$ apart. The results obtained with capillary 2.5 are given in table 8 . The micrometer eyepiece w as not accurately calibrated, and therefore the numbers in the table are in arbitrary units. The precision of the measurements was about 1 part in 500 . The ends of this tube were designated as 1 and 2, and the distances to the points at which the diameter measurements were made were taken from end 1 .

TABLE 8. Optical measurements of the diameter of capillary 2.5, arbitrary units

\begin{tabular}{|c|c|c|c|c|}
\hline \multirow{2}{*}{$\begin{array}{l}\text { Distance } \\
\text { from end } 1\end{array}$} & \multicolumn{4}{|c|}{ Radial direction- } \\
\hline & $0^{\circ}$ & $45^{\circ}$ & $90^{\circ}$ & $135^{\circ}$ \\
\hline $\mathrm{cm}$ & & & & \\
\hline 1 & 1124 & 1123 & 1128 & a 1120 \\
\hline 5 & 1124 & 1121 & 1127 & 1121 \\
\hline 10 & 1125 & 1127 & 1124 & 1123 \\
\hline 15 & 1129 & 1123 & 1131 & 1126 \\
\hline 20 & 1127 & 1122 & 1131 & 1123 \\
\hline 25 & 1124 & 1124 & 1123 & 1129 \\
\hline 30 & 1125 & 1121 & 1126 & 1128 \\
\hline 35 & 1122 & 1121 & 1131 & 1123 \\
\hline 40 & 1129 & 1127 & 1131 & 1124 \\
\hline 45 & 1129 & 1123 & a 1132 & 1124 \\
\hline 49 & a 1120 & 1124 & 1124 & 1126 \\
\hline
\end{tabular}

s Highest and lowest values.
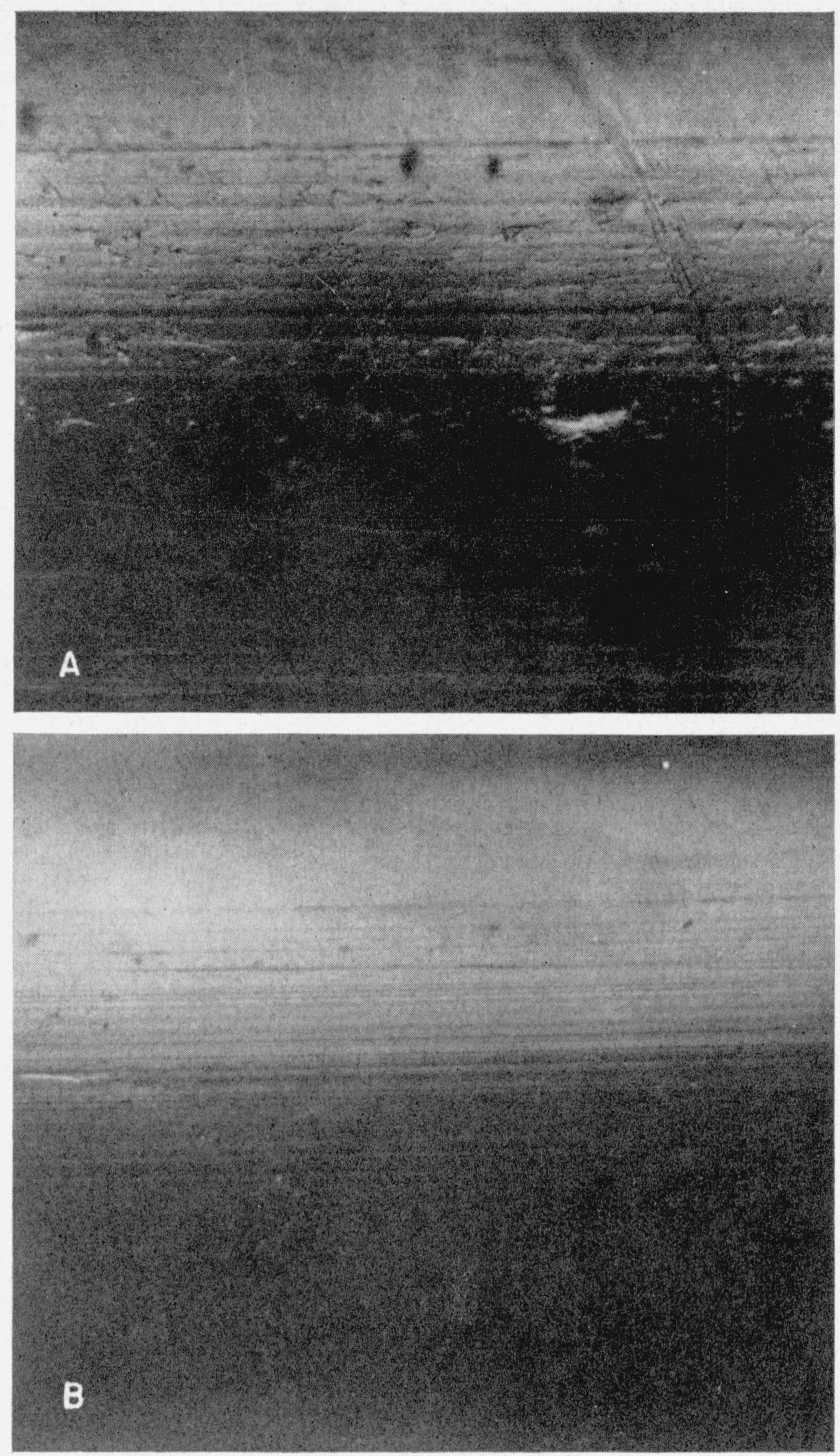

FIGURE 3. Photomicrographs of surface of capillary bores. Magnification $\times 200$. A, typical of Jena glass; B, typical of Pyrex glass.

It is seen that the maximum variation shown by the measurements given in table 8 is only 1 percent. The effect of variations of this order will be discussed later under "Caliber corrections."

Similar measurements made on capillary 1.4 are given in table 9 . The ends of this tube were numbered 4 and 5 , and the distances are measured from end 4 . The bore of this capillary is seen to be about as uniform as that of capillary 2.5, showing a maximum variation of 1.3 percent.

Following this selection, the ends of the capillaries were fitted with glass terminal pieces so that the bores terminate in circular planes $1 \mathrm{~cm}$ in diameter. The end planes of the terminals were ground normal to the axis of the bores and then polished until good sharp edges were obtained at the intersections of the cylindrical bores with the terminal planes.

When the longer capillaries 2.5 and 1.4 were cut in half, new terminal pieces were cemented at the cut 
TABLE 9. Optical measurements of the diameter of capillary 1.4, arbitrary units

\begin{tabular}{|c|c|c|c|c|}
\hline \multirow{2}{*}{$\begin{array}{l}\text { Distance } \\
\text { from end } 4\end{array}$} & \multicolumn{4}{|c|}{ Radial direction- } \\
\hline & $0^{\circ}$ & $45^{\circ}$ & $90^{\circ}$ & $135^{\circ}$ \\
\hline $\mathrm{cm}$ & & & & \\
\hline 1 & 895 & 892 & 887 & 892 \\
\hline 5 & 896 & 892 & 889 & 892 \\
\hline 10 & 893 & 895 & 888 & 891 \\
\hline 15 & 895 & 894 & 888 & 893 \\
\hline 20 & 889 & 893 & 892 & 892 \\
\hline 25 & 893 & 895 & 893 & 895 \\
\hline 30 & 892 & 891 & 891 & 892 \\
\hline 35 & 891 & 895 & 888 & a 897 \\
\hline 40 & 890 & 892 & 889 & 896 \\
\hline 44 & 889 & 890 & a 885 & 892 \\
\hline
\end{tabular}

a Highest and lowest values.

ends only. Thus, the shorter capillaries $2.5 \mathrm{a}$ and 1.4a each had one new end and one end from the original tube. Capillary 2.5a retained the original end number 1 from capillary 2.5, and its new end was numbered 3. Similarly, capillary $1.4 \mathrm{a}$ had the original end No. 4, and the new end was numbered 6 . These numbers will be used later in identifying the direction of flow through the capillaries during the flow measurements.

The ends of the bores of the capillaries are shown in figure 4. The finished edges of the bores were not always perfect, as shown particularly by $\mathrm{A}$ and $\mathrm{F}$. The badly chipped edges shown in D occurred after the flow measurements involving this end had been nearly completed. The three series of flow measurements had been completed with capillary 1.4, and the chipped places appeared on disassembling the apparatus after the first series with capillary $1.4 \mathrm{a}$. The second series with $1.4 \mathrm{a}$ was made after the chips were discovered. It will be apparent from the data given later that these chipped places did not measurably affect the results.

\subsection{Mean Radii of the Capillaries by the Gravimetric Method}

Although optical measurements of diameter are useful in describing the variations in shape and area of cross section of the bore along a tube, such measurements cannot be made with sufficient accuracy to deduce a mean radius that mav be used in calculating the resistance to viscous flow offered by the tube. Consequently, other methods were used to obtain the mean radii of the capillaries.

The first method used involves the weighing of the quantity of mercury required to fill the tube. The mean area of cross section is calculated by using the known density of mercury and the length of the tube.

For these determinations a clamp was made so that one end of the capillary could be closed off by means of a glass optical flat clamped against the polished face of the terminal piece. The optical flat extended sufficiently bevond the edge of the terminal piece to permit a nickel ring to be cemented to it to hold mercury as a vacuum seal when the capillary was supported vertically. By means of a ground glass joint, the terminal piece at the upper end of the capillary was cemented to a vacuum system. The tube was then filled under vacuum with double-distilled mercury and disconnected
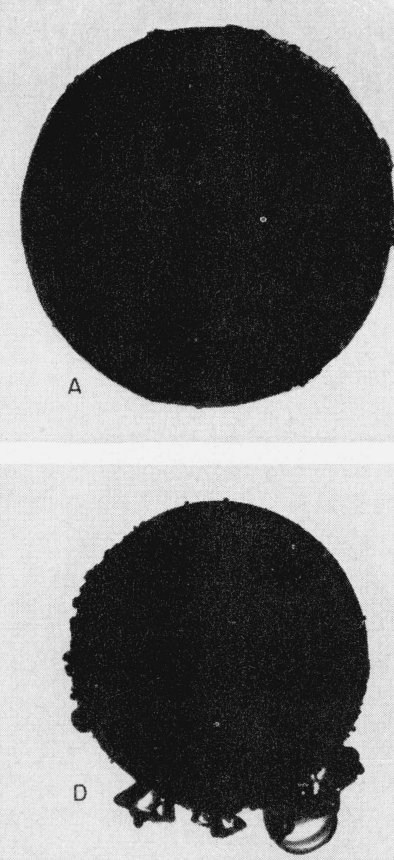
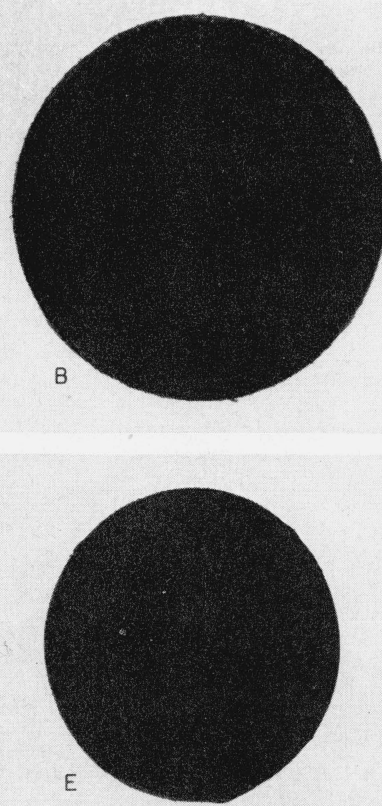
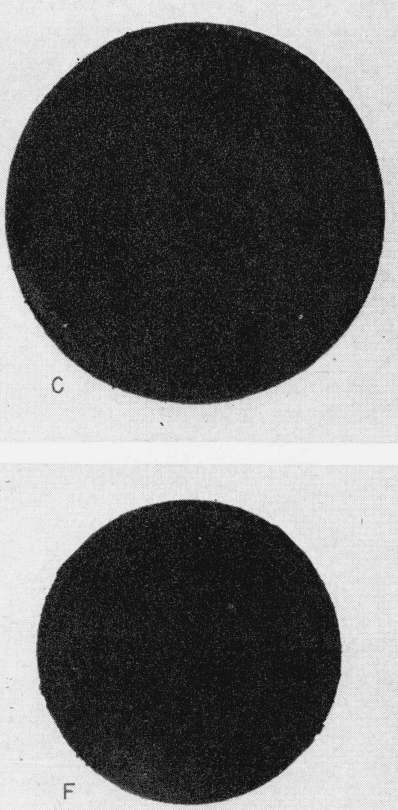

Figure 4. Photomicrographs of the ends of the capillaries.

Magnification $\times 75$. A, Capillary 2.5, end 1; B, capillary 2.5, end 2; C, capillary 2.5 , end $3 ; \mathrm{D}$, capillary 1.4 , end $4 ; \mathrm{E}$, capillary 1.4 , end $5 ; \mathrm{F}$, capillary 1.4 , end 6 . 
from the vacuum system. The mercury-filled tube was mounted vertically in a well-stirred water bath with temperature control. A platinum resistance thermometer was used to determine the temperature of the water in the bath. The upper end of the capillary was allowed to extend about $4 \mathrm{~mm}$ above the water level, and on the flat horizontal surface of the end piece was placed a small glass optical flat through which the suitably illuminated end of the bore could be observed with the aid of a magnifying glass. Observations were then made to determine the exact temperature at which the bore was completely filled. As the temperature was increased the area of contact between the mercury and the optical flat increased until the area became equal to the cross-sectional area of the bore. The appearance of the interference fringes between the flat and the face of the end piece aided in determining when the flat was in close contact with the face and not pushed up by the mercury.

Having determined the temperature at which the bore was just full, the bath temperature was lowered until the mercury was no longer in contact with the flat. The flat was then removed and the capillary taken out of the bath and dried. The mercury in the bore was then ready to transfer to a small bottle for weighing. This was accomplished by first carefully removing the mercury from the seal at the clamped end. The capillary was mounted in a position about $30^{\circ}$ from horizontal with the closed end high, and the clamp seal was opened slowly allowing the mercury to flow into the weighing bottle. Occasionally the mercury thread would break leaving a small filament of mercury in the end of the tube. This was removed by the gentle application of air pressure at the opposite end. The capillary was then examined with a magnifying glass to make certain that no mercury remained.

Measurements of the air temperature made in the region up to about $3 \mathrm{~cm}$ above the liquid level in the bath showed that, under the prevailing conditions, the temperatures were about 0.5 to $1 \mathrm{deg}$ $\mathrm{C}$ above that of the bath. This was found to be the case for bath temperatures between $20^{\circ}$ and $31^{\circ} \mathrm{C}$ for all room temperatures experienced. On this basis, the error in determining the mass of mercury required to fill the capillary, introduced by not correcting for the temperature of the $4 \mathrm{~mm}$ of capillary exposed above the bath liquid, was less than 3 parts per million for any of the capillaries used.

A further calculation showed that the dilation of the tube and the compression of the mercury caused by the pressure exerted by the column of mercury changed the mass required to fill the tube by not more than 3 parts per million for any of the capillaries. This correction was also neglected.

As the capillaries were to be used at $20^{\circ} \mathrm{C}$, the dimensions at this temperature were required.

If $M_{\theta}$ is the mass of mercury that just fills the capillary at $\theta^{\circ} \mathrm{C}, D_{20}$ is the density of mercury at $20^{\circ} \mathrm{C}, \alpha$ is the temperature coefficient of linear expansion of glass, $\beta$ is the temperature coefficient of density of mercury, $\Delta \theta=(\theta-20)$, and $r_{20}$ and $l_{20}$ are the capillary radius and length at $20^{\circ} \mathrm{C}$, we can write

$$
M_{\theta}=\pi r_{20}^{2}(1+\alpha \Delta \theta)^{2} l_{20}(1+\alpha \Delta \theta) D_{20}(1-\beta \Delta \theta) .
$$

Also

$$
M_{20}=\pi r_{20}^{2} l_{20} D_{20}
$$

in which $M_{20}$ is the mass of mercury that would be required to fill the capillary at $20^{\circ} \mathrm{C}$. Combining eq 18 and 19, we can say, with more than sufficient accuracy for the purpose,

$$
M_{20}=\frac{M_{\theta}}{1+(3 \alpha-\beta) \Delta \theta} .
$$

Through use of eq 19 and 20, values of $r_{20}$ are computed corresponding to the measured quantities $\theta$ and $M_{\theta}$.

The capillaries were cleaned prior to each measurement of the radius. The cleaning procedures involved the discreet use of either nitric or chromic acids, followed by distilled water and drying air. When chromic acid was used, after the removal of the bulk of acid and preliminary rinsing, the bores were soaked with distilled water for at least 1 hour before the final rinsing with water. The cleaning agents and distilled water, as well as the drying air, were always passed through a sintered-glass filter before being introduced into the capillary. Radius measurements made at various times provide good evidence that the sizes of the bores were not changed by any of these cleaning procedures by any measurable amounts (see table 11).

The measurements of the lengths of the four capillaries were made by the Gage Section of the Bureau by comparison with Hoke end gages.

The results are as follows:

\begin{tabular}{|c|c|}
\hline Capillary & $l_{20}$ \\
\cline { 2 - 2 } & \\
\hline 2.5 & 48.736 \\
$2.5 \mathrm{a}$ & 24.316 \\
1.4 & 25.208 \\
\hline $1.4 \mathrm{a}$ & \\
\hline
\end{tabular}

It is believed that all the figures given are significant.

The weighings of the quantities of mercury were made by the Mass Section of the Bureau. The details of the weighings concerned with capillary 2.5 are not known. For the other capillaries each quantity of mercury was weighed twice. In connection with the weighings made on the fillings of capillaries 2.5a and $1.4 \mathrm{a}$, a detailed study of the behavior of the glass weighing bottles used in the measurements was made in the Mass Section under the direction of L. B. Macurdy. The results of this study are given in appendix $\mathrm{C}$.

It was concluded that the masses of the samples 
from the fillings of capillaries 2.5a, 1.4, and $1.4 \mathrm{a}$ were known with an accuracy of $\pm 0.01 \mathrm{mg}$ or better. The samples from the fillings of capillary 2.5 were probably weighed with comparable accuracy.

In the calculation of $M_{20}$ through the use of eq 20 the values used for $\alpha$ were those recommended by the manufacturers. These values are $3.6 \times 10^{-6} /{ }^{\circ} \mathrm{C}$ for the Jena Duran Glass 3891-III, of which capillaries 2.5 and $2.5 \mathrm{a}$ are made, and $3.2 \times 10^{-6} /{ }^{\circ} \mathrm{C}$ for Pyrex capillaries 1.4 and $1.4 \mathrm{a}$. The density of mercury at $20^{\circ} \mathrm{C}$ was taken as $13.54589 \mathrm{~g} / \mathrm{cm}^{3}$ and $\beta$ as $180.9 \times 10^{-6}$. These values were obtained from the work of Beattie [12] (see appendix A).

Five separate fillings of each capillary were made, the results of which are shown in table 10 . The temperatures given are those at which the bores were judged to be exactly filled. The values of $M_{\theta}$ given for capillaries $2.5 \mathrm{a}, 1.4$, and $1.4 \mathrm{a}$ are the means of the two weighings made on each quantity of mercury. The values of $M_{20}$ are calculated by using eq 20.

TABLE 10. Computations of mean radii by the gravimetric method

\begin{tabular}{|c|c|c|c|c|c|c|}
\hline $\begin{array}{l}\text { Cap- } \\
\text { il- } \\
\text { lary }\end{array}$ & Date & $\theta$ & $M_{\theta}$ & $M_{20}$ & $r_{20}^{2}$ & $r_{20}$ \\
\hline 2.5 & $\begin{array}{l}5 / 10 / 41 \\
5 / 14 / 41 \\
5 / 15 / 41 \\
5 / 16 / 41 \\
5 / 17 / 41\end{array}$ & $\begin{array}{l}{ }^{\circ} \mathrm{C} \\
19.91 \\
20.18 \\
19.22 \\
19.82 \\
20.94\end{array}$ & $\begin{array}{lc}g & g \\
1.313 & 12 \\
1.313 & 19 \\
1.313 & 36 \\
1.313 & 15 \\
1.312 & 84\end{array}$ & \begin{tabular}{cc}
\multicolumn{2}{c}{$g$} \\
1.31310 \\
1.31323 \\
1.31319 \\
1.31311 \\
1.31305
\end{tabular} & $c m^{2}$ & $\mathrm{~cm}$ \\
\hline $2.5 \mathrm{a}$ & $\begin{array}{l}1 / 17 / 50 \\
1 / 18 / 50 \\
1 / 19 / 50 \\
1 / 20 / 50 \\
1 / 23 / 50\end{array}$ & $\begin{array}{l}27.19 \\
25.62 \\
27.79 \\
24.23 \\
27.12\end{array}$ & $\begin{array}{r}\text { Mean } \\
0.654305 \\
.654488 \\
.654187 \\
.654641 \\
.654326\end{array}$ & $\begin{array}{r}1.31314 \\
0.655106 \\
.655114 \\
\text { a. } 655055 \\
.655113 \\
.655119\end{array}$ & 6. $3315 \times 10^{-4}$ & 2. $5162 \times 10^{-2}$ \\
\hline 1.4 & $\begin{array}{l}11 / 22 / 48 \\
11 / 23 / 48 \\
11 / 24 / 48 \\
11 / 30 / 48 \\
11 / 30 / 48\end{array}$ & $\begin{array}{l}23.28 \\
23.59 \\
24.68 \\
23.26 \\
24.82\end{array}$ & $\begin{array}{r}\text { Mean } \\
0.774995 \\
.774943 \\
.774733 \\
.774983 \\
.774774\end{array}$ & $\begin{array}{r}0.655113 \\
0.775431 \\
.775420 \\
\text { ๑. } 775355 \\
.775416 \\
.775414\end{array}$ & 6. 3309 & 2. 5161 \\
\hline \multirow[t]{2}{*}{ 1. $4 \mathrm{a}$} & $\begin{array}{l}1 / 24 / 50 \\
1 / 25 / 50 \\
1 / 26 / 50 \\
1 / 27 / 50 \\
1 / 27 / 50\end{array}$ & $\begin{array}{l}27.52 \\
31.39 \\
29.87 \\
28.14 \\
30.68\end{array}$ & $\begin{array}{r}\text { Mean } \\
0.386255 \\
.386015 \\
.386099 \\
.386217 \\
.386052\end{array}$ & $\begin{array}{r}0.775420 \\
0.386753 \\
.386770 \\
.386753 \\
.386756 \\
.386759\end{array}$ & 4. 0305 & 2. 0076 \\
\hline & & & Mean.... & 0.386758 & 4. 0348 & 2. 0087 \\
\hline
\end{tabular}

a Determinations discarded.

With capillary 2.5a the result of the third filling shows a deviation from the mean of the order of 10 times as great as the other four. This is also the case with the third filling with capillary 1.4. As no discrepancies are found in the weighings, it seems evident that in these cases there was an undetected loss of mercury in the transfer írom the capillary into the weighing bottle, and the results of these two fillings were discarded. The values of $r_{20}^{2}$ given in the table were calculated from the mean values of $\mathrm{M}_{20}$ for each capillary and represent the squares of the radii of right circular cylinders of the same volumes and lengths as the capillaries measured.

\subsection{Mean Radii of the Capillaries by the Electric Resistance Method}

The second method used for the precise determination of the mean radii of the boresof the capillaries is based upon the electric resistances of the bores when filled with mercury.

The electric resistance, $R$, of a cylindrical conductor of length $l$, radius $r$, and resistivity $\rho$ is given by

$$
R=\frac{\rho l}{\pi r^{2}}
$$

As the resistivity of mercury is accurately known, eq 21 affords a means of calculating the mean crosssectional area of the bore of a capillary.

To adapt this method to the measurement of the mean radii of the capillaries, glass terminal bulbs were constructed with ground joints to fit the terminal pieces of the capillaries. A capillary with the terminal bulbs cemented in place is shown mounted in its supporting frame in figure 5. The bulbs are cylindrical with hemispherical ends and are $5 \mathrm{~cm}$ long with an internal diameter of $2.2 \mathrm{~cm}$. Two tubes of 0.5-cm inside diameter are brought up from each terminal bulb, as shown in the figure. The distance from the face of the terminal piece of the capillary to the level of the side tube in the upper bulb is $2.4 \mathrm{~cm}$. The corresponding distance in the lower bulb is $1.5 \mathrm{~cm}$.

For making a measurement, the apparatus was evacuated and completely filled with double-distilled mercury up to a level within about $1 \mathrm{~cm}$ of the tops of the four tubes leading up from the terminal bulbs. Special electric connectors were placed on the tops of the four tubes, as shown in the figure. Each connector was made from a short piece of glass tubing sealed at the middle to separate the two end portions of the tube. A platinum wire was passed through the seal to make electric connection between the end portions of the tube. The connectors fitted loosely on the tubes leading from the terminal bulbs with the platinum wires making contact with the mercury in the tubes. The connectors were filled above the glass seals with mercury, into which the copper lead wires to the resistance bridge were dipped. The ends of the copper lead wires were amalgamated electrolytically, and the platinum wires were immersed in mercury for several months before use. With these connectors good electric contact is made without contaminating the mercury in the capillary with copper from the lead wires.

The resistance measurements were made with a Mueller resistance bridge. With the two leads connected to each terminal bulb, the procedure was similar to that used with a four-lead resistance thermometer. The mean of the two readings taken was the resistance of the mercury between the branch points in the two terminal bulbs. This resistance, corrected for the resistance in the terminal bulbs, yielded the resistance of the column of mercury in the capillary bore.

It has been shown (see, for example, Maxwell [13]) 


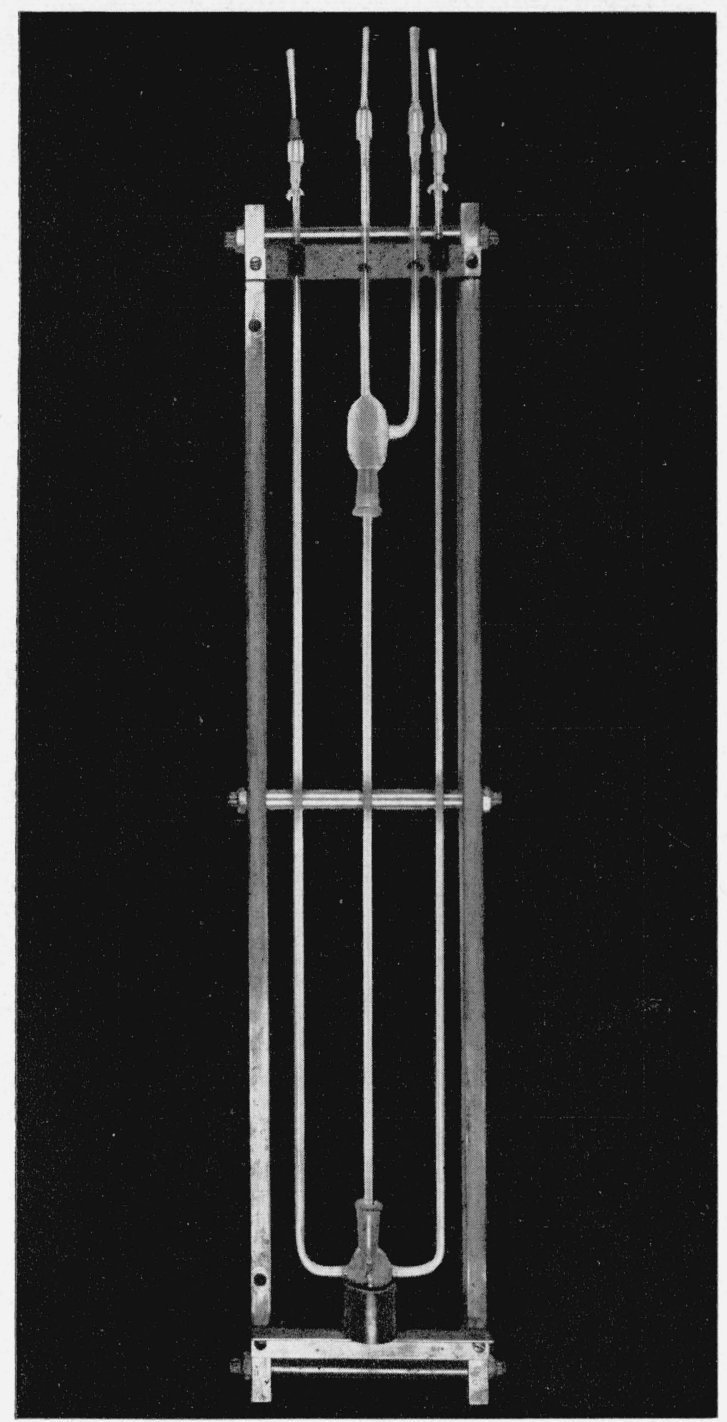

Figure 5. Capillary mounted for the determination of its mean radius by the electric resistance method

that the amount to be added to the measured resistance to account for the flow of electricity at the end of a tube may be expressed as an additional length equal to a constant times the radius of the bore at the end. A calculation by Rayleigh [14] yields a value of 0.82 for this constant. As the optical measurements of the diameters of the four capillaries showed that the mean radii at the ends of a capillary never differed from the mean for the whole tube by more than 0.3 percent, we can say that the sum of the corrections for the two ends is $2 \times 0.82 \times r$, where $r$ is the mean radius for the whole tube. Including the corrections for the ends, eq 21 then becomes

$$
R=\frac{\rho(l+1.64 r)}{\pi r^{2}} .
$$

If subscripts refer to the temperature in ${ }^{\circ} \mathrm{C}$, we can introduce the coefficient of expansion of the glass into eq 22 , which then becomes

$$
R_{\theta}=\frac{\rho_{\theta}\left(l_{20}+1.64 r_{20}\right)(1+\alpha \Delta \theta)}{\pi r_{20}^{2}(1+\alpha \Delta \theta)^{2}},
$$

from which

$$
r_{20}^{2}=\frac{\rho_{\theta}}{R_{\theta}}\left[\frac{l_{20}+1.64 r_{20}}{\pi(1+\alpha \Delta \theta)}\right] .
$$

For the solution of this equation, an approximate value of $r_{20}$ is substituted in the second term on the right.

In all of this work the resistances are measured in absolute ohms. The following equation was used to calculate the resistivity of mercury in absolute ohmcentimeters at the temperature of the measurement:

$$
\begin{aligned}
\rho_{\theta}= & 94.1232 \times \\
& 10^{-6}\left(1+889.15 \times 10^{-6} \cdot \theta+0.99360 \times 10^{-6} \cdot \theta^{2}\right),
\end{aligned}
$$

in which $\theta$ is in ${ }^{\circ} \mathrm{C}$, and $94.1232 \times 10^{-6}$ is the resistivity of mercury at $0^{\circ} \mathrm{C}$. (See appendix A.)

The diameter of each capillary was measured at several different times by this method. For these measurements the capillary with the attached terminal bulbs was immersed either in a liquid bath, whose temperature was controlled within close limits, or in an ice-and-water bath. The results

\begin{tabular}{|c|c|c|c|c|c|}
\hline $\begin{array}{l}\text { Capil- } \\
\text { lary }\end{array}$ & Date & $\theta$ & $R_{\theta}$ & $r_{20}^{2}$ & $r_{20}$ \\
\hline \multirow[t]{2}{*}{$2.5 \ldots$} & \multirow[t]{2}{*}{$\begin{array}{l}3 / 25 / 41 \\
3 / 25 / 41 \\
3 / 27 / 41 \\
3 / 29 / 41 \\
7 / 11 / 47 \\
4 / 20 / 48 \\
4 / 28 / 48\end{array}$} & \multirow[t]{2}{*}{$\begin{array}{c}\circ C \\
+20.000 \\
+41.336 \\
+31.971 \\
+8.259 \\
+20.000 \\
-0.007 \\
+23.912\end{array}$} & $\begin{array}{c}\text { Ohms } \\
2.35007 \\
2.39665 \\
2.37596 \\
2.32532 \\
2.35013 \\
2.30827 \\
2.35846\end{array}$ & \begin{tabular}{l}
\multicolumn{1}{c}{$c m^{2}$} \\
$6.3315 \times 10^{-4}$ \\
6.3316 \\
6.3315 \\
6.3315 \\
6.3313 \\
6.3315 \\
6.3315
\end{tabular} & \multirow{3}{*}{ 2. $5162 \times 10^{-2}$} \\
\hline & & & Mean... & 6.3315 & \\
\hline \multirow[t]{2}{*}{$2.5 \mathrm{a}_{--}$} & \multirow[t]{2}{*}{$\begin{array}{r}2 / 18 / 49 \\
5 / 3 / 49 \\
11 / 19 / 49\end{array}$} & \multirow[t]{2}{*}{$\begin{array}{r}-0.002 \\
-.003 \\
-.006\end{array}$} & $\begin{array}{l}\text { 1. } 15287 \\
\text { 1. } 15282 \\
1.15287\end{array}$ & $\begin{array}{l}6.3302 \\
6.3305 \\
6.3302\end{array}$ & \\
\hline & & & Mean... & 6. 3303 & \multirow[t]{2}{*}{ 2. 5160} \\
\hline $1.4 \ldots$ & $\begin{array}{r}10 / 18 / 48 \\
11 / 17 / 48 \\
1 / 10 / 49 \\
2 / 16 / 49\end{array}$ & $\begin{array}{r}-0.003 \\
-.004 \\
-.001 \\
-.001\end{array}$ & $\begin{array}{l}\text { 3. } 36341 \\
\text { 3. } 36334 \\
\text { 3. } 36333 \\
\text { 3. } 36332\end{array}$ & $\begin{array}{l}\text { 4. } 0302 \\
\text { 4. } 0303 \\
\text { 4. } 0303 \\
\text { 4. } 0303\end{array}$ & \\
\hline \multirow[t]{2}{*}{$1.4 a_{-}$} & \multirow[t]{2}{*}{$\begin{array}{l}8 / 18 / 49 \\
10 / 7 / 49\end{array}$} & \multirow[t]{2}{*}{$\begin{array}{r}-0.005 \\
-.004\end{array}$} & $\begin{array}{c}\text { Mean } \\
1.67520 \\
1.67520\end{array}$ & $\begin{array}{l}\text { 4. } 0303 \\
\text { 4. } 0347 \\
\text { 4. } 0347\end{array}$ & 2. 0076 \\
\hline & & & Mean... & 4. 0347 & 2.0087 \\
\hline
\end{tabular}
obtained with the four capillaries are given in table 11.

TABLE 11. Computations of mean radii by the electric resistance method

The measurements on capillary 2.5 made over quite a range of temperatures are in good agreement, which tends to confirm the values of the constants in eq 25 in this temperature range. However, as it is believed that the resistivity of mercury is known best at $0^{\circ} \mathrm{C}$, of the later measurements only those made close to $0^{\circ} \mathrm{C}$ were included in the calculations of the radii. The coefficient of expansion of the 
glass need not be known accurately for use in eq 24 , because an uncertainty in its value of as much as 1 part in 32 will result in an uncertainty of only 2 parts in a million in the value of $r_{20}^{2}$ as calculated from a measurement made at $0^{\circ} \mathrm{C}$.

The radius measurements on a particular capillary were always made at times embracing the period during which the capillary was being used in the flow measurements. With each capillary, the agreement among the different determinations is good, and there is no evidence of any trend with time or use, even with capillary 2.5 , on which measurements were made during 1941 and later in 1947 and 1948.

\subsection{Caliber Corrections}

The derivation of eq 2 , expressing the resistance to the viscous flow of a liquid through a tube, is based upon the bore having the shape of a right circular cylinder. The optical measuraments of the diameters of the capillaries used here have shown that they all depart somewhat from this ideal condition. Consequently, a correction must be applied to a measured radius to account for the difference between the viscous resistance in the actual capillary used and in an equally long one of uniform circular cross section. The determination of the mean radius by the gravimetric method has yielded the radius of a right circular cylinder of length and volume equal to those of the bore of the capillary. This radius may then be corrected appropriately for substitution in eq 2. However, the resistance to flow of electricity is also affected by the variable cross section of a tube. Therefore, the radii of the capillaries as measured by the electric resistance method must first be corrected to yield the radii of equally long capillaries of uniform cross-sectional areas and then be corrected again for substitution in the equation for the resistance to viscous flow.

In estimating the magnitudes of these corrections, the data given in tables 8 and 9 are used for describing the actual shapes of the capillaries. Various investigations of the effects of conicality and ellipticity of bore upon viscosity measurements have been made, but the above data on these tubes show that they cannot be considered conical. Their cross sections are irregular and resemble an ellipse in only a few places. The tubes are therefore treated as circular in section but with the area of section varying along the tubes. The mean of the diameters measured in the four radial directions at a particular point is taken as the diameter of the assumed circular section at that point. The mean diameters at the points measured along capillaries 2.5 and 1.4 are given in tables 12 and 13 . The areas of section $S$ calculated for each measured point are also given in these tables. Since only arbitrary units are used, $S$ is taken equal to $d^{2}$ and, for the present purpose, can be assumed to be known exactly. Part of the data given in these two tables also apply to capillaries $2.5 \mathrm{a}$ and $1.4 \mathrm{a}$, as they were cut from the longer capillaries 2.5 and 1.4 .

Figure 6 shows values of $S$ plotted against position along the tube for each of the four capillaries.
These areas are represented by the plotted points, and the mean cross section for each capillary is shown by a horizontal dashed line.

TABLE 12. Variations in cross-sectional area along capillary 2.5, arbitrary units

\begin{tabular}{|c|c|c|}
\hline $\begin{array}{c}\text { Position along } \\
\text { tube }\end{array}$ & Mean diameter & $\begin{array}{c}\text { Area of cross } \\
\text { section }\end{array}$ \\
\cline { 1 - 1 }$c m$ & & \\
1 & 1123.75 & 126281 \\
5 & 1123.25 & 126169 \\
10 & 1124.75 & 126506 \\
15 & 1127.25 & 127069 \\
20 & 1125.75 & 126731 \\
& & \\
25 & 1125.00 & 126563 \\
30 & 1125.00 & 126563 \\
35 & 1124.25 & 126394 \\
40 & 1127.75 & 127182 \\
45 & 1127.00 & 127013 \\
49 & 1123.50 & 126225 \\
& & \\
& &
\end{tabular}

TABLE 13. Variations in cross-sectional area along capillary 1.4 , arbitrary units

\begin{tabular}{|c|c|c|}
\hline $\begin{array}{c}\text { Position along } \\
\text { tube }\end{array}$ & Mean diameter & $\begin{array}{c}\text { Area of cross } \\
\text { Section }\end{array}$ \\
\cline { 1 - 1 }$c m$ & & \\
1 & & 79477 \\
5 & 891.5 & 79620 \\
10 & 892.3 & 79531 \\
15 & 891.8 & 79656 \\
20 & 892.5 & 79477 \\
25 & 891.5 & 79924 \\
30 & 894.0 & 79477 \\
35 & 891.5 & 79709 \\
40 & 892.8 & 79531 \\
44 & 891.8 & 79032 \\
& 889.0 & \\
\hline & &
\end{tabular}

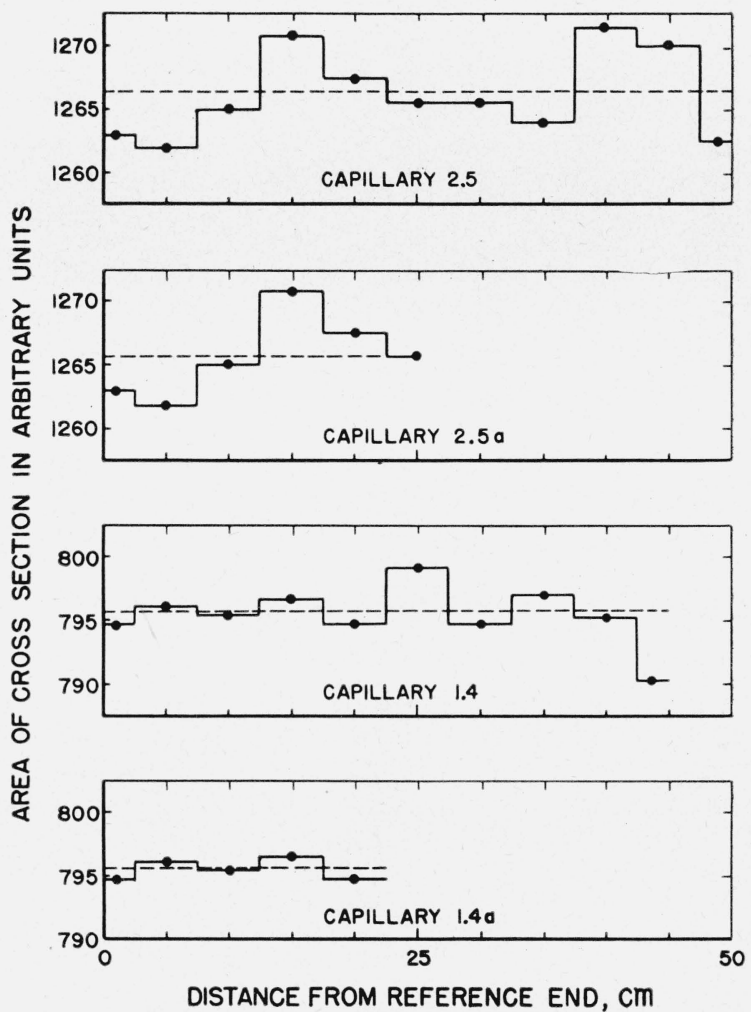

FIGURE 6. Cross-sectional area of bore at regular positions along the capillaries. 
For one method of calculating the effects of such variations on the electric and viscous resistance offered by a capillary, the bore is assumed to be made up of a series of right circular cylinders, each having a cross-sectional area equal to the value of the corresponding plotted points and a length equal to the distance between the points. The area of section is then assumed to vary along the tube, as indicated by the stepped curve. Suppose the capillary of length $l$ be divided into $n$ such intervals of equal length $l_{i}$. Let $S$ be the cross-sectional area in any interval and $S_{m}$ be the mean cross-sectional area for the whole tube, as calculated by the relation $S_{m}=(1 / n) \Sigma S$. Then the resistance to the flow of electricity through the variable cross section is proportional to $\Sigma\left(l_{i} / S\right)$, and the electric resistance offered by a tube of the same length but having a uniform cross-sectional area $S_{m}$ is proportional to $l / S_{m}$. From these relations the percentage increase in the resistance to the flow of electricity of the nonuniform tube over the uniform one is given by

$$
\frac{\Sigma\left(l_{i} / S\right)-l / S_{m}}{l / S_{m}} \times 100
$$

For the laminar flow of liquids through the tubes, the viscous resistance is proportional to $\Sigma\left(l_{i} / S^{2}\right)$ for the nonuniform case and to $l / S_{m}^{2}$ for a uniform tube. In this case the percentage increase in the viscous resistance is given by

$$
\frac{\sum\left(l_{i} / S^{2}\right)-l / S_{m}^{2}}{l / S_{m}^{2}} \times 100
$$

As an example, this method is applied to the data on capillary 2.5 in the following way. The value of $S$ calculated from the readings taken at the $5-\mathrm{cm}$ position is assumed to be the mean for the 5 -cm interval from 2.5 to $7.5 \mathrm{~cm}$. As shown by the stepped curve in figure 6 , this is repeated for each position, giving nine $5-\mathrm{cm}$ intervals covering the length from 2.5 to $47.5 \mathrm{~cm}$. The two $2.5-\mathrm{cm}$ lengths at each end of the tube are combined to give a tenth 5 -cm interval with a value of $S$ equal to the mean of the areas at $1 \mathrm{~cm}$ and $49 \mathrm{~cm}$. These data are then substituted in eq. 26 and 27 to give the desired corrections.
Similar procedures were followed with the otherthree capillaries, and the results obtained with all four are given in table 14. The signs are applied as. follows: The signs are such as to correct the square of the radius as measured by the electric resistance method to yield the square of the radius of a uniform tube. The signs of the correction for viscous resistance are such as to correct the radius, calculated on the basis of a uniform bore, appropriately for substitution in the equations for viscous flow. It should be noted that the corrections given in the table are applied to the radius squared in the electric resistance measurements, whereas those for correcting the viscous resistance are applied to the fourth power of the radius.

TABLE 14. Corrections to electric and viscous resistance

\begin{tabular}{|c|c|c|}
\hline \multirow{2}{*}{ Capillary } & \multicolumn{2}{|c|}{$\begin{array}{l}\text { Corrections in parts per } \\
\text { million }\end{array}$} \\
\hline & $\begin{array}{l}\text { Electric } \\
\text { resistance }\end{array}$ & $\begin{array}{l}\text { Viscous } \\
\text { resistance }\end{array}$ \\
\hline 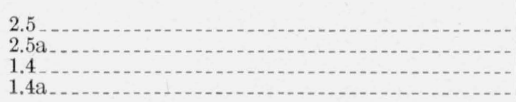 & $\begin{array}{l}+6 \\
+6 \\
+5 \\
+1\end{array}$ & $\begin{array}{l}-21 \\
-23 \\
-19 \\
-3\end{array}$ \\
\hline
\end{tabular}
measurements as a result of nonuniformity of bore

It is seen in figure 6 that capillaries $2.5,2.5 \mathrm{a}$, and 1.4 show roughly harmonic variations in $S$. Assuming this type of variation, integration under these curves yields essentially the same corrections as those given in table 14 .

As a third method of describing the variations in area of section, straight lines are drawn between the plotted points, and the integration is performed underthese irregular curves. As would be expected, this method usually leads to somewhat smaller corrections than those obtained by the other two treatments.

The only case where these corrections are of any significance is the correction for viscous resistance in capillary 2.5. This correction was applied by usingthe value given in the table.

A summary of the measurements of the dimensions of the four capillaries is given in table 15 . The values.

TABLE 15. Final dimensions of the capillaries

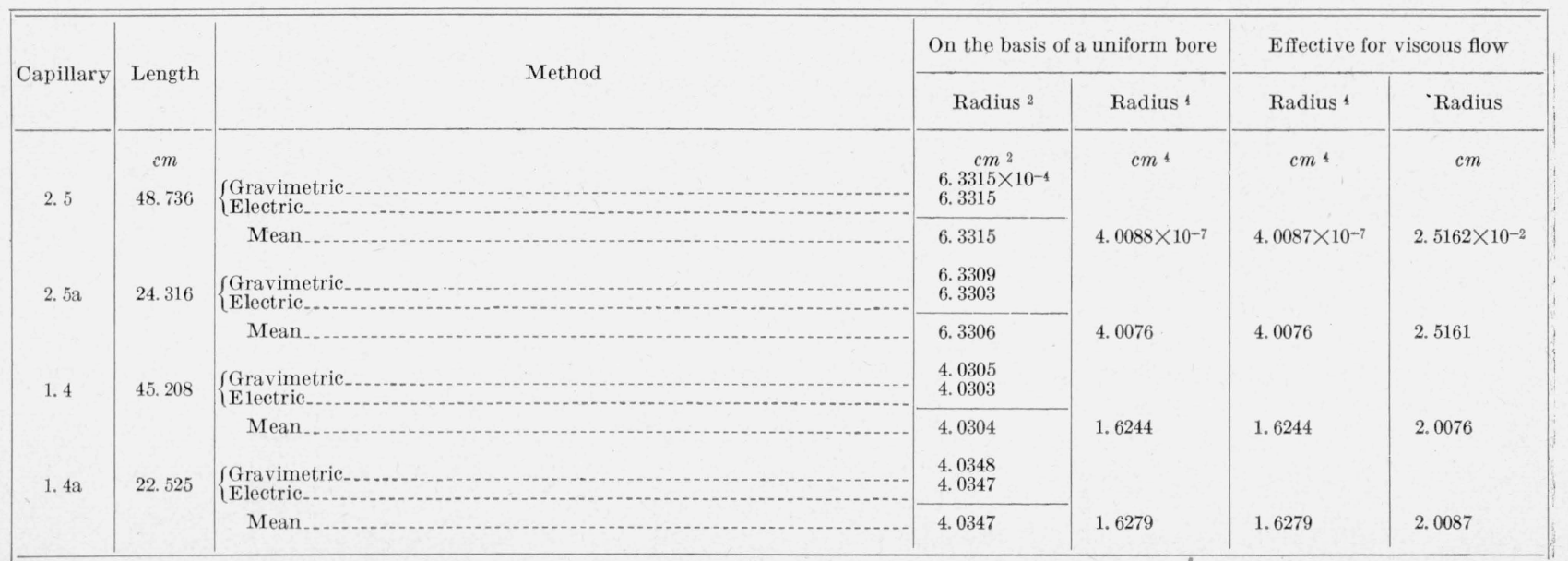


of the radius squared, as obtained by the two independent methods, were weighted equally, and the mean value was used for each capillary. It is seen that in each case the agreement between the two methods is very good. The maximum discrepancy occurred with capillary 2.5a and is only about 1 part in 10,000 .

\section{Viscosity Determinations}

The viscometer was assembled and filled for the first series of tests at $20^{\circ} \mathrm{C}$ in the fall of 1940 . The measurements made with this filling were designated as series I. In this series several independent observations of the pressure drop through the capillary were made at each of four rates of flow. Each measurement of the pressure drop corresponding to a particular rate of flow was assigned a run number in the order in which it was obtained within the series. In general, check runs at a given rate of flow were separated by measurements made at other rates of flow in order that the observations in a given run be as independent as possible of the influence of a preceding run. A similar procedure was followed each time the viscometer was filled, and a new roman series number was assigned to identify the particular filling. Between fillings the viscometer and manometer were disassembled and thoroughly cleaned.

The series I tests were used primarily for developing operating techniques and acquiring experience with the apparatus. The results of this series are therefore not considered as reliable as those of the succeeding 11 flow series and are not included in the final calculations. As a consequence of these preliminary flow tests, the experimental procedure that finally evolved is as follows:

After assembling the viscometer and manometer some mercury is injected into the entrance chamber of the viscometer and both arms of the manometer. Freshly distilled water from a laboratory still is introduced into the system through the open tube at the top of the overflow reservoir until the desired level is reached. Trapped air is removed by working the main injector back and forth through its stroke. The air trapped in the top of the short arm is forced out through the bleed tube (shown in fig. 1) by a forward stroke of the injector. After all of the air is removed and the tube is filled with water, the gas-tight valve at the top end of the tube is shut off.

All of the baths are adjusted to their proper temperatures, and mercury is introduced into the short arm of the manometer until the proper height is indicated by the fixed electric contactor. The longest of the gage rods, number 50, is then fixed in the depth-gage head, inserted in the long arm of the manometer, and the gage head is clamped in position. The gage head is set at its expected reading for the "manometer zero", and mercury is injected into the long arm until proper contact is made with the tip of the rod. The two arms of the manometer are now opened to each other. Any change in the height of mercury in the long arm with time is observed, and mercury is added or withdrawn in sufficient quantity so that when the final equilibrium position is established, the mercury in the short arm makes proper contact with the fixed contactor, and the level in the long arm is at the same height. In judging when this equilibrium position is reached, due consideration is given to the time constant for the particular capillary being used. These adjustments and readings of course are made when there is no flow of mercury from the main injector into the entrance chamber of the viscometer. The head reading of the micrometer for this final equilibrium condition is referred to as the "manometer zero" and is designated by $M_{0}$.

Manometer heights under flow conditions are measured in a similar manner. The change gears in the main injector drive are selected to give the desired rate of flow, and the mercury in the long arm of the manometer is preset at an expected height, using the gage rod of proper length. The injection of mercury into the entrance chamber of the viscometer is started, and the two arms of the manometer are then opened to each other. As in determining the manometer zero, mercury is added or withdrawn until the quantity of mercury in the manometer is such that the mercury level is at the contactor in the short arm when the equilibrium pressure corresponding to the particular rate of flow through the capillary is reached. It is often the case that this condition is not realized during a single stroke of the injector. In these cases the long arm of the manometer is shut off before stopping the main injector. With the manometer still closed the stroke of the injector is then reversed. After the forward stroke of the injector is started a second time, the manometer is again opened. In this manner the stroke of the injector is repeated as many times as are necessary to establish equilibrium. The reading of the micrometer head for this equilibrium condition is designated by $M_{Q}$. This process comprises a run, and a run number is assigned. Usually two or three such runs, together with a repeat observation of the manometer zero, can be completed in a working day. In this manner all of the flow data on a single filling of the viscometer may be obtained in about 2 weeks.

There is no known reason for measurable variations in readings of the manometer zero made with the same filling of the viscometer, and any observed differences in its value are attributed to experimental error. Consequently, at the completion of a series of flow tests all of the observations of $M_{0}$ are averaged and the mean value is used in calculating the pressure drop for each run. However, the value of $M_{0}$ will differ between different fillings of the viscometer as a result of the dismantling and reassembly of the short arm for cleaning purposes.

When measurements are being made a second operator keeps a continuous check on the temperature of the viscometer bath and records the thermometer readings every 5 minutes. Occasional readings of the temperatures of the other baths are taken, to be assured that they are operating properly. From these records the mean temperature in the viscometer bath is judged for each period during which a run is being made. 
In general, this procedure was followed, beginning with series II, except for the following changes:

(a). In series II, readings of the manometer depth gage were recorded to 0.0001 in. In view of the general sensitivity encountered with the depth gage, together with other considerations, the readings in series III and the subsequent series were recorded only to the nearest 0.0005 in.

(b). As mentioned previously, beginning with series IV, a centering disk was used with the depthgage rods for restricting the possible region of contact of the tips to a central area of the mercury meniscus.

(c). During all of the experiments intermittent electric contact was observed between the gage rods and surfaces in the manometer. This was caused by vibration of the stirring motor and pumps associated with the thermostating of the viscometer bath. During the first six series the manometer readings were taken matching the fluctuations in the readings of the microammeter in the long-arm circuit with those in the short arm. It was felt that in this manner the effects of these motions in the mercury surfaces would be minimized. However, beginning with series VII, after equilibrium had been reached, as shown by observations made in the above manner, both arms of the manometer were shut off, and the stirring motor and other sources of vibration were stopped. Readings were then taken with the mercury surfaces quiet. The two methods of taking the readings usually yielded essentially the same calculated height of the mercury column. Nevertheless, in a few instances differences as great as 0.006 in. were found. In the cases where any differences were shown, the readings taken with the quiet surfaces were used.

The results obtained in flow series II, III, and IV with capillary 2.5 are given in table 16 . In the first column the arabic number accompanying the series number indicates the end of the capillary that was mounted as the lower, or entrance, end in the viscometer. The rates of flow $Q$ were calculated from the calibrated delivery rate of the main injector, together with the gear ratios of the particular combinations of change gears used. The identical gear ratios were used in series III and IV as were used in
II, the differences in the values of $Q$ being a consequence of the different delivery rates of the injector. The injector was thermostated at $35^{\circ} \mathrm{C}$ for series II, and the mean delivery rate shown in table 1 was used. For series III and IV a longer stroke of the injector piston was used with the injector thermostated at $30^{\circ} \mathrm{C}$, and the rates of flow were calculated from the mean rate of delivery given in table 3 . In the third column of the table, values of the Reynolds number corresponding to each rate of flow are given to indicate the range covered in the experiments. The values given for $P$, the pressure drop through the capillary, are in each case the mean of several runs at the particular rate of flow. The detailed calculations of the values of $P$ are given in appendix D.

Using the data in table 16 , the values given for the viscosity were calculated by means of eq 4 . This equation is equivalent to

in which

$$
\frac{P}{Q}=a+b Q,
$$

and

$$
a=\frac{8}{\pi r^{4}}(l+n r) \eta
$$

$$
b==\frac{m D}{\pi^{2} r^{4}}
$$

Introducing the measured dimensions of capillary 2.5 and the known density of water at $20^{\circ} \mathrm{C}$, and taking the value of $n$ as 0.57 , the values of $\eta$ were obtained from the relation

$$
\eta=3.2292 \times 10^{-9} \times a .
$$

Similarly, the values of $m$ for the capillary were calculated by the equation

$$
m=3.9635 \times 10^{-6} \times b .
$$

The values of $a$ and $b$ were obtained from leastsquares solutions of the straight lines represented by

\begin{tabular}{|c|c|c|c|c|c|c|c|c|c|c|}
\hline $\begin{array}{c}\text { Series } \\
\text { number- } \\
\text { entrance } \\
\text { end }\end{array}$ & 0 & $\begin{array}{l}\text { Reynolds } \\
\text { number }\end{array}$ & $P$ & $\begin{array}{c}P / O \\
\text { observed }\end{array}$ & $a$ & $b$ & $\eta$ & $m$ & $\begin{array}{c}P / O \\
\text { calculated }\end{array}$ & $\begin{array}{l}\text { Deviation } \\
\text { from line, } \\
\text { observed } \\
\text {-calculated }\end{array}$ \\
\hline II-2 & $\begin{array}{c}c m^{3} / \mathrm{sec} \\
0.072232 \\
.128412 \\
.192618 \\
.256824\end{array}$ & $\begin{array}{l}182 \\
324 \\
486 \\
648\end{array}$ & $\begin{array}{c}\text { Dynes/cm }{ }^{2} \\
0.225581 \times 10^{6} \\
.403177 \\
.608355 \\
.815885\end{array}$ & $\begin{array}{l}\text { 3. } 12301 \times 10^{6} \\
\text { 3. } 13971 \\
\text { 3. } 15835 \\
\text { 3. } 17683\end{array}$ & $3.10213 \times 10^{6}$ & 0. $2913 \times 10^{6}$ & $\begin{array}{c}\text { Poise } \\
0.010017\end{array}$ & 1. 15 & $\begin{array}{l}3.12317 \times 10^{6} \\
3.13954 \\
3.15824 \\
3.17694\end{array}$ & $\begin{array}{l}-160 \\
+170 \\
+110 \\
-110\end{array}$ \\
\hline III-2 & $\begin{array}{l}.072277 \\
.128492 \\
.192739 \\
.256985\end{array}$ & $\begin{array}{l}182 \\
324 \\
486 \\
648\end{array}$ & $\begin{array}{l}.225762 \\
.403487 \\
.608767 \\
.816622\end{array}$ & $\begin{array}{l}3.12357 \\
3.14017 \\
3.15850 \\
3.17770\end{array}$ & 3.10245 & .2923 & .010018 & 1. 16 & $\begin{array}{l}\text { 3. } 12358 \\
3.14001 \\
3.15879 \\
\text { 3. } 17757\end{array}$ & $\begin{array}{r}-10 \\
+160 \\
-290 \\
+130\end{array}$ \\
\hline \multirow[t]{2}{*}{ IV -1} & $\begin{array}{l}.072277 \\
.128492 \\
.192739 \\
.256985\end{array}$ & $\begin{array}{l}182 \\
324 \\
486 \\
648\end{array}$ & $\begin{array}{l}.225775 \\
.403718 \\
.608808 \\
.816800\end{array}$ & $\begin{array}{l}3.12375 \\
3.14197 \\
3.15872 \\
3.17840\end{array}$ & 3. 10323 & .2919 & .010021 & 1. 16 & $\begin{array}{l}\text { 3. } 12433 \\
\text { 3. } 14074 \\
\text { 3. } 15949 \\
\text { 3. } 17824\end{array}$ & $\begin{array}{r}-580 \\
+1230 \\
-770 \\
+160\end{array}$ \\
\hline & & & & Mean values -- & 3. 10260 & 0. 2918 & 0.010019 & 1. 16 & & \\
\hline
\end{tabular}
eq 28. In these solutions, $Q$ was assumed to be without error, and the corresponding values of $P / Q$ were weighted equally. These assumptions seem

TABLE 16. Results of flow tests at $20^{\circ} \mathrm{C}$ with capillary 2.5 
justified from the spread of the pressure data shown in tables 26 through 36 in appendix D, which indicate that the probable accuracy of $P / Q$ is essentially independent of pressure. Furthermore, the results of the repeat calibrations of the injector suggest that $Q$ was always known better than the corresponding equilibrium pressure, and hence $Q$ was taken as without error.

The calculated values of $P / Q$ given in table 16 were obtained by using eq 28 and substituting the values of $a$ and $b$ as given for each series. The deviations of the observed points from the calculated straight lines are also given and serve to indicate the constancy of $m$ and $n$ over the rates of flow covered.

With series II and III the observed values of $P / Q$ are all within 0.01 percent of the calculated line. Differences of these magnitudes are attributable to experimental error, and $m$ and $n$ are demonstrated to be constant within the accuracy of the measurements. The relatively larger deviations shown for series IV are not explained, there being no known reason for questioning any of these data.

The spread in the values of $a$ and $b$ between the three series was taken to be experimental error, and therefore the values of $\eta$ and $m$ calculated from the mean values of $a$ and $b$ are believed best to represent the results of the flow measurements with this capillary alone.
Similar treatments of the flow data for the other three capillaries are given in tables 17,18 , and 19 . With these capillaries also there is no evidence that $m$ and $n$ are not constant, the data being well represented by straight lines in agreement with eq 28 . With these capillaries also the flow data are believed to be represented best by using the mean values of $a$ and $b$ as given in the tables.

The calculation of the viscosity by using the flow data with each capillary as an independent determination, as is done in tables 16 through 19 , mav be in error as a result of the uncertainty in the choice of a value for the constant $n$. However, as was outlined previously, the effect of an uncertainty in the value of $n$ may be rendered negligible by simultaneous treatment of the flow measurements with each pair of capillaries. Taking capillaries 2.5 and $2.5 \mathrm{a}$ as one pair and 1.4 and 1.4a as another, the capillaries in each pair have very nearly the same radii but different lengths. The dimensions and flow data for each pair can then be substituted in eq 9 and the viscosity calculated without assuming a value for $n$. However, in making the actual calculations eq 9 was transformed somewhat.

If the least-squares line, based on the mean values of $a$ and $b$, best represents the flow data for a particular capillary, that is equivalent to saying that the calculated value of $P / Q$ at a particular value of

TABLE 17. Results of flow tests at $20^{\circ} \mathrm{C}$ with capillary $2.5 \mathrm{a}$

\begin{tabular}{|c|c|c|c|c|c|c|c|c|c|c|}
\hline $\begin{array}{l}\text { Series } \\
\text { number- } \\
\text { entrance } \\
\text { end }\end{array}$ & $Q$ & $\begin{array}{l}\text { Reynolds } \\
\text { number }\end{array}$ & $P$ & $P / Q$, observed & $a$ & $b$ & $\eta$ & $m$ & $P / Q$, calculated & $\begin{array}{l}\text { Deviation } \\
\text { from line, } \\
\text { observed- } \\
\text { calculated }\end{array}$ \\
\hline VII-1 & $\left\{\begin{array}{c}\mathrm{cm}^{3} / \mathrm{sec} \\
0.096376 \\
.128502 \\
.192753 \\
.257004\end{array}\right.$ & $\begin{array}{l}243 \\
324 \\
486 \\
648\end{array}$ & $\begin{array}{l}\text { Dynes/cm }{ }^{2} \\
0.151899 \times 10^{6} \\
.203807 \\
.309368 \\
.417293\end{array}$ & $\begin{array}{l}\text { 1. } 57611 \times 10^{6} \\
\text { 1. } 58602 \\
1.60500 \\
1.62368\end{array}$ & 1. $54783 \times 10^{6}$ & $0.2957 \times 10^{6}$ & $\begin{array}{c}\text { Poise } \\
0.010012\end{array}$ & 1. 17 & $\begin{array}{l}\text { 1. } 57633 \times 10^{6} \text { ] } \\
\text { 1. } 58583 \\
\text { 1. } 60483 \\
\text { 1. } 62382\end{array}$ & $\begin{array}{l}-220 \\
+190 \\
+170 \\
-140\end{array}$ \\
\hline IX -3 & $\left\{\begin{array}{l}.096376 \\
.128502 \\
.192753 \\
.257004\end{array}\right.$ & $\begin{array}{l}243 \\
324 \\
486 \\
648\end{array}$ & $\begin{array}{l}.151927 \\
.203825 \\
.309333 \\
.417303\end{array}$ & $\begin{array}{l}\text { 1. } 57640 \\
\text { 1. } 58616 \\
\text { 1. } 60482 \\
\text { 1. } 62372\end{array}$ & 1. 54822 & .2938 & .010015 & 1. 16 & $\begin{array}{l}1.57654 \\
1.58597 \\
1.60485 \\
1.52373\end{array}$ & $\begin{array}{r}-140 \\
+190 \\
-30 \\
-10\end{array}$ \\
\hline \multirow[t]{2}{*}{$\mathrm{X}-1$} & $\left\{\begin{array}{l}.096376 \\
.128502 \\
.192753 \\
.257004\end{array}\right.$ & $\begin{array}{l}243 \\
324 \\
486 \\
648\end{array}$ & $\begin{array}{l}.151915 \\
.203741 \\
.309305 \\
.417349\end{array}$ & $\begin{array}{l}1.57627 \\
1.58551 \\
1.60467 \\
1.62390\end{array}$ & 1. 54749 & .2970 & .010010 & 1. 18 & $\begin{array}{l}1.57611 \\
1.58566 \\
1.60474 \\
1.62382\end{array}$ & $\begin{array}{r}+160 \\
-150 \\
-70 \\
+80\end{array}$ \\
\hline & & & & Mean values.... & 1.54785 & .2955 & .010012 & 1. 17 & & \\
\hline
\end{tabular}

TABLE 18. Results of flow tests at $20^{\circ} \mathrm{C}$ with capillary 1.4

\begin{tabular}{|c|c|c|c|c|c|c|c|c|c|c|}
\hline $\begin{array}{l}\text { Series } \\
\text { number- } \\
\text { entrance } \\
\text { end }\end{array}$ & $Q$ & $\begin{array}{l}\text { Reynolds } \\
\text { number }\end{array}$ & $P$ & $P / Q$, observed & $a$ & $b$ & $\eta$ & $m$ & $P / Q$, calculated & $\begin{array}{l}\text { Deviation } \\
\text { from line, } \\
\text { observed- } \\
\text { calculated }\end{array}$ \\
\hline $\mathrm{V}-5$ & $\begin{array}{c}\mathrm{cm}^{3} / \mathrm{sec} \\
0.033674 \\
.072282 \\
.096376 \\
.128502\end{array}$ & $\begin{array}{l}106 \\
228 \\
305 \\
406\end{array}$ & $\begin{array}{c}\text { Dynes/cm } 2 \\
0.239859 \times 10^{6} \\
.516662 \\
.690667 \\
.923673\end{array}$ & $\begin{array}{l}7.12297 \times 10^{6} \\
7.14786 \\
7.16636 \\
7.18800\end{array}$ & $7.09913 \times 10^{6}$ & $0.6911 \times 10^{6}$ & $\begin{array}{c}\text { Poise } \\
0.010015\end{array}$ & 1.11 & $\begin{array}{l}7.12240 \times 10^{6} \\
7.14908 \\
7.16574 \\
7.18794\end{array}$ & $\begin{array}{r}+570 \\
-1220 \\
+620 \\
+60\end{array}$ \\
\hline VI-4 & $\begin{array}{r}033674 \\
.072282 \\
.096376 \\
.128502\end{array}$ & $\begin{array}{l}106 \\
228 \\
305 \\
406\end{array}$ & $\begin{array}{l}.239831 \\
.516787 \\
.690695 \\
.923732\end{array}$ & $\begin{array}{l}7.12214 \\
7.14959 \\
7.16665 \\
7.18846\end{array}$ & 7.09874 & .7009 & .010014 & 1.13 & $\begin{array}{l}7.12234 \\
7.14940 \\
7.16629 \\
7.18881\end{array}$ & $\begin{array}{l}-200 \\
+190 \\
+360 \\
-340\end{array}$ \\
\hline VIII-4 & $\begin{array}{r}.033674 \\
.072282 \\
.096376 \\
.128502\end{array}$ & $\begin{array}{l}106 \\
228 \\
305 \\
406\end{array}$ & $\begin{array}{l}.239866 \\
.516874 \\
.690736 \\
.923917\end{array}$ & $\begin{array}{l}7.12318 \\
7.15080 \\
7.16708 \\
7.18990\end{array}$ & 7.09965 & .7023 & .010015 & 1.13 & $\begin{array}{l}7.12330 \\
7.15041 \\
7.16733 \\
7.18990\end{array}$ & $\begin{array}{r}-120 \\
+390 \\
-250 \\
0\end{array}$ \\
\hline & s & & & Mean values.... & 7.09917 & .6981 & .010015 & 1.12 & & \\
\hline
\end{tabular}


TABLE 19. Results of flow tests at $20^{\circ} \mathrm{C}$ with capillary $1.4 \mathrm{a}$

\begin{tabular}{|c|c|c|c|c|c|c|c|c|c|c|}
\hline $\begin{array}{l}\text { Series } \\
\text { number- } \\
\text { entrance } \\
\text { end }\end{array}$ & $Q$ & $\begin{array}{l}\text { Reynolds } \\
\text { number }\end{array}$ & $P$ & $P / Q$, observed & $a$ & $b$ & $\eta$ & $m$ & $P / Q$, calculated & $\begin{array}{l}\text { Deviation } \\
\text { from line, } \\
\text { observed- } \\
\text { calculated }\end{array}$ \\
\hline $\mathrm{XI}-4$ & $\begin{array}{l}\mathrm{cm}^{3} / \mathrm{sec} \\
0.033674 \\
.072282 \\
.096376 \\
.128502\end{array}$ & $\begin{array}{l}106 \\
228 \\
305 \\
406\end{array}$ & $\begin{array}{l}\text { Dynes/cm² } \\
0.119681 \times 10^{6} \\
.258981 \\
.346951 \\
.465395\end{array}$ & $\begin{array}{l}\text { 3. } 55411 \times 10^{6} \\
3.58292 \\
3.59996 \\
3.62169\end{array}$ & 3. $53065 \times 10^{6}$ & $0.7136 \times 10^{6}$ & $\begin{array}{c}\text { Poise } \\
0.010015\end{array}$ & 1.15 & $\begin{array}{l}3.55468 \times 10^{6} \\
3.58223 \\
3.59942 \\
3.62235\end{array}$ & $\begin{array}{l}-570 \\
+690 \\
+540 \\
-660\end{array}$ \\
\hline \multirow[t]{2}{*}{ XII-4 } & $\begin{array}{l}.033674 \\
.072282 \\
.096376 \\
.128502\end{array}$ & $\begin{array}{l}106 \\
228 \\
305 \\
406\end{array}$ & $\begin{array}{l}.119687 \\
.258938 \\
.346882 \\
.465379\end{array}$ & $\begin{array}{l}3.55429 \\
3.58233 \\
3.59925 \\
3.62157\end{array}$ & 3.53066 & .7096 & .010015 & 1.14 & $\begin{array}{l}3.55456 \\
3.58195 \\
3.59905 \\
3.62185\end{array}$ & $\begin{array}{l}-270 \\
+380 \\
+200 \\
-280\end{array}$ \\
\hline & & & & Mean values.... & 3.53066 & .7116 & .010015 & 1.15 & & \\
\hline
\end{tabular}

$Q$ is better than an observed value. Hence, the best values of the pressure drops through the capillaries for substitution in eq 9 will be those obtained from the calculated values of $P / Q$. Toillustrate this treatment, any particular value of $Q$ may be chosen that is within the rates of flow common to the data on both capillaries in the pair. The values of $a$ and $b$ appropriate to the longer capillary are substituted in eq 28 , and the value of $P / Q$ is calculated for the particular rate of flow chosen. Multiplying this value of $P / Q$ by $Q$ gives the value of $P_{1}$, the pressure drop through the capillary. In a similar manner the value of $P_{2}$ is calculated for the shorter capillary at the same rate of flow. These values of the pressure drops corresponding to the rate of flow $Q$ in each capillary are then substituted in eq 9 , together with the capillary dimensions and the mean values of $m$ as determined for the two capillaries. The identical results are obtained more simply, however, by a calculation using the intercepts for the two capillaries.

In a manner similar to that in which eq 8 and 9 were derived, it may be shown that

$$
\eta=\frac{\pi}{8}\left[\frac{a_{1} r_{1}^{4}-a_{2} r_{2}^{4}}{\left(l_{1}-l_{2}\right)+\left(n_{1} r_{1}-n_{2} r_{2}\right)}\right]
$$

in which $a_{1}$ is the intercept in eq 28 for the longer capillary, and $a_{2}$ is the intercept for the shorter. As before, if $r_{1}$ and $r_{2}$ do not differ greatly, the quantity $\left(n_{1} r_{1}-n_{2} r_{2}\right)$ may be neglected.

The values of the measured quantities in eq 29 are given in table 20 for each of the four capillaries. The intercepts used are the mean values for each capillary, as given in tables 16 through 19 . The values of the viscosity as calculated from the data for the pairs 2.5 and $2.5 \mathrm{a}$, and 1.4 and $1.4 \mathrm{a}$ are given in table 21. These two calculations result in values that cover about the same range as the spread of values obtained in the previous calculations, using each capillary individually. For these two pairs it is evident that the quantity $\left(n_{1} r_{1}-n_{2} r_{2}\right)$ may be neglected.

In addition, calculations were made pairing capillary 2.5 with $1.4 \mathrm{a}$ and 1.4 with $2.5 \mathrm{a}$. These results are also given in table 21 . The value of 0.57 was used for both $n_{1}$ and $n_{2}$. The magnitude of the quantity $\left(n_{1} r_{1}-n_{2} r_{2}\right)$ is small in comparison with
TABLE 20. Quantities used in the calculation of the viscosity, by means of equation 29

\begin{tabular}{|c|c|c|c|c|}
\hline Capillary & $a$ & $a r^{4}$ & $l$ & $0.57 r$ \\
\hline $\begin{array}{l}2.5 \\
2.5 \mathrm{a}\end{array}$ & $\begin{array}{l}3.10260 \times 10^{6} \\
\text { 1. } 54785\end{array}$ & $\begin{array}{l}\text { 1. } 24374 \\
0.62032\end{array}$ & $\begin{array}{c}c m \\
48.736 \\
24.316\end{array}$ & $\begin{array}{r}c m \\
0.014 \\
.014\end{array}$ \\
\hline $\begin{array}{l}\text { 1. } 4 \\
1.4 \mathrm{a}\end{array}$ & $\begin{array}{l}7.09917 \\
3.53066\end{array}$ & $\begin{array}{l}1.15319 \\
0.57476\end{array}$ & $\begin{array}{r}45.208 \\
-22.525\end{array}$ & $\begin{array}{l}.011 \\
.011\end{array}$ \\
\hline
\end{tabular}

TABLE 21. Values of the viscosity $\eta$, calculated from the data for pairs of capillaries

\begin{tabular}{|c|c|c|c|c|}
\hline Pair & $\eta$ at $20^{\circ} \mathrm{C}$ & $\begin{array}{c}\eta \text { at } 20^{\circ} \mathrm{C} \\
\text { mean } \\
\text { values }\end{array}$ & $l_{1}-l_{2}$ & $n_{1} r_{1}-n_{2} r_{2}$ \\
\hline $\begin{array}{l}2.5 \text { and } 2.5 \mathrm{a} \\
1.4 \text { and } 1.4 \mathrm{a}\end{array}$ & $\begin{array}{c}\text { Poise } \\
0.010022 \\
.010014\end{array}$ & $\begin{array}{c}\text { Poise } \\
0.010018\end{array}$ & $\left\{\begin{array}{c}c m \\
24.420 \\
22.683\end{array}\right.$ & $\begin{array}{l}c m \\
0.000 \\
.000\end{array}$ \\
\hline $\begin{array}{l}2.5 \text { and } 1.4 \mathrm{a} \\
1.4 \text { and } 2.5 \mathrm{a}\end{array}$ & $\begin{array}{l}.010022 \\
.010018\end{array}$ & .010020 & $\left\{\begin{array}{l}26.211 \\
20.892\end{array}\right.$ & $\begin{array}{l}+.003 \\
-.003\end{array}$ \\
\hline
\end{tabular}

$\left(l_{1}-l_{2}\right)$ in each case, and therefore the calculations are not seriously affected by uncertainties in $n_{1}$ and $n_{2}$. The agreement between the values of the viscosity as calculated through the use of these four pairs indicates an over-all consistency in the data.

\section{Discussion of Results}

\subsection{General}

In work of this nature, where the result is dependent upon so many individual factors, it is difficult to evaluate the final result in terms of the estimated accuracy of each factor. It is believed that the error in each contributing measurement was reduced to 1 part in 10,000 , or better, except perhaps in the measurement of the equilibrium pressures less than $10 \mathrm{in}$. of mercury. As the calculation of the viscosity involves the extrapolation of the observed data, however, the final result would not necessarily be this accurate.

The calculation of the viscosity by means of eq 29 probably represents the most reliable treatment of the data, because uncertainties in the magnitude of the constant $n$ are minimized. The values given in table 21 for the results with the capillary pairs 
$2.5+2.5 \mathrm{a}$ and $1.4+1.4 \mathrm{a}$ are completely independent of the magnitude of $n$. The calculations for the pairs $2.5+1.4 \mathrm{a}$ and $1.4+2.5 \mathrm{a}$, however, are given equal weight, because the introduction of any reasonable value for $n$ will not affect the mean of these two by as much as 1 part in 10,000 . The mean of the four values given in table 21 is

\section{$0.010019 \pm 0.000002$}

where the deviation given is the standard deviation of the mean.

The values of the viscosity calculated by eq 28 , obtained by treating the data for each capillary individually, and given in tables 16 through 19, show a spread from 0.010012 to 0.010019 poise, with a mean value of 0.010015 . This would indicate that 0.57 is too high for the value of $n$. By taking these same data and assuming $n=0$ for all four capillaries, the following values result:

\begin{tabular}{|c|c|}
\hline Capillary & $\eta$ \\
\cline { 2 - 2 } & \\
\hline 2.5 & 0.010022 \\
$2.5 \mathrm{a}$ & .010018 \\
1.4 & 010017 \\
\hline $1.4 \mathrm{a}$ & .010020 \\
\hline
\end{tabular}

The mean of these values is 0.010019 , which is the same as was obtained in the calculations with the capillaries in pairs. Although the assumption that $n=0$ results in better over-all agreement in the calculated values of the viscosity, the measurements are so insensitive for the evaluation of $n$, that no accurate conclusions may be reached as to its magnitude. It is pertinent, however, to note that the results of the calculations with eq 29 given in table 21 are not significantly changed by taking $n=0$. For $n=0$ the value of the viscosity calculated by using capillaries 2.5 and $1.4 \mathrm{a}$ is increased to 0.010023 poise, and the value derived from the pair $1.4+2.5 \mathrm{a}$ is reduced to 0.010017 . Thus the mean value remains the same, but the standard deviation of the mean is increased to \pm 0.000003 . In consideration of this uncertainty in the value of $n$, the best result obtained from the data is

$$
\eta_{20}=0.010019 \pm 0.000003 \text {. }
$$

No attempt is made to assign an accurate value to the constant $m$ on the basis of this work, as the values of the slope $b$ given in tables 16 to 19 may be appreciably in error as a result of heating effects in the capillaries. The incomplete dissipation of the heat generated by work done against viscous forces results in a temperature rise in the flowing liquid. The possible effects of such temperature rises in the capillaries were investigated through the use of equations developed by Hersey [15] and Hersey and Zimmer [16]. Their equations were expected to yield either too high or too low an effective temperature rise, depending upon what extreme conditions of temperature distribution in the capillary were assumed. Calculations based on these equations show that for any of the conditions covered by these equations, the values of the intercepts $a$, as given in tables 16 to 19 , are unchanged. Hence, for the purpose of calculating the viscosity, it is not necessary to attempt to evaluate the effects of heating in the capillaries.

On the other hand, the heating effects may have a marked influence upon the calculated values of $m$. In fact, if certain assumptions are made with regard to the distribution of temperatures in the capillaries, it is possible to account for the differences in the calculated values of $m$ for the four capillaries. As the real distribution of temperatures in the capillaries under the particular flow conditions is not known, no reliance is placed upon such calculations.

In attempting to compare the value obtained here for the absolute viscosity of water at $20^{\circ} \mathrm{C}$ with the results of other observers, it is found that all of the earlier determinations are subject to criticism, and therefore no good agreement is to be expected. The three most recent careful determinations were made by Thorpe and Rodger [17], Hosking [18], and Bingham and White [19]. Their results at $20^{\circ} \mathrm{C}$ are given in table 22 . With regard to these results, it should be pointed out that none of these investigators attempted to make their measurements with the accuracy of the present work. Furthermore, with the capillaries that they were able to obtain, the deviations of the bores from right circular cylinders were large and in most cases not accurately known.

TABLE 22. Viscosity of water at $20^{\circ} \mathrm{C}$ by other investigators

\begin{tabular}{|c|c|c|c|}
\hline Investigator & $\eta_{20}$ & $m$ & $n$ \\
\hline $\begin{array}{l}\text { Thorpe and Rodger (1894) } \\
\text { Hosking (1909) } \\
\text { Bingham and White (1912) }\end{array}$ & $\begin{array}{l}\text { Poise } \\
0.010015 \\
.01006 \\
.01005\end{array}$ & $\begin{array}{l}\text { 1. } 00 \\
1.158 \\
1.12\end{array}$ & $\begin{array}{l}0 \\
1.64 \\
0\end{array}$ \\
\hline
\end{tabular}

In all three of the determinations referred to in table 22 the viscosity was calculated from the observed pressures and rates of flow by means of eq 2 . It is seen that Thorpe and Rodger's value is in best agreement with the value of 0.010019 obtained here. Seemingly, this is simply fortuitous, as there is no evidence that their determination was made with greater accuracy than the other two given in the table. They made no determination of $m$ for their capillary, and the value of 1.00 , which they used on theoretical grounds (probably not sound) is lower than most experimentally determined values. They were not convinced of the existence of the length correction involving the constant $n$, and hence assumed that $n=0$.

In Hosking's work neither the value of $m$ nor $n$ may be regarded as determined. He evaluated $m$ for both directions of flow through each of four capillaries and obtained results varying from 1.128 to 1.216 , with a mean of 1.158 . He then recalculated some of his earlier results obtained with other capillaries, taking $m=1.158$ and $n=1.64$ and arrived 
at $\eta_{20}=0.01006$ as the best result from his work. The value of $n=1.64$ was assumed, as with this correction, certain of his data were more self-consistent.

Bingham and White assumed that $m=1.12$ on the basis of calculations presented in a series of papers by Boussinesq [20]. They determined the value of $n$ for several combinations of capillaries and concluded that its best value was zero. This value was then assumed for the capillary in which the determination of the viscosity of water was made.

In view of the uncertainties in all three of these determinations the lack of agreement with the present determination is not significant.

\subsection{Application in Practical Viscometry}

One aim in this investigation was to obtain a value for the absolute viscosity of water at $20^{\circ} \mathrm{C}$ that could be used as a standard in practical viscometry. Accordingly, beginning on July 1, 1952, the National Bureau of Standards is planning to use the value of 0.01002 poise for the absolute viscosity of water at $20^{\circ} \mathrm{C}$ as the basis for the calibration of viscometers and standard sample oils. It is recommended that other laboratories adopt this value as the primary reference standard for comparative measurements of viscosity.

In evaluating the work reported here, consideration is now given to any limitations in the general applicability of the results obtained under the particular conditions of these experiments. In this connection, various factors must be considered.

(a) Purity of the water with respect to deuterium oxide. At $20^{\circ} \mathrm{C}, \mathrm{D}_{2} \mathrm{O}$ is about 1.245 times as viscous as $\mathrm{H}_{2} \mathrm{O}$ [21], and consequently the deuterium content in the water used must be considered. Fortunately, surveys (for example, [22] have shown that the variation in the isotopic concentration in water from a variety of world-wide sources is only a few parts per million. This variation is not great enough to affect the viscosity by as much as 0.01 percent [23].

(b) Other impurities. Unpublished results, obtained with water from various types of stills at the Bureau, have shown that a simple distillation, such as is accomplished by a commercial laboratory still, yields water of sufficiently uniform composition.

(c) Change of viscosity with pressure. Hardy and Cottington [21, p. 575], using a Master Fenske viscometer, found no measurable effect of pressure in the range, 1 to $3.4 \mathrm{~atm}$.

(d) Change of viscosity with rate of shear. The fact that the data presented here are well represented by eq 28 may be considered as evidence that the viscosity does not vary with rate of shear in the range covered (5,000 to 20,000 reciprocal seconds). Furthermore, Griffiths and Vincent [24] could detect no difference between the viscosity of water measured at a rate of shear of 0.013 reciprocal second and that measured at 5,000 to 10,000 reciprocal seconds.

The authors acknowledge the following contributions to the project: N. E. Dorsey and C. S. Cragoe for their advice and encouragement; R. L. Cottington for his painstaking assistance in gathering many of the data.

\section{References}

[1] E. C. Bingham and R. F. Jackson, Standard substances for the calibration of viscometers, Bull. BS 14 (1918) S298.

[2] E. C. Bingham, Notes on the fluidity of water in the vicinity of $20^{\circ} \mathrm{C}, \mathrm{J}$. Rheology $\boldsymbol{2}, 403$ (1931).

[3] J. R. Coe, Progress report on the determination of absolute viscosity, Physics 4, 274 (1933).

[4] J. R. Coe and T. B. Godfrey, Viscosity of water, J. Applied Phys. 15, 625 (1944).

[5] L. Prandtl and O. G. Tietjens, Applied hydro- and aeromechanics chap. II (McGraw-Hill Book Co., Inc., New York, N.Y., 1934).

[6] S. Erk, On the deviations of the pressure drop in a capillary from the Poiseuille law, J. Rheology 2, 205 (1931).

[7] G. Barr, A monograph of viscometry, chap. II (Humphrey Milford, New York, N. Y., 1931).

[8] W. N. Bond, Viscosity determination by means of orifices and short tubes, Proc. Phys. Soc. (London) 34, 139 (1922).

[9] Ostwald-Luther, Physico-Chemische Messungen, 5th ed., p. 467 (Leipzig, Germany, 1931).

[10] Informal communication of results obtained in the Thermal Expansion Section of the National Bureau of Standards.

[11] B. E. Blaisdell, The physical properties of fluid interfaces of large radius of curvature, Part I, J. Math. and Phys., MIT 19, 186 (1940).

[12] J. A. Beattie, B. E. Blaisdell, J. Kaye, H. T. Gerry, and C. A. Johnson, The thermal expansion and compressibility of vitreous silica and the thermal dilation of mercury, Proc. Am. Acad. Arts Sci. 74, 371 (1941).

[13] Maxwell, Treatise on electricity and magnetism, 3d ed., I, Art. 308, 309 (Oxford, Clarendon Press, 1873).

[14] Rayleigh, On the approximate solution of certain problems relating to the potential, Proc. Math. Soc. VII, 74 (1876).

[15] M. D. Hersey, Note on heat effects in capillary flow, Physics \%, 403 (1936).

[16] M. D. Hersey and J. C. Zimmer, Heat effects in capillary flow at high rates of shear, J. Applied Phys. 8, 359 (1937).

[17] T. E. Thorpe and J. W. Rodger, On the relations between the viscosity (internal friction) of liquids and their chemical nature, Roy. Soc. (London) Phil. Trans. 185A, 397 (1894).

[18] R. Hosking, The viscosity of water, Phil. Mag. [6] 18, 260 (1909).

[19] E. C. Bingham and G. E. White, Fluiditat und die $\mathrm{Hy}$ drattheorie, 1. Die Viskositat von Wasser, $Z$. Physik, Chem. 80, 670 (1912).

[20] J. Boussinesq, Compt. rend. 110, 1160, 1238, 1292 (1890); 113, 9, 49 (1891).

[21] R. C. Hardy and R. L. Cottington, Viscosity of deuterium oxide and water in the range $5^{\circ}$ to $125 \mathrm{C}$, J. Research NBS 42, 573 (1949) RP1994.

[22] E. W. Washburn and E. R. Smith, An examination of water from various natural sources for variations in isotopic composition, BS J. Research 12, 305 (1934) RP656.

[23] G. Jones and H. J. Fornwalt, The viscosity of deuterium oxide and its mixtures with water at $25^{\circ} \mathrm{C}, \mathrm{J}$. Chem. Phys. 4, 30 (1936).

[24] A. Griffiths and P. C. Vincent, The viscosity of water at low rates of flow, Proc. Phys. Soc. (London) 38, 291 (1926).

[25] W. Jaeger and H. von Steinwehr, Die Widerstandsanderung des Quecksilbers swischen $0^{\circ}$ und $100^{\circ}$, Ann. Physik [4] 45, 1089 (1914).

[26] N. E. Dorsey, Properties of ordinary water substance (Reinhold Pub. Co., Inc., New York, N. Y., 1940). 
[27] K. L. Cook, Gravity measurements in the buildings of the U. S. Bureau of Standards, Washington, D. C., unpublished report of the U. S. Department of the Interior, Geological Survey (March 1948).

[28] Units of Weights and Measures, NBS Misc. Pub. 121 (1936).

\section{Appendix A. Values of the Various Con- stants and Quantities Used in the Calcu- lations}

\subsection{Density of Mercury}

From the work of Beattie, et al. [12], and using the relation $1 \mathrm{ml}=1.000027 \mathrm{~cm}^{3}$,

Also,

$$
\mathrm{D}_{\mathrm{Hg}, 0_{0} \mathrm{C}}=13.59546 \mathrm{~g} / \mathrm{ml} \text {, or } 13.59509 \mathrm{~g} / \mathrm{cm}^{3} \text {. }
$$

$$
\mathrm{D}_{\mathrm{Hg}},{ }_{20} \mathrm{C}=13.54589 \mathrm{~g} / \mathrm{cm}^{3} \text {. }
$$

The values of $\beta$ for use in eq 20 were calculated from Beattie's results and found to be as follows in the ranges in which they were used:

\begin{tabular}{|c|c|}
\hline Temperature range & \multicolumn{1}{c|}{$\beta$} \\
\cline { 1 - 2 }${ }^{\circ} C$ & \\
19 through $24 \ldots$ & $180.9 \times 10^{-6}$ \\
25 through $32 \ldots \ldots$ & 181.0 \\
\hline
\end{tabular}

\subsection{Resistivity of Mercury}

From the ICT value of $9.40766 \times 10^{-4}$ international ohm-mm, and converting, using the relation 1 international $\mathrm{ohm}=1.000495$ absolute ohms,

$$
\boldsymbol{\rho}_{0}=9.41232 \times 10^{-4} \text { absolute ohm-mm. }
$$

The equation of Jaeger and von Steinwehr [25],

$$
\rho_{\theta}=\rho_{0}\left(1+889.15 \times 10^{-6} \theta+0.99360 \times 10^{-\ell} \theta^{2}\right),
$$

is used to calculate the resistivity at other temperatures.

\subsection{Density of Water}

The density of water at $20^{\circ} \mathrm{C}$, used in the calculation of the pressure drop through a capillary from the height of mercury in the manometer, was calculated from the properties of water as given by Dorsey [26]. He gives the value of $0.9982336 \mathrm{~g} / \mathrm{ml}$, or $0.998207 \mathrm{~g} / \mathrm{cm}^{3}\left(1 \mathrm{ml}=1.000027 \mathrm{~cm}^{3}\right)$, for the density of air-free water at $20^{\circ} \mathrm{C}$ and a pressure of $1 \mathrm{~atm}$. From Dorsey's table 92, the corresponding value for water saturated with air is $0.998206 \mathrm{~g} / \mathrm{cm}^{3}$.

The pressure on the water, and therefore its density, varies throughout the viscometer and manometer system, and also varies with the height of mercury in the manometer. In appendix $\mathrm{D}$ the calculations of the pressure drops were made on the basis of a mean value for the density of water. This mean was calculated on the basis of a mean pressure of 1.25 atm on the water in the apparatus. The density at this pressure was calculated from the data given in table 105 of Dorsey's book and found to be $0.99822 \mathrm{~g} / \mathrm{cm}^{3}$

The use of this mean value of the density instead of the actual densities for each condition will in no case introduce an error greater than 2 parts per million in the calculation of the pressure drop through the capillary.

\subsection{Acceleration of Gravity}

The value used for the acceleration of gravity is 980.080 $\mathrm{cm} / \mathrm{sec}^{2}$, absolute gravity, Dryden reduction. This value is based upon accurate measurements [27] made on the same floor of the building in which the work was done.

\section{Appendix B. Calibration of the Gage Rods Used With the Mercury Manometer}

The calibration of a gage rod consists in the determination of the interval of length between that rod and the longest gage rod. The result is expressed as a correction to the nominal length of the interval.

The rods were calibrated with Hoke gage blocks in a room where the temperature was controlled close to $20^{\circ} \mathrm{C}$. A shallow glass dish about $10 \mathrm{~cm}$ in diameter and containing mercury was placed on a leveled surface plate. A steel plate with a $3 / 4$-in.-diameter hole was supported above the dish on parallel bars which rested on the surface plate. Hoke gage blocks, wrung together in suitable combinations, were placed vertically on the ground surface of this plate, and the micrometer depth gage was seated on top of the gage blocks. The gage rods were clamped successively in the depth gage, passing through the holes in the gage blocks and steel plate to make contact with the surface of mercury in the dish. Contact was indicated by the same electric circuit as that employed in the manometer.

In this way the intervals between the longest rod and each of the others were determined on various occasions, with the results as given in table 23. After the first two calibrations, only the rods that covered the particular heights used in the tests were further calibrated.

\section{TABLE 23. Calibration of gage rods}

The values given are corrections to the nominal lengths of the intervals in ter thousand ths of an inch]

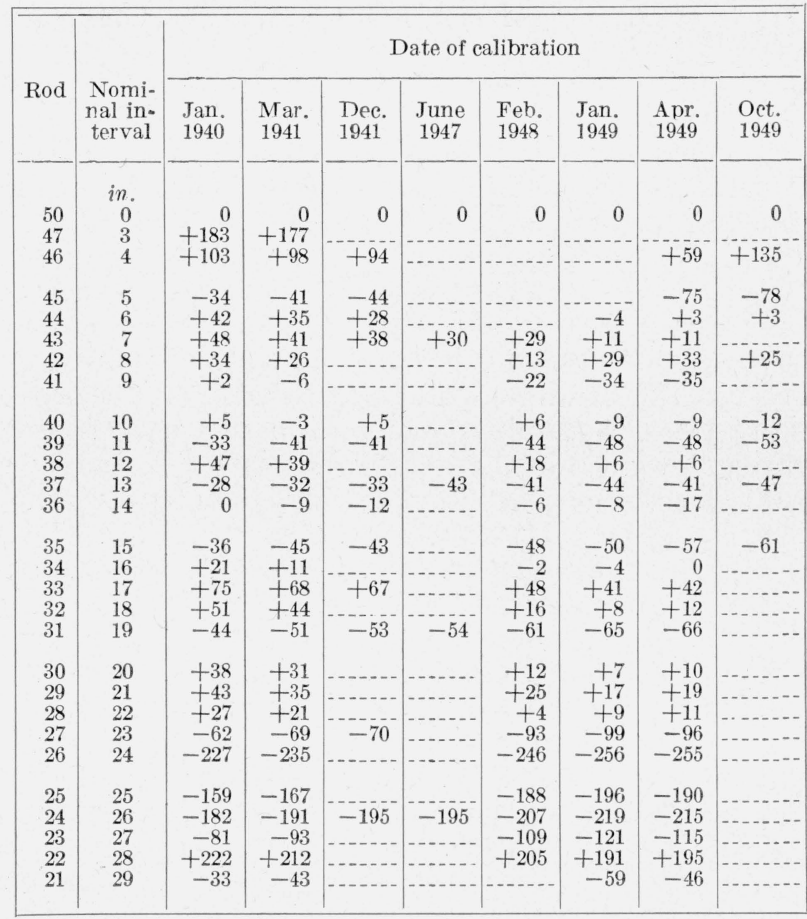

The rods were numbered according to their nominal lengths in inches. The second column gives the nominal difference in length between each rod and rod 50, which was the one used in obtaining the manometer zero. The corrections given for each rod are corrections to the nominal length of the corresponding interval in inches. In all of the calibrations, measurements with each rod were repeated at least once, and the corrections entered in the table are mean values. Repeated measurements on a given rod showed agreement within 0.0002 in. in almost all cases.

It was not possible to attribute the changes in the lengths to any one cause. In general, the changes were in the direction of the intervals shortening with time, but the magnitudes of the changes were not proportional to the interval 
lengths and therefore were not explained by uniform shrinkage of the rods. It is probable that growth and shrinkage of the rods, together with possible electrolytic wear of the tips, were all involved in varying extents. However, these changes were followed closely, and it is felt that the corrections were known to within at least $0.0004 \mathrm{in}$. of their true values at all times when flow measurements were being made.

\section{Appendix C. Radii by the Gravimetric Method. Details of the Weighings}

For determining the mean radii of the capillaries by the gravimetric method, the quantities of mercury from the fillings of the capillaries were weighed in small glass-stoppered bottles.

In the weighings concerned with capillaries 2.5 and $1.4 \mathrm{a}$, three bottles, 3,6 and 25, were used. Bottles 3 and 6 were used in the weighing of the mercury, and bottle 25 was weighed each time as a blank. The weighing procedure was designed to determine the effects, if any, of possible variations in the surface condition of the glass upon the constancy of weight of the bottles. The three bottles were first weighed empty, and the mercury was transferred from the capillary to bottle 3 and weighed. It was then transferred to bottle 6 and weighed. After this, the mercury was discarded, and bottle 6 was weighed again empty. Before each weighing the bottles were held in steam momentarily to condense moisture of the surface so as to dissipate any electrostatic charges. The bottle caps were loosened and replaced. Then the bottles were placed in the balance and weighed after about 5 minutes.

The results of the weighings of the empty bottles are given in table 24. The weighings show small erratic changes, and

TABLE 24. Mass of weighing bottles, empty

\begin{tabular}{|c|c|c|c|c|}
\hline \multirow{2}{*}{ Date } & \multirow{2}{*}{$\begin{array}{l}\text { Relative } \\
\text { humidity }\end{array}$} & \multicolumn{3}{|c|}{ Bottle- } \\
\hline & & 3 & 6 & 25 \\
\hline $1 / 17 / 50$ & $\begin{array}{c}\text { Percent } \\
18\end{array}$ & $\left\{\begin{array}{c}m g \\
2199.037 \\
2199.038\end{array}\right.$ & $\begin{array}{c}m g \\
2291.281 \\
2291.278\end{array}$ & $\begin{array}{c}m g \\
2401.135 \\
2401.134\end{array}$ \\
\hline $1 / 17 / 50$ & 17 & $\left\{\begin{array}{c}2199.042 \\
-\end{array}\right.$ & $\begin{array}{l}2291.283 \\
2291.282\end{array}$ & 2401.135 \\
\hline $1 / 18 / 50$ & 31 & $\left\{\begin{array}{l}-\cdots \\
-\cdots\end{array}\right.$ & $\begin{array}{l}2291.290 \\
2291.287\end{array}$ & 2401.147 \\
\hline $1 / 19 / 50$ & 18 & $\left\{\begin{array}{r}2199.046 \\
-\end{array}\right.$ & $\begin{array}{l}2291.289 \\
2291.291\end{array}$ & 2401.146 \\
\hline $1 / 20 / 50$ & 15 & $\left\{\begin{array}{l}2199.049 \\
2199.040\end{array}\right.$ & $\begin{array}{l}2291.294 \\
2291.294\end{array}$ & 2401.151 \\
\hline $1 / 23 / 50$ & 38 & $\left\{\begin{array}{c}2199.059 \\
-\end{array}\right.$ & $\begin{array}{l}2291.295 \\
2291.302\end{array}$ & 2401.151 \\
\hline $1 / 24 / 50$ & 40 & $\left\{\begin{array}{c}2199.062 \\
-\end{array}\right.$ & $\begin{array}{l}2291.298 \\
2291.302\end{array}$ & $\begin{array}{r}2401.156 \\
\end{array}$ \\
\hline $1 / 25 / 50$ & 48 & $\left\{\begin{array}{c}2199.053 \\
-\end{array}\right.$ & $\begin{array}{l}2291.299 \\
2291.301\end{array}$ & 2401.153 \\
\hline $1 / 26 / 50$ & 44 & $\left\{\begin{array}{c}2199.051 \\
-\end{array}\right.$ & $\begin{array}{l}2291.300 \\
2291.300\end{array}$ & 2401.156 \\
\hline $1 / 27 / 50$ & 27 & $\left\{\begin{array}{l}2199.053 \\
-\end{array}\right.$ & $\begin{array}{l}2291.300 \\
2291.299\end{array}$ & 2401.164 \\
\hline $1 / 27 / 50$ & 22 & 2199.058 & $\begin{array}{l}2291.297 \\
2291.306\end{array}$ & 2401.163 \\
\hline
\end{tabular}

evidence a definite over-all gain in weight of all three bottles during the period of their use. The gain in weight of bottles 3 and 6 is probably not attributable to residues left by the mercury samples, as bottle 25 showed the same increase.

In the course of the weighings, the relative humidity in the room where the weighings were made was varied through the wide range given in the table. Apparently the weighings were not affected by these variations.
The results of the two weighings of each sample of mercury are given in table 25. Samples A to $\mathrm{E}$ were from repeat fillings of capillary $2.5 \mathrm{a} ; \mathrm{F}$ to $\mathrm{J}$ were from capillary $1.4 \mathrm{a}$. The agreement between the two weighings of each sample is better than $0.01 \mathrm{mg}$ in all cases. The mean values of these duplicate weighings are given in table 10 and were used in the calculations. Considering all sources of error, it is probable that these mean values are within $0.01 \mathrm{mg}$ of the true masses of the samples.

TABLE 25. Mass of samples of mercury from fillings of capillaries $2.5 a$ and $1.4 a$

\begin{tabular}{|c|c|c|c|}
\hline \multirow{2}{*}{ Sample } & \multirow{2}{*}{ Date } & \multicolumn{2}{|c|}{ Weighed in bottle- } \\
\hline & & 3 & 6 \\
\hline $\begin{array}{l}\mathrm{A} \\
\mathrm{B} \\
\mathrm{B} \\
\mathrm{C} \\
\mathrm{D}- \\
\mathrm{E}\end{array}$ & $\begin{array}{l}1 / 17 / 50 \\
1 / 18 / 50 \\
1 / 19 / 50 \\
1 / 20 / 50 \\
1 / 23 / 50\end{array}$ & $\begin{array}{c}m g \\
654.303 \\
654.490 \\
654.185 \\
654.638 \\
654.329\end{array}$ & $\begin{array}{l}m g \\
654.307 \\
654.485 \\
654.190 \\
654.643 \\
654.324\end{array}$ \\
\hline $\begin{array}{l}\mathrm{F} \\
\mathrm{G} \\
\mathrm{H} \\
\mathrm{H} \\
\mathrm{J}\end{array}$ & $\begin{array}{l}1 / 24 / 50 \\
1 / 25 / 50 \\
1 / 26 / 50 \\
1 / 27 / 50 \\
1 / 27 / 50\end{array}$ & $\begin{array}{l}386.252 \\
386.016 \\
386.099 \\
386.214 \\
386.056\end{array}$ & $\begin{array}{l}386.258 \\
386.013 \\
386.099 \\
386.221 \\
386.047\end{array}$ \\
\hline
\end{tabular}

\section{Appendix D. Data and Calculation of the Pressure Drops Through the Capillaries}

Tables 26 to 36 give the observations made in the 11 series of flow measurements and the detailed calculations of the pressure drops. The values of $Q$ given in column 3 of these tables were calculated by the relation

$$
Q=\text { speed of drive shaft } \times \frac{\text { grams mercury }}{\text { turn of drive shaft }} \times \frac{1}{D_{\mathrm{Hg}, 20 \circ \mathrm{C}}} .
$$

The speeds of the drive shaft in revolutions per second were calculated from the motor speed and the ratio of the gears used in each case. The rate of delivery of the injector in grams per turn of the drive shaft was taken appropriately from table 1,3 or 5 . The value used for the density of mercury at $20^{\circ} \mathrm{C}$ is $13.59546 \mathrm{~g} / \mathrm{cm}^{3}$ (see appendix $\mathrm{A}$ ).

The gage-rod corrections given in appendix B were plotted as a function of time, and the corrections entered in column 5 were taken from these curves.

Each observation of the manometer zero is entered in the lower part of the tables. The mean of the observations in a particular series was used in the computation of the pressures for that series.

Values of $M_{0}$, the micrometer depth-gage head readings under the flow conditions, are given in column 6 . In column 7, $\Delta=$ mean $M_{0}-M_{Q}$

The differential heights of mercury in the manometer are given in column 8 . These are computed by the relation

$$
h_{\theta}=\Delta+\text { interval }+ \text { rod correction, }
$$

in which the interval is the nominal difference in length between the rod and rod 50 .

The difference between the actual temperature of each run and $20^{\circ} \mathrm{C}$ is entered in column 9. On the basis of these temperature differences, the corrections to $h_{\theta}$ entered in column 11 were computed by using $0.0025 \% / 0.001 \mathrm{deg} \mathrm{C}$ for the change in the viscosity of water with temperature at temperatures close to $20^{\circ} \mathrm{C}$ [4]. The sign of each correction is such that $h_{20}=\mathrm{h}_{\theta}+\Delta h$, in which $h_{20}$ is the height of mercury for a corresponding run at $20^{\circ} \mathrm{C}$. Expansions or contractions in the duralumin frame, gage rods, mercury in the manometer, etc. were computed and found to be completely negligible for these small temperature differences.

The mean value of $h_{20}$ for each rate of flow is given in column 12, and the standard deviation of the mean is given in column 13 . 
The pressure drops in dynes per square centimeter were calculated from the mean values of $h_{20}$ and entered in column 14. The calculations were made using the relation

$$
p_{20}=2.540005 \times g \times\left(\mathrm{D}_{\mathrm{Hg}}-\mathrm{D}_{\mathrm{W}}\right)_{20}{ }^{\circ} \mathrm{C} \times h_{20},
$$

in which 2.540005 is the factor for converting inches to centimeters [30]. Substituting for $g$ and $\left(\mathrm{D}_{\mathrm{Hg}}-\mathrm{D}_{\mathrm{W}}\right)_{20^{\circ} \mathrm{C}}$ their values from appendix A,

$$
p_{20}=3.12363 \times 10^{4} \times h_{20} \text {. }
$$

As was mentioned in the description of the manometer, the values of $p_{20}$ given in column 14 include the pressure drop through the side tube connecting the exit chamber with the long arm of the manometer. Values of this pressure drop, which is equal to the second term on the right hand side in eq 16, are given in column 15. This correction was applied to $p_{20}$ yielding the pressure drops across the capillary alone, which are entered in column 16. Standard deviations in dynes per square centimeter are entered in column 17.

TABLE 26. Series II, capillary 2.5

[Calculation of the pressure drops]

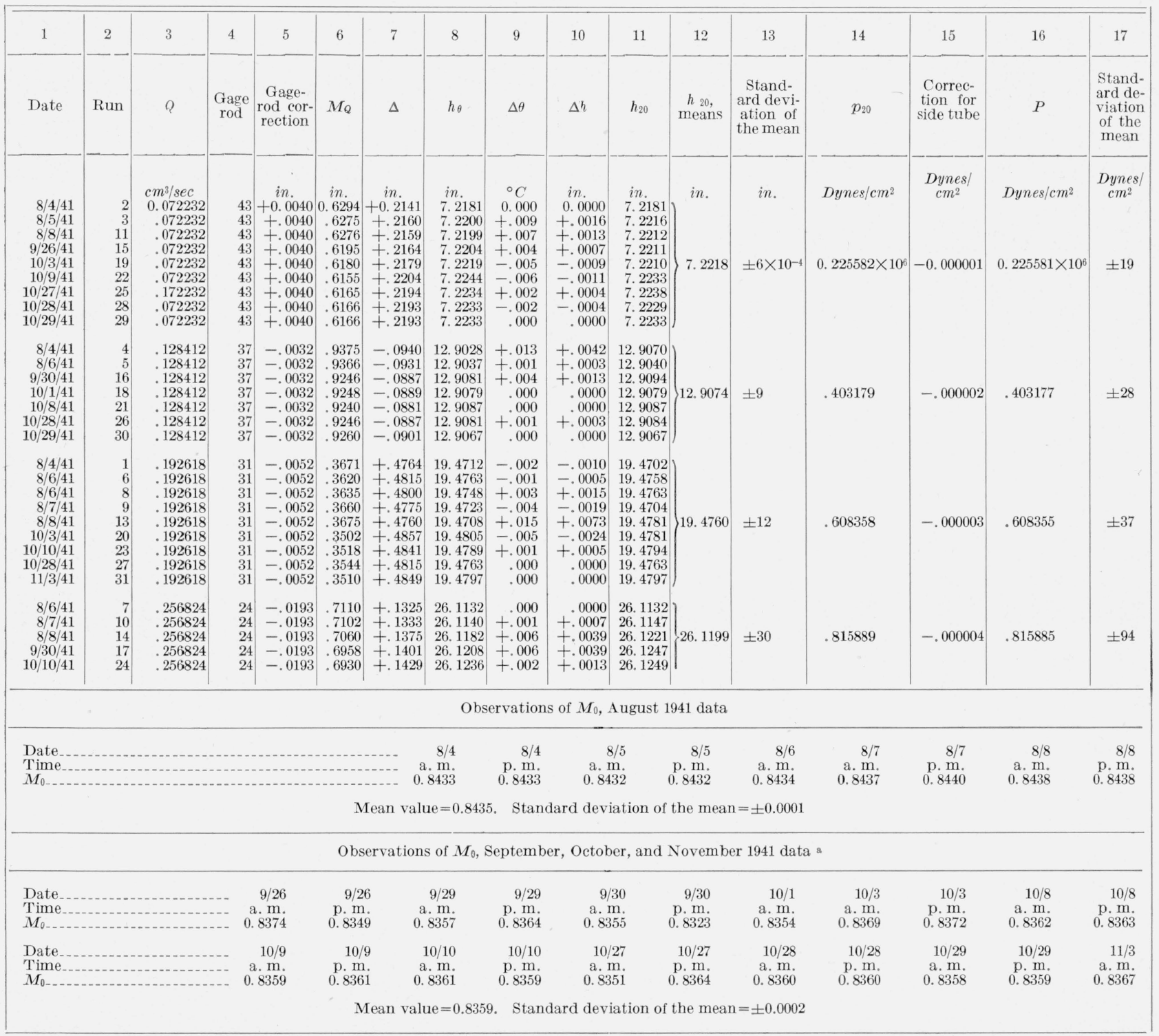

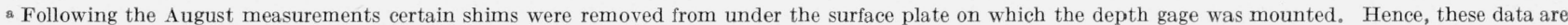
expected to be different from the August data. 
TABLE 27. Series III, capillary 2.5

[Calculation of the pressure drops]

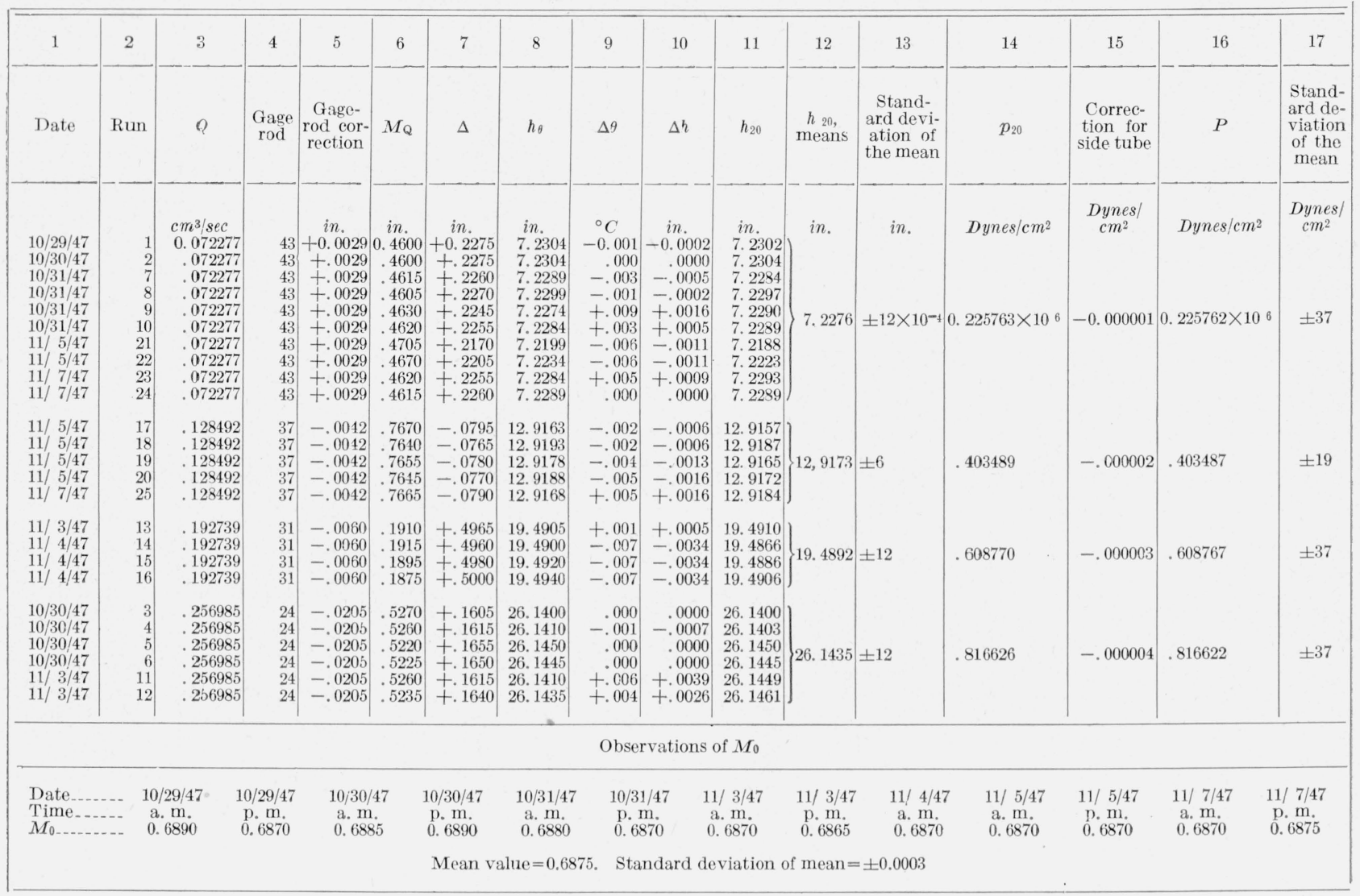

Table 28. Series IV, capillary 2.5

[Calculation of the pressure drops]

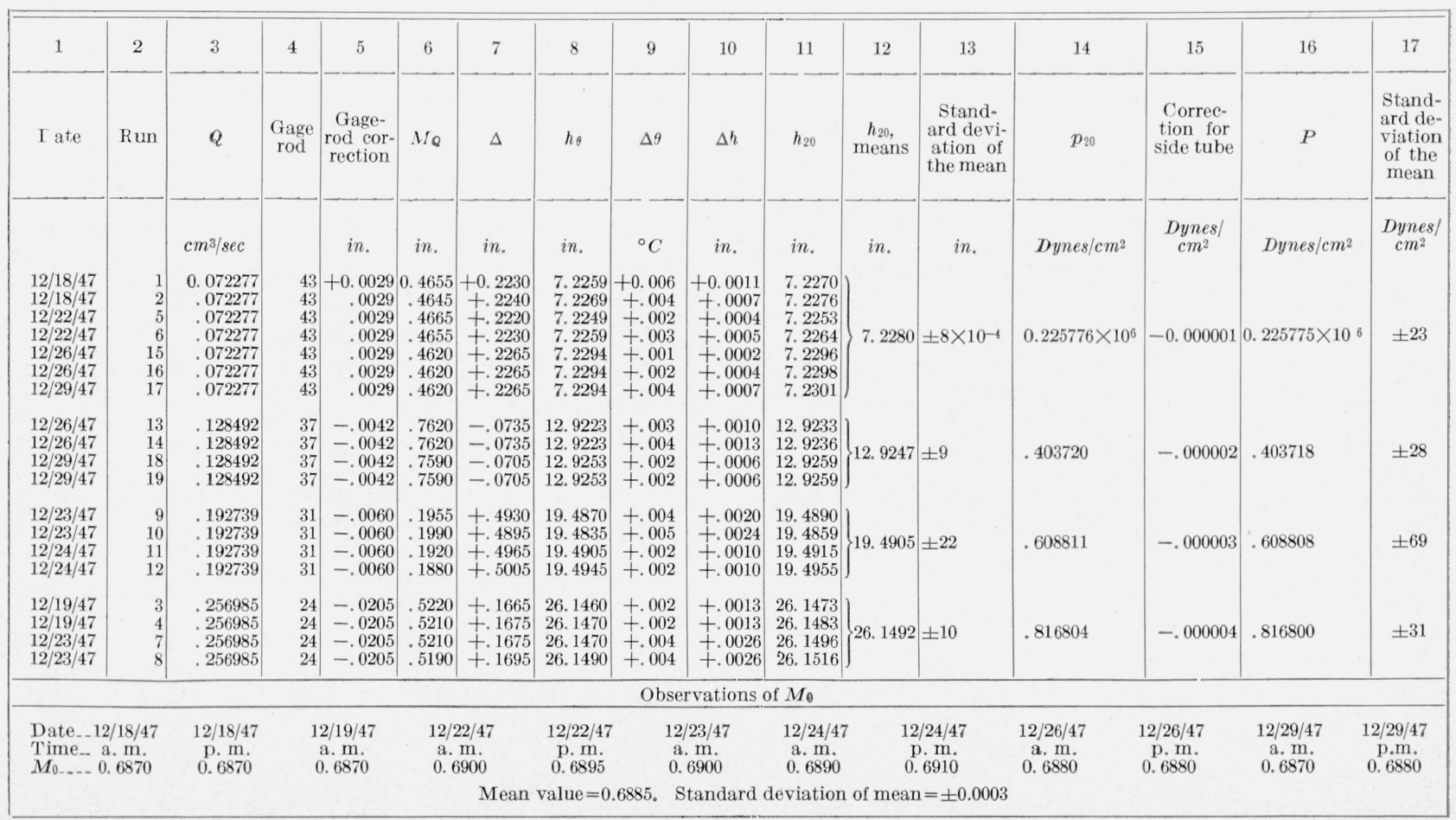


TABle 29. Series VII, capillary 2.5a

[Calculation of the pressure drops]

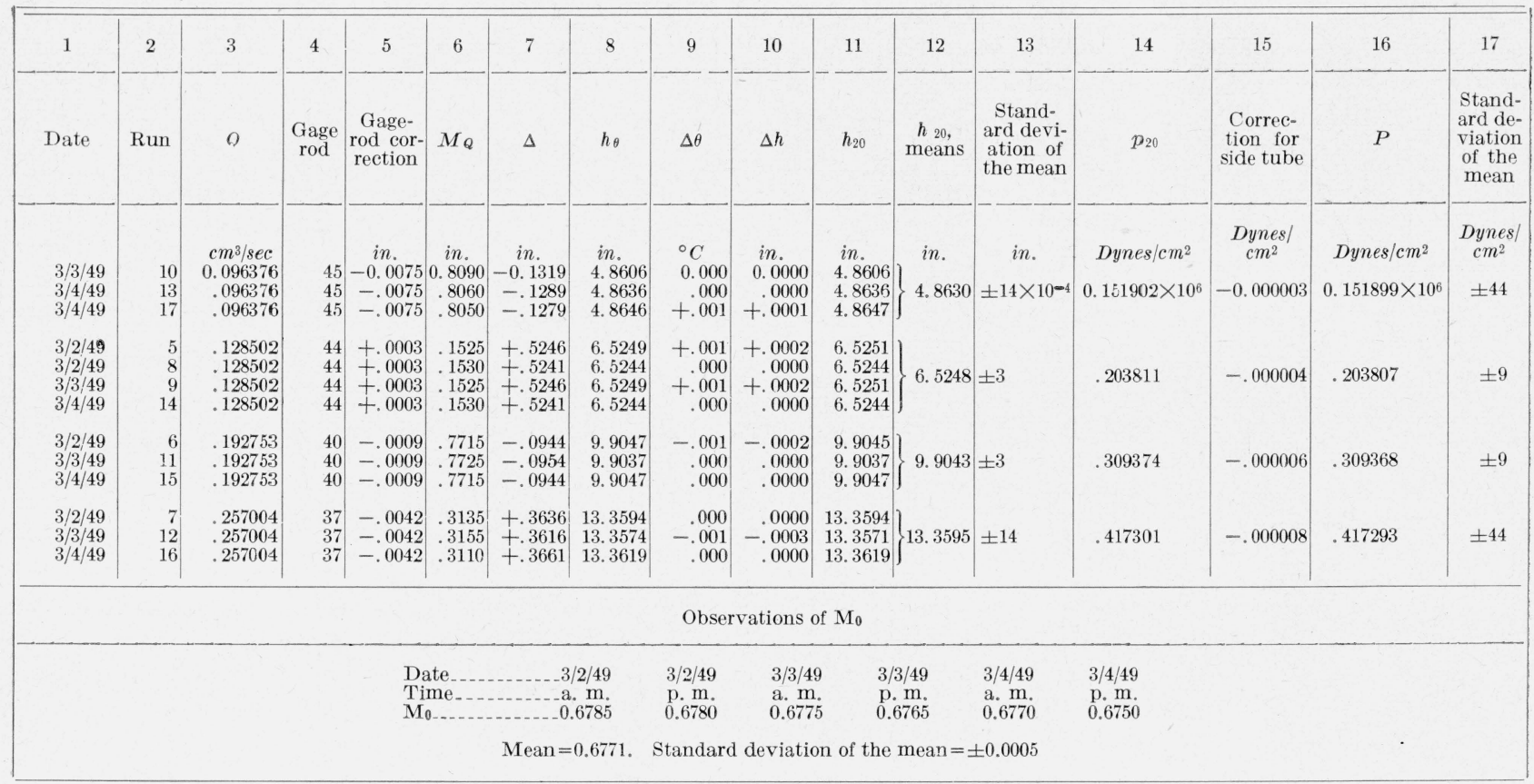

TABLE 30. Series $I X$, capillary $2.5 a$

[Calculation of the pressure drops]

\begin{tabular}{|c|c|c|c|c|c|c|c|c|c|c|c|c|c|c|c|c|}
\hline 1 & 2 & 3 & 4 & 5 & 6 & 7 & 8 & 9 & 10 & 11 & 12 & 13 & 14 & 15 & 16 & 17 \\
\hline Date & Run & Q & $\begin{array}{c}\text { Gage } \\
\text { rod }\end{array}$ & $\begin{array}{c}\text { Gage- } \\
\text { rod cor- } \\
\text { rection }\end{array}$ & $M_{Q}$ & $\Delta$ & $h_{\theta}$ & $\Delta 9$ & $\Delta \eta$ & $h_{20}$ & $\begin{array}{c}h_{20}, \\
\text { means }\end{array}$ & $\begin{array}{c}\text { Stand- } \\
\text { ard devi- } \\
\text { ation of } \\
\text { the mean }\end{array}$ & $p_{20}$ & $\begin{array}{l}\text { Correc- } \\
\text { tion for } \\
\text { side tube }\end{array}$ & $P$ & $\begin{array}{l}\text { Stand- } \\
\text { ard de- } \\
\text { viation } \\
\text { of the } \\
\text { mean }\end{array}$ \\
\hline $\begin{array}{l}3 / 28 / 49 \\
3 / 30 / 49 \\
3 / 31 / 49\end{array}$ & $\begin{array}{r}6 \\
8 \\
14\end{array}$ & $\begin{array}{c}\mathrm{cm}^{3} / \mathrm{sec} \\
0.096376 \\
.096376 \\
.096376\end{array}$ & $\begin{array}{l}45 \\
45 \\
45\end{array}$ & $\begin{array}{c}\text { in. } \\
-0.0075 \\
-.0075 \\
-.0075\end{array}$ & $\begin{array}{c}i n . \\
0.8570 \\
.8560 \\
.8540\end{array}$ & $\begin{array}{c}\text { in. } \\
-0.1300 \\
-.1290 \\
-.1270\end{array}$ & $\begin{array}{l}\text { in. } \\
4.8625 \\
4.8635 \\
4.8655\end{array}$ & $\begin{array}{c}{ }^{\circ} \mathrm{C} \\
0.000 \\
+.001 \\
.000\end{array}$ & $\begin{array}{l}\text { in. } \\
0.0000 \\
+.0001 \\
.0000\end{array}$ & $\begin{array}{l}\text { in. } \\
4.8625 \\
4.8636 \\
4.8655\end{array}$ & $\left\{\begin{array}{l}\text { in. } \\
4.8639\end{array}\right.$ & $\begin{array}{c}\text { in. } \\
\pm 10 \times 10^{-4}\end{array}$ & $\begin{array}{c}\text { Dynes } / \mathrm{cm}^{2} \\
0.151930 \times 10^{6}\end{array}$ & $\begin{array}{c}\text { Dynes/ } \\
c m^{2} \\
-0.000003\end{array}$ & $\begin{array}{c}\text { Dynes } / \mathrm{cm}^{2} \\
0.151927 \times 10^{6}\end{array}$ & $\begin{array}{c}\begin{array}{c}\text { Dynes/ } \\
\text { cm }^{2}\end{array} \\
\pm 31\end{array}$ \\
\hline $\begin{array}{l}3 / 28 / 49 \\
3 / 30 / 49 \\
3 / 31 / 49\end{array}$ & \begin{tabular}{r|r}
7 \\
9 \\
15
\end{tabular} & \begin{tabular}{r|}
.128502 \\
.128502 \\
.128502
\end{tabular} & $\begin{array}{l}44 \\
44 \\
44\end{array}$ & $\begin{array}{l}+.0003 \\
+.0003 \\
+.0003\end{array}$ & $\begin{array}{r}.2020 \\
.2025 \\
.2015\end{array}$ & $\begin{array}{l}+.5250 \\
+.5245 \\
+.5255\end{array}$ & $\begin{array}{l}6.5253 \\
6.5248 \\
6.5258\end{array}$ & $\begin{array}{r}.000 \\
.000 \\
+.001\end{array}$ & $\begin{array}{r}.0000 \\
.0000 \\
+.0002\end{array}$ & $\begin{array}{l}6.5253 \\
6.5248 \\
6.5260\end{array}$ & 6. 5254 & \pm \pm 4 & .203829 & -.000004 & .203825 & \pm 12 \\
\hline $\begin{array}{l}3 / 30 / 49 \\
3 / 30 / 49 \\
3 / 31 / 49\end{array}$ & $\begin{array}{l}10 \\
12 \\
16\end{array}$ & $\begin{array}{l}.192753 \\
.192753 \\
.192753\end{array}$ & $\begin{array}{l}40 \\
40 \\
40\end{array}$ & $\begin{array}{l}-.0009 \\
-.0009 \\
-.0009\end{array}$ & $\begin{array}{l}.8250 \\
.8220 \\
.8220\end{array}$ & $\begin{array}{l}-.0980 \\
-.0950 \\
-.0950\end{array}$ & $\begin{array}{l}\text { 9. } 9011 \\
9.9041 \\
9.9041\end{array}$ & $\begin{array}{r}.000 \\
.000 \\
+.001\end{array}$ & $\begin{array}{r}.0000 \\
.0000 \\
+.0002\end{array}$ & $\begin{array}{l}\text { 9. } 9011 \\
\text { 9. } 9041 \\
9.9043\end{array}$ & 9. 9032 & \pm 12 & .309339 & -.000006 & 309333 & \pm 38 \\
\hline $\begin{array}{l}3 / 30 / 49 \\
3 / 31 / 49 \\
3 / 31 / 49\end{array}$ & \begin{tabular}{l|l}
11 \\
13 \\
17
\end{tabular} & $\begin{array}{l}.257004 \\
.257004 \\
.257004\end{array}$ & $\begin{array}{l}37 \\
37 \\
37\end{array}$ & $\begin{array}{l}-.0042 \\
-.0042 \\
-.0042\end{array}$ & $\begin{array}{l}.3640 \\
.3635 \\
.3615\end{array}$ & $\begin{array}{r}+.3630 \\
+.3635 \\
+.3655\end{array}$ & $\begin{array}{l}\text { 13. } 3588 \\
13.3593 \\
13.3613\end{array}$ & $\begin{array}{l}.000 \\
.000 \\
.000\end{array}$ & $\begin{array}{l}.0000 \\
.0000 \\
.0000\end{array}$ & $\begin{array}{l}\text { 13. } 3588 \\
13.3593 \\
13.3613\end{array}$ & $\{13.3598$ & \pm 9 & .417311 & -.000008 & . 417303 & \pm 28 \\
\hline \multicolumn{17}{|c|}{ Observations of $M_{0}$} \\
\hline & & & & $\begin{array}{l}\text { Date_. } \\
\text { Time } \\
M_{0} \ldots\end{array}$ & . & $\begin{array}{r}-.3 / 28 / \\
-\alpha . m \\
\hdashline-0.72\end{array}$ & & $\begin{array}{c}3 / 28 / 49 \\
\text { p.m. } \\
0.7275\end{array}$ & $\begin{array}{l}3 / 30 / 49 \\
\text { a.m. } \\
0.7260\end{array}$ & & $\begin{array}{l}30 / 49 \\
\text { o.m. } \\
7270\end{array}$ & $\begin{array}{l}\text { 3/31/49 } \\
\text { a.m. } \\
0.7255\end{array}$ & $\begin{array}{c}3 / 31 / 49 \\
\text { p.m. } \\
0.7270\end{array}$ & & & \\
\hline
\end{tabular}


TABLE 31. Series $X$, capillary $2.5 a$

[Calculation of the pressure drops]

\begin{tabular}{|c|c|c|c|c|c|c|c|c|c|c|c|c|c|c|c|c|}
\hline 1 & 2 & 3 & 4 & 5 & 6 & 7 & 8 & 9 & 10 & 11 & 12 & 13 & 14 & 15 & 16 & 17 \\
\hline Date & Run & ? & $\begin{array}{c}\text { Gage } \\
\text { rod }\end{array}$ & $\begin{array}{l}\text { Gage- } \\
\text { rod cor- } \\
\text { rection }\end{array}$ & $M_{Q}$ & $\Delta$ & $h_{\theta}$ & $\Delta \theta$ & $\Delta h$ & $h_{20}$ & $\begin{array}{c}h_{20}, \\
\text { means }\end{array}$ & $\begin{array}{l}\text { Stand- } \\
\text { ard devi- } \\
\text { ation of } \\
\text { the mean }\end{array}$ & $p_{20}$ & $\begin{array}{l}\text { Correc- } \\
\text { tion for } \\
\text { side tube }\end{array}$ & $P$ & $\begin{array}{l}\text { Stand- } \\
\text { ard de- } \\
\text { viation } \\
\text { of the } \\
\text { mean }\end{array}$ \\
\hline $\begin{array}{l}8 / 12 / 49 \\
8 / 12 / 49 \\
8 / 15 / 49 \\
8 / 16 / 49\end{array}$ & $\begin{array}{r}1 \\
5 \\
7 \\
12\end{array}$ & $\begin{array}{c}c m^{3} / s e c \\
0.096376 \\
096376 \\
.096376 \\
.096376\end{array}$ & $\begin{array}{l}45 \\
45 \\
45 \\
45\end{array}$ & $\begin{array}{r}\text { in. } \\
-0.0078 \\
-.0078 \\
-.0078 \\
-.0078\end{array}$ & $\begin{array}{r}\text { in. } \\
0.9635 \\
.9650 \\
.9650 \\
.9640\end{array}$ & $\begin{array}{c}\text { in. } \\
-0.1280 \\
-.1295 \\
-.1295 \\
-.1285\end{array}$ & \begin{tabular}{l|} 
in. \\
4.8642 \\
4.8627 \\
4.8627 \\
4.8637
\end{tabular} & $\begin{array}{r}{ }^{\circ} \mathrm{C} \\
0.000 \\
+.006 \\
.000 \\
.000\end{array}$ & \begin{tabular}{r|} 
in. \\
0.0000 \\
+.0007 \\
.0000 \\
.0000
\end{tabular} & \begin{tabular}{l|} 
in. \\
4.8642 \\
4.8634 \\
4.8627 \\
4.8637
\end{tabular} & $\begin{array}{l}\text { in. } \\
4.8635\end{array}$ & $\begin{array}{c}\text { in. } \\
\pm 3 \times 10^{-4}\end{array}$ & $\begin{array}{c}\text { Dynes } / \mathrm{cm}^{2} \\
0.151918 \times 10^{6}\end{array}$ & $\begin{array}{c}\begin{array}{c}\text { Dynes/ } \\
\text { cm }^{2}\end{array} \\
-0.000003\end{array}$ & $\begin{array}{c}\text { Dynes } / \mathrm{cm}^{2} \\
0.151915 \times 10^{6}\end{array}$ & $\begin{array}{c}\begin{array}{c}\text { Dynes/ } \\
\text { cm }^{2}\end{array} \\
\pm 9\end{array}$ \\
\hline $\begin{array}{l}8 / 12 / 4^{9} \\
8 / 12 / 49 \\
8 / 15 / 49 \\
8 / 16 / 49\end{array}$ & $\begin{array}{r}2 \\
6 \\
8 \\
13\end{array}$ & $\begin{array}{l}.128502 \\
.128502 \\
.128502 \\
.128502\end{array}$ & $\begin{array}{l}44 \\
44 \\
44 \\
44\end{array}$ & $\begin{array}{r}+.0003 \\
+.0003 \\
+.0003 \\
+.0003\end{array}$ & $\begin{array}{l}.3125 \\
.3130 \\
.3115 \\
.3155\end{array}$ & $\begin{array}{r}+.5230 \\
+.5225 \\
+.5240 \\
+.5200\end{array}$ & $\begin{array}{l}\text { 6. } 5233 \\
6.5228 \\
6,5243 \\
6.5203\end{array}$ & $\begin{array}{l}.000 \\
.000 \\
.000 \\
.000\end{array}$ & $\begin{array}{l}.0000 \\
.0000 \\
.0000 \\
.0000\end{array}$ & $\begin{array}{l}\text { 6. } 5233 \\
6.5228 \\
6.5243 \\
6.5203\end{array}$ & 6. 5227 & \pm 9 & .203745 & -.000004 & .203741 & \pm 27 \\
\hline $\begin{array}{l}8 / 12 / 49 \\
8 / 15 / 49 \\
8 / 15 / 49 \\
8 / 16 / 49\end{array}$ & $\begin{array}{r}3 \\
9 \\
11 \\
14\end{array}$ & $\begin{array}{l}.192753 \\
.192752 \\
.192753 \\
.192753\end{array}$ & $\begin{array}{l}40 \\
40 \\
40 \\
40\end{array}$ & $\begin{array}{l}-.0012 \\
-.0012 \\
-.0012 \\
-.0012\end{array}$ & $\begin{array}{l}.9335 \\
.9330 \\
.9310 \\
.9310\end{array}$ & $\begin{array}{l}-.0980 \\
-.0975 \\
-.0955 \\
-.0955\end{array}$ & $\begin{array}{l}\text { 9. } 9008 \\
\text { 9. } 9013 \\
\text { 9. } 9033 \\
9.9033\end{array}$ & $\begin{array}{r}+.001 \\
.000 \\
.000 \\
+.001\end{array}$ & $\begin{array}{r}+.0002 \\
.0000 \\
+.0000 \\
+.0002\end{array}$ & $\begin{array}{l}\text { 9. } 9010 \\
9.9013 \\
9.9033 \\
9.9035\end{array}$ & 9.9023 & \pm 8 & 309311 & -.000006 & .309305 & \pm 25 \\
\hline $\begin{array}{l}8 / 12 / 49 \\
8 / 15 / 49 \\
8 / 16 / 49\end{array}$ & $\begin{array}{r}4 \\
10 \\
15\end{array}$ & $\begin{array}{l}.257004 \\
.257004 \\
.257004\end{array}$ & $\begin{array}{l}37 \\
37 \\
37\end{array}$ & $\begin{array}{l}-.0047 \\
-.0047 \\
-.0047\end{array}$ & $\begin{array}{l}.4700 \\
.4700 \\
.4685\end{array}$ & $\begin{array}{r}+.3655 \\
+.3655 \\
+.3670\end{array}$ & \begin{tabular}{|l|}
13.3608 \\
13.3608 \\
13.3623
\end{tabular} & $\begin{array}{l}.000 \\
.000 \\
.000\end{array}$ & $\begin{array}{l}.0000 \\
.0000 \\
.0000\end{array}$ & $\begin{array}{l}\text { 13. } 3608 \\
13.3608 \\
13.3623\end{array} \mid$ & \}13.3613 & \pm 8 & .417357 & -.000008 & .417349 & \pm 24 \\
\hline \multicolumn{17}{|c|}{ Observations of $M_{0}$} \\
\hline $\begin{array}{l}\text { Date_... } \\
\text { Time } \\
M_{0} \ldots \ldots\end{array}$ & ...... & $\begin{array}{l}8 / 12 / 49 \\
\text { - a. m. } \\
0.8355\end{array}$ & \multicolumn{2}{|c|}{$\begin{array}{l}8 / 12 / 49 \\
\text { p. m. } \\
0.8345\end{array}$} & $\begin{array}{l}8 / 15 / 49 \\
\text { a. m. } \\
0.8335\end{array}$ & $\begin{array}{l}8 / 1 \\
p . \\
0 .\end{array}$ & $\begin{array}{l}8 / 15 / 49 \\
\text { p. m. } \\
0.8360\end{array}$ & $\begin{array}{l}8 / 16 / 49 \\
\text { a. m. } \\
0.8355\end{array}$ & \multicolumn{2}{|c|}{$\begin{array}{c}8 / 16 / 49 \\
\text { Noon } \\
0.8360\end{array}$} & \multicolumn{2}{|l|}{$\begin{array}{c}\text { 8/16/49 } \\
\text { p.m. m. } \\
0.8375\end{array}$} & & & & \\
\hline \multicolumn{8}{|c|}{ Mean $=0.8355$. } & Standard & A deviatio & on of the & mean $= \pm$ & \pm 0.0004 & & & & \\
\hline
\end{tabular}

TABLe 32. Series $V$, capillary 1.4

[Calculation of the pressure drops]

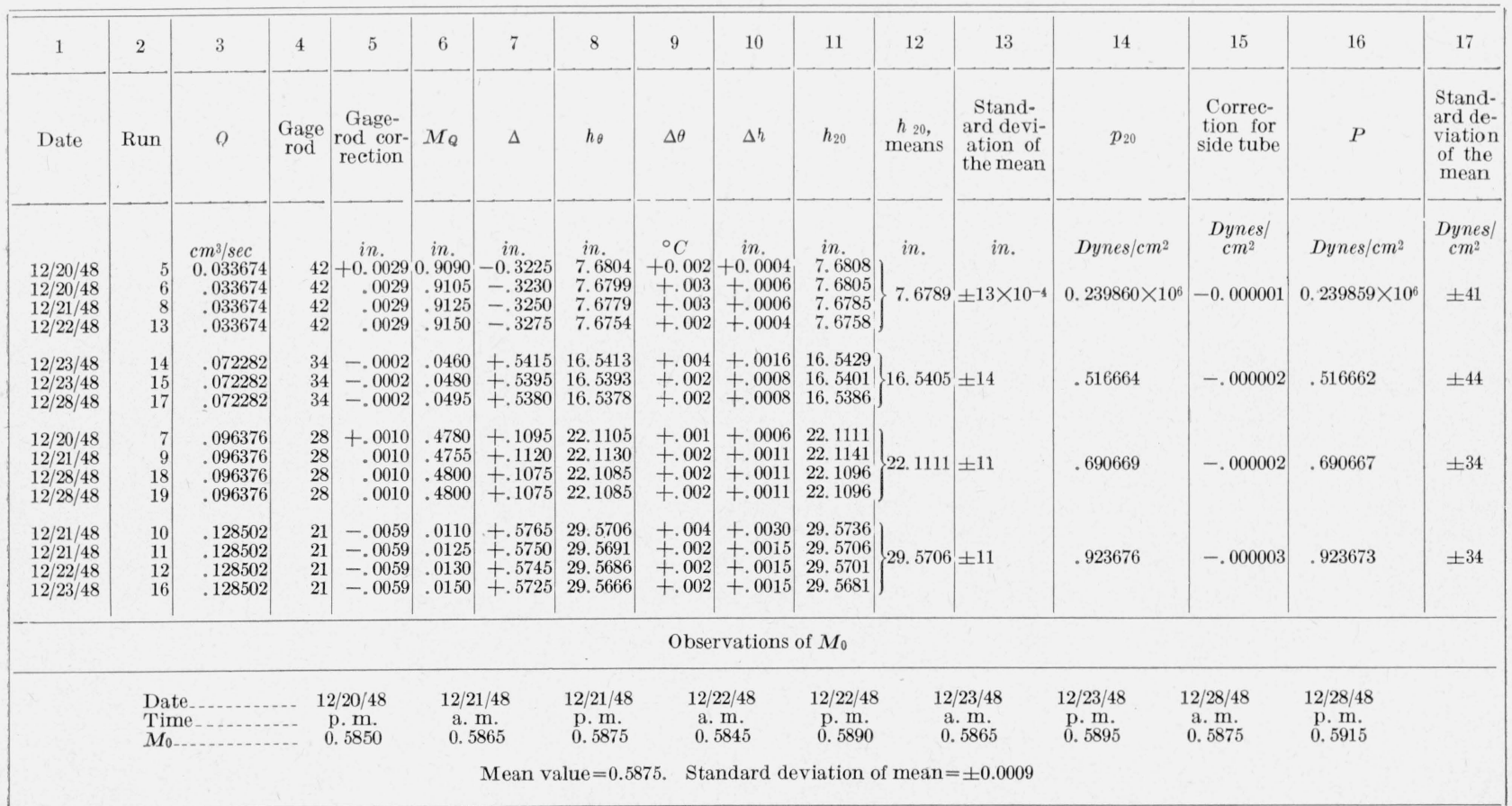


TABLE 33. Series VI, capillary 1.4

[Calculation of the pressure drops]

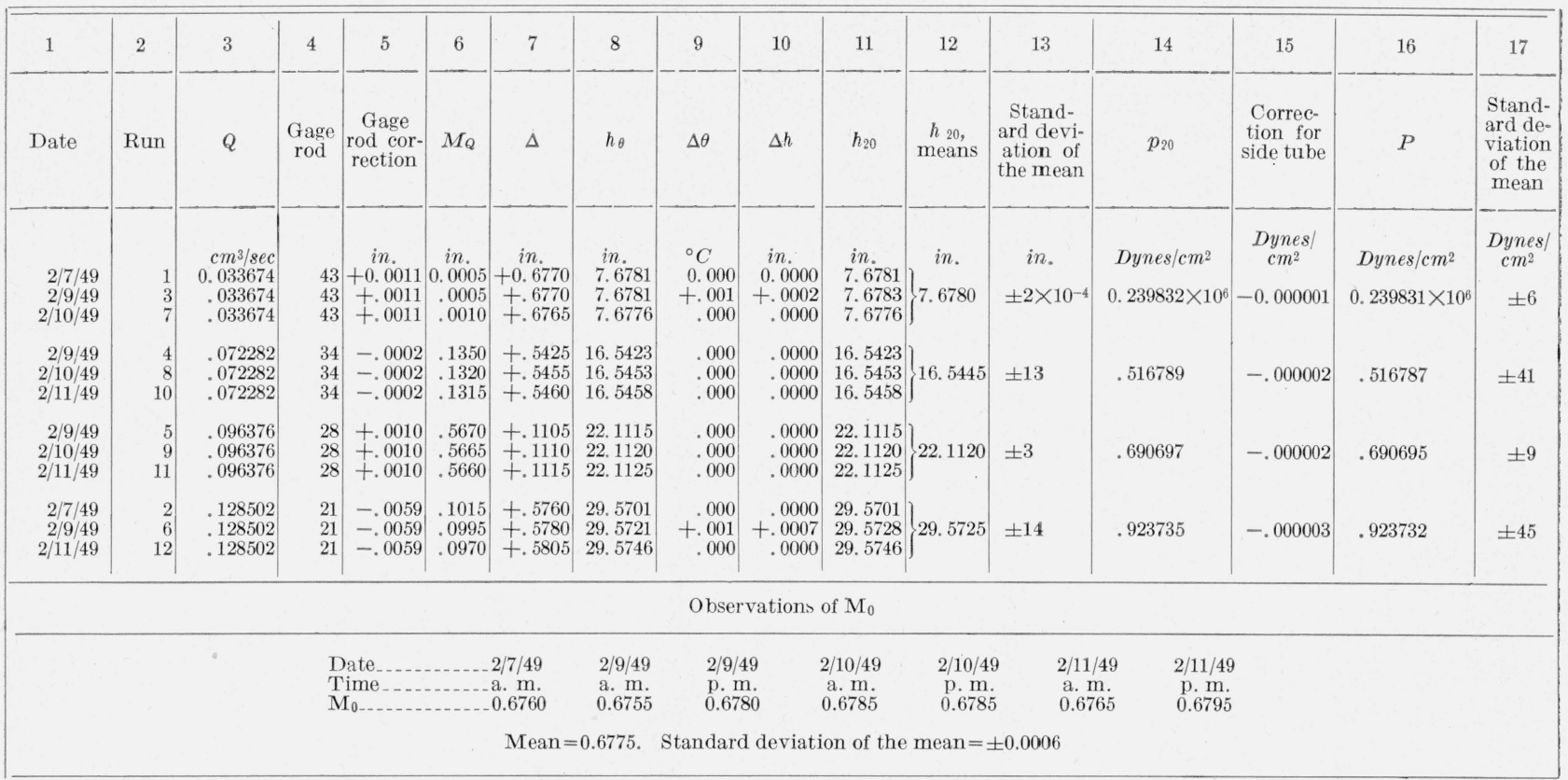

TABLE 34. Series VIII, capillary 1.4

[Calculation of the pressure drops]

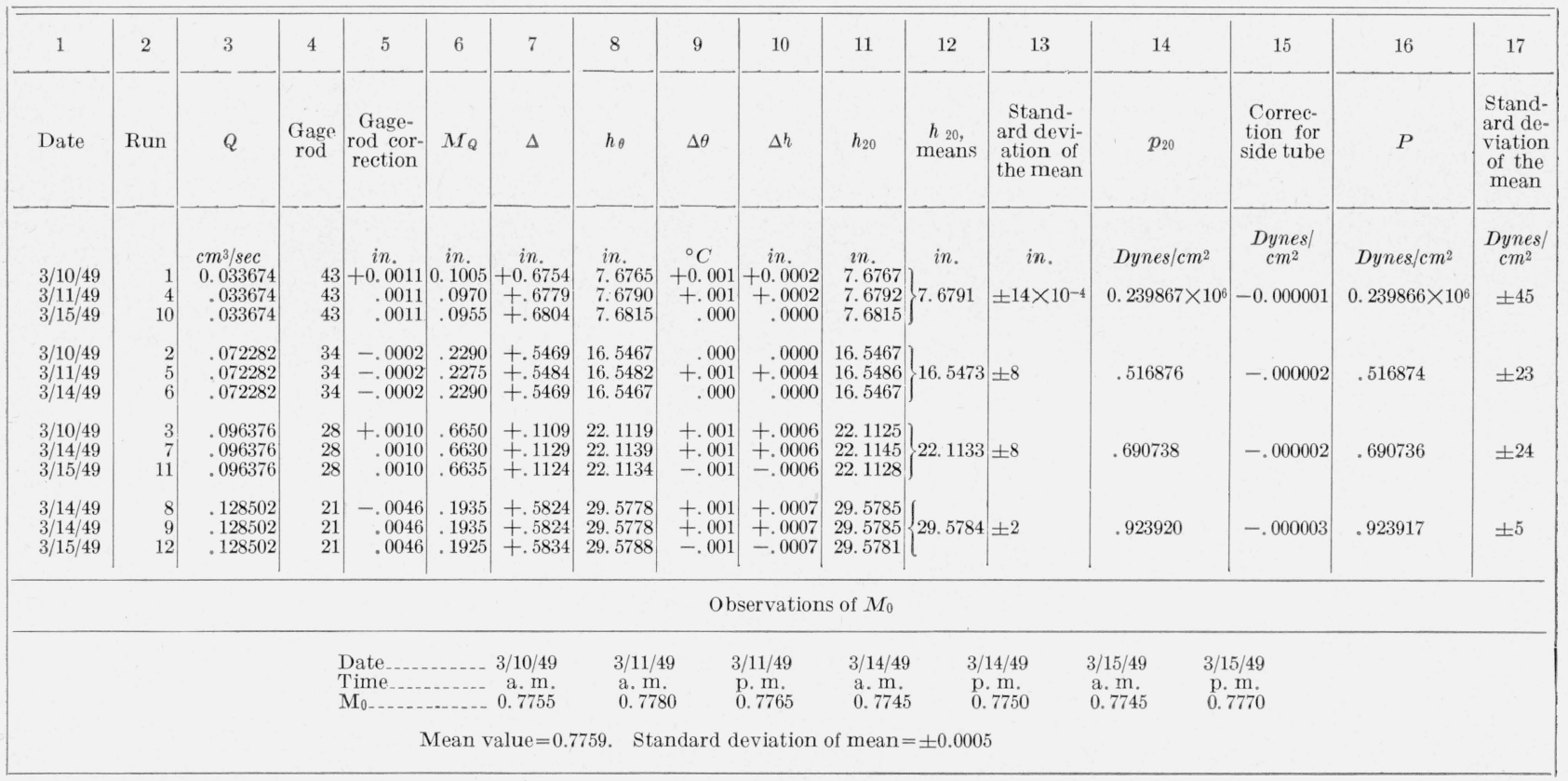


TABle 35. Series XI, capillary $1.4 a$

[Calculation of the pressure drops]

\begin{tabular}{|c|c|c|c|c|c|c|c|c|c|c|c|c|c|c|c|c|}
\hline 1 & 2 & 3 & 4 & 5 & 6 & 7 & 8 & 9 & 10 & 11 & 12 & 13 & 14 & 15 & 16 & 17 \\
\hline Date & Run & Q & $\begin{array}{c}\text { Gage } \\
\text { rod }\end{array}$ & $\begin{array}{c}\text { Gage- } \\
\text { rod cor- } \\
\text { rection }\end{array}$ & $M_{Q}$ & $\Delta$ & $h_{\theta}$ & $\Delta \theta$ & $\Delta h$ & $h_{20}$ & $\begin{array}{c}h_{20} \text {, } \\
\text { means }\end{array}$ & $\begin{array}{l}\text { Stand- } \\
\text { ard devi- } \\
\text { ation of } \\
\text { the mean }\end{array}$ & $p_{20}$ & $\begin{array}{l}\text { Correc- } \\
\text { tion for } \\
\text { side tube }\end{array}$ & $P$ & $\begin{array}{l}\text { Stand- } \\
\text { ard de- } \\
\text { viation } \\
\text { of the } \\
\text { mean }\end{array}$ \\
\hline $\begin{array}{l}9 / 14 / 49 \\
9 / 15 / 49 \\
9 / 15 / 49\end{array}$ & $\begin{array}{l}1 \\
5 \\
9\end{array}$ & $\begin{array}{l}\mathrm{cm}^{3} / \mathrm{sec} \\
0.033674 \\
.033674 \\
.033674\end{array}$ & $\begin{array}{l}47 \\
47 \\
47\end{array}$ & $\begin{array}{r}\text { in. } \\
+0.0135 \\
+.0135 \\
+.0135\end{array}$ & $\begin{array}{c}\text { in } \\
0.0830 \\
.0810 \\
.0840\end{array}$ & $\begin{aligned} & i n . \\
+ & 0.8176 \\
+ & .8196 \\
+ & .8166\end{aligned}$ & $\begin{array}{l}\text { in. } \\
\text { 3. } 8311 \\
\text { 3. } 8331 \\
\text { 3. } 8301\end{array}$ & $\begin{array}{r}{ }^{\circ} \mathrm{C} \\
0.000 \\
.000 \\
+.001\end{array}$ & $\begin{array}{c}\text { in. } \\
0.0000 \\
.0000 \\
+.0001\end{array}$ & $\begin{array}{l}\text { in. } \\
\text { 3. } 8311 \\
\text { 3. } 8331 \\
\text { 3. } 8302\end{array}$ & \}$^{i n} .8315$ & $\begin{array}{c}\text { in. } \\
\pm 10 \times 10^{-4}\end{array}$ & $\begin{array}{c}\text { Dynes/cm }{ }^{2} \\
0.119682 \times 10^{6}\end{array}$ & $\begin{array}{c}\text { Dynes/ } \\
\text { cm }^{2} \\
-0.000001\end{array}$ & $\begin{array}{c}\text { Dynes } / \mathrm{cm}^{2} \\
0.119681 \times 10^{6}\end{array}$ & $\begin{array}{c}\begin{array}{c}\text { Dynes/ } \\
\text { cm }^{2}\end{array} \\
\pm 31\end{array}$ \\
\hline $\begin{array}{l}9 / 14 / 49 \\
9 / 15 / 49 \\
9 / 15 / 49\end{array}$ & $\begin{array}{r}2 \\
6 \\
10\end{array}$ & $\begin{array}{r}.072282 \\
.072282 \\
.072282\end{array}$ & $\begin{array}{l}42 \\
42 \\
42\end{array}$ & $\begin{array}{r}+.0025 \\
+.0025 \\
+.0025\end{array}$ & $\begin{array}{l}.6105 \\
.6125 \\
.6130\end{array}$ & $\begin{array}{r}+.2901 \\
+.2881 \\
+.2876\end{array}$ & $\begin{array}{l}\text { 8. } 2926 \\
\text { 8. } 2906 \\
\text { 8. } 2901\end{array}$ & $\begin{array}{l}.000 \\
.000 \\
.000\end{array}$ & $\begin{array}{l}.0000 \\
.0000 \\
.0000\end{array}$ & $\begin{array}{l}\text { 8. } 2926 \\
\text { 8. } 2906 \\
\text { 8. } 2901\end{array}$ & \}. 2911 & \pm 9 & .258983 & -.000002 & .258981 & \pm 28 \\
\hline $\begin{array}{l}9 / 14 / 49 \\
9 / 15 / 49 \\
9 / 15 / 49\end{array}$ & $\begin{array}{r}3 \\
7 \\
11\end{array}$ & $\begin{array}{l}.096376 \\
.096376 \\
.096376\end{array}$ & $\begin{array}{l}39 \\
39 \\
39\end{array}$ & $\begin{array}{l}-.0053 \\
-.0053 \\
-.0053\end{array}$ & $\begin{array}{l}.7855 \\
.7875 \\
.7905\end{array}$ & $\begin{array}{l}+.1151 \\
+.1131 \\
+.1101\end{array}$ & $\begin{array}{l}\text { 11. } 1098 \\
\text { 11. } 1078 \\
\text { 11. } 1048\end{array}$ & $\begin{array}{r}-.002 \\
+.000 \\
+.001\end{array}$ & $\begin{array}{r}-.0006 \\
+.0000 \\
+.0003\end{array}$ & $\begin{array}{l}\text { 11. } 1092 \\
\text { 11. } 1078 \\
11.1051\end{array}$ & \} 11.1074 & \pm 13 & .346954 & -.000003 & .346951 & \pm 41 \\
\hline $\begin{array}{l}9 / 14 / 49 \\
9 / 15 / 49 \\
9 / 15 / 49\end{array}$ & $\begin{array}{r}4 \\
8 \\
12\end{array}$ & $\begin{array}{r}.128502 \\
.128502 \\
.128502\end{array}$ & $\begin{array}{l}35 \\
35 \\
35\end{array}$ & $\begin{array}{l}-.0061 \\
-.0061 \\
-.0061\end{array}$ & $\begin{array}{l}.9940 \\
.9950 \\
.9965\end{array}$ & $\begin{array}{r}-.0934 \\
-.0944 \\
-.0959\end{array}$ & $\begin{array}{l}\text { 14. } 9005 \\
\text { 14. } 8995 \\
\text { 14. } 8980\end{array}$ & $\begin{array}{r}-.001 \\
.000 \\
+.001\end{array}$ & $\begin{array}{r}-.0004 \\
+.0000 \\
+.0004\end{array}$ & $\begin{array}{l}\text { 14. } 9001 \\
\text { 14. } 8995\end{array}$ & $\{14.8993$ & \pm 6 & .465399 & -.000004 & .465395 & \pm 19 \\
\hline \multicolumn{17}{|c|}{ Observations of $M_{0}$} \\
\hline & & & & & & \multicolumn{3}{|c|}{ 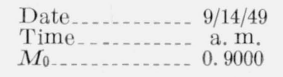 } & \multicolumn{2}{|c|}{$\begin{array}{l}9 / 14 / 49 \\
\text { p. m. } \\
0.9005\end{array}$} & $\begin{array}{l}9 / 15 / 49 \\
\text { a.m. } \\
0.9005\end{array}$ & \multicolumn{2}{|l|}{$\begin{array}{l}\text { 9/15/49 } \\
\text { p. m. } \\
0.9015\end{array}$} & & & \\
\hline
\end{tabular}

TABLE 36. Series XII, capillary $1.4 a$

[Calculation of the pressure drops]

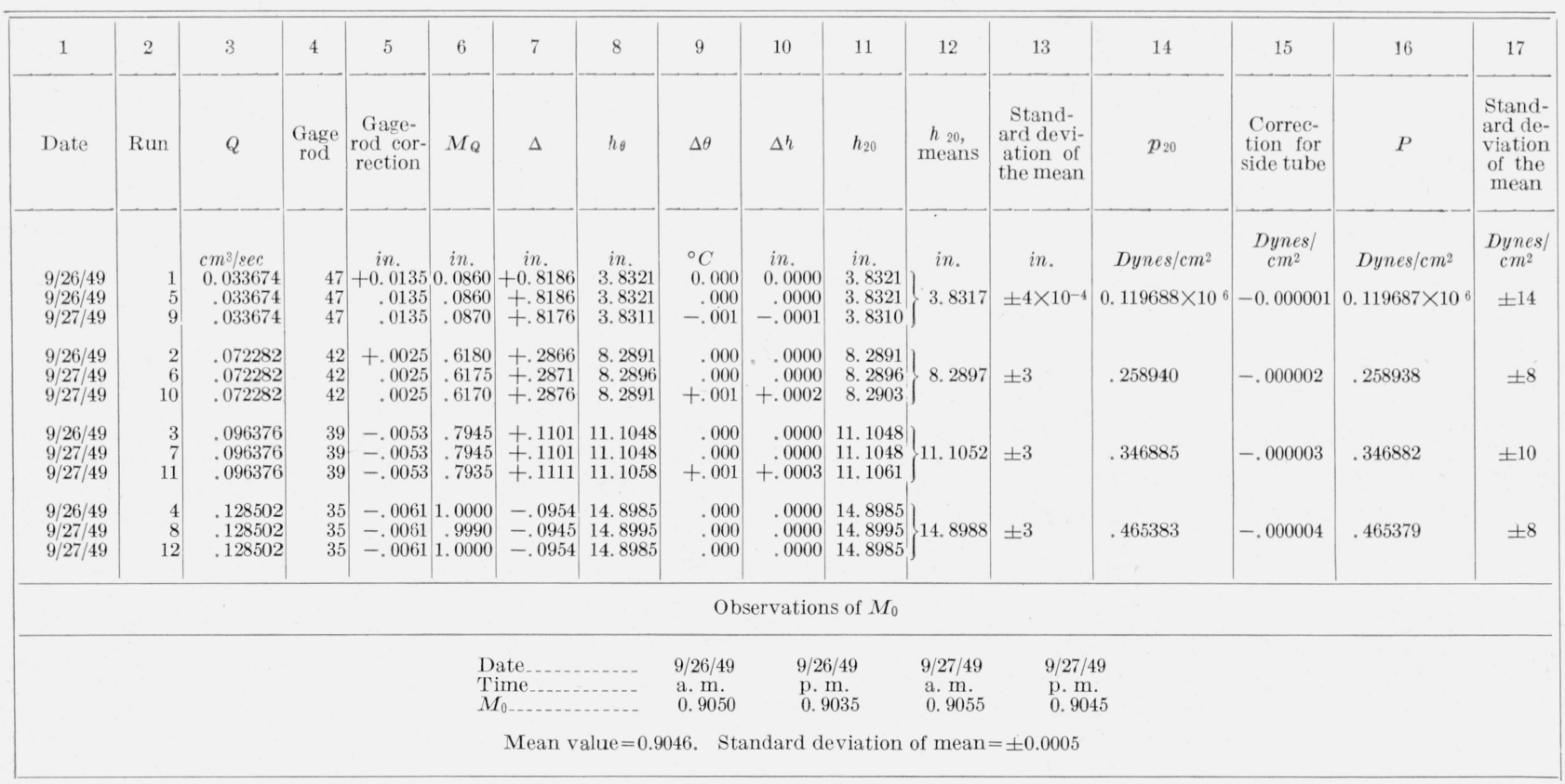

Washington, February 16, 1951. 